UNIVERSIDAD NACIONAL DE LA PLATA

CENTRO INUS

MAESTRÍA EN SALUD PÚBLICA

\title{
ANÁLISIS DE LAS ESTRATEGIAS DE VINCULACIÓN DE LOS VARONES AL PROGRAMA DE SALUD SEXUAL $Y$ PROCREACIÓN RESPONSABLE DE LA MUNICIPALIDAD DE LA PLATA
}

\author{
Tesis para obtener el título de \\ MAGISTER EN SALUD PÚBLICA
}

Tesista

SANDRA MILENA RODRÍGUEZ MORENO

\author{
DIRECTOR \\ DR. GUSTAVO MARÍN
}

La Plata, Argentina

2014 


\section{TABLA DE CONTENIDO}

1. RESUMEN.

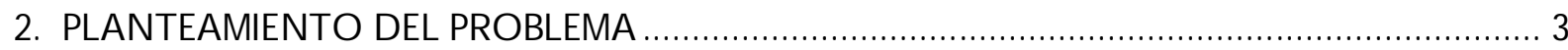

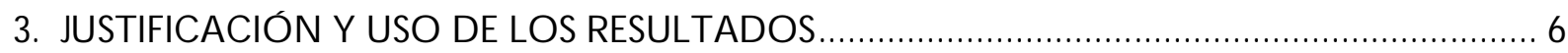

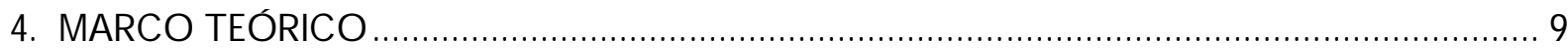

4.1. La salud sexual y reproductiva en el marco normativo internacional................................ 9

4.1.1. Conferencia Internacional de Derechos Humanos, Teherán ...................................... 9

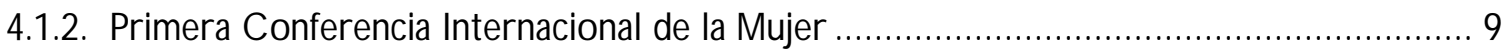

4.1.3. Convención sobre la Eliminación de Todas las Formas de Discriminación Contra la Mujer

4.1.4. Segunda Conferencia Internacional de la Mujer ...................................................11

4.1.5. Tercera Conferencia Internacional Sobre la Mujer .............................................11

4.1.6. Conferencia Internacional de Población y Desarrollo.............................................11

4.1.7. Cumbre Mundial Sobre Desarrollo Social .......................................................... 14

4.1.8. Cuarta Conferencia Mundial de la Mujer .......................................................... 15

4.1.9. Dedaración de Derechos Sexuales..................................................................... 17

4.1.10. Objetivos del Desarrollo del Milenio(19)(20) ....................................................... 19

4.1.11. Política de Igualdad de Género - Organización Panamericana de la Salud.....................20

4.2. La salud sexual y reproductiva en el marco normativo nacional de la Argentina...................23

4.2.1. Marco normativo nacional de la salud sexual y reproductiva....................................23

4.2.3. Marco normativo provincial de la salud sexual y reproductiva.....................................26

4.2.4. Programa de Salud Sexual y Procreación Responsable de la provincia de Buenos Aires(7)

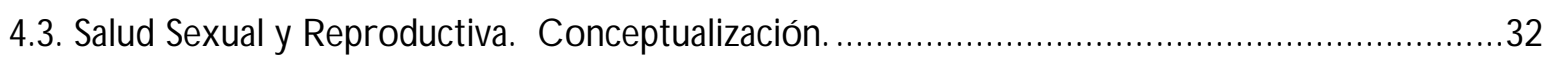

4.4. Importancia de la vinculación del varón en la salud sexual y reproductiva. Conceptualización.34

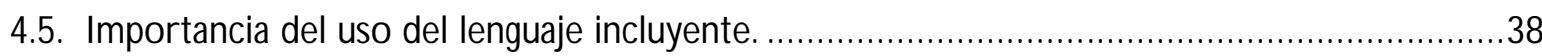

4.5.1. Lenguaje induyente escrito. Conceptualización..................................................38

4.5.2. Lenguaje incluyente visual. Conceptualización ...........................................................43

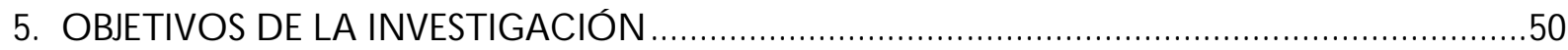

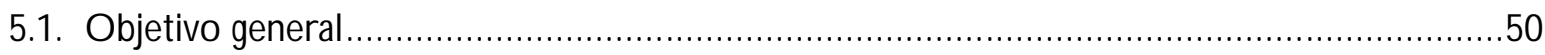


5.2. Objetivos específicos.. . .50

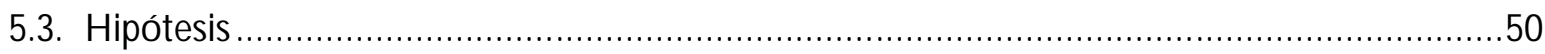

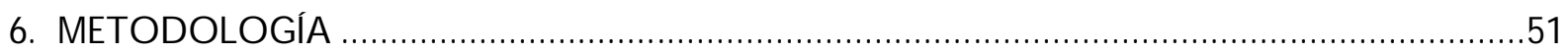

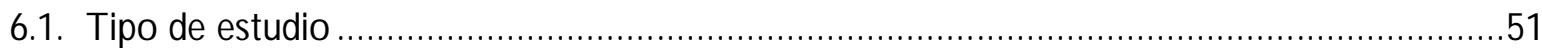

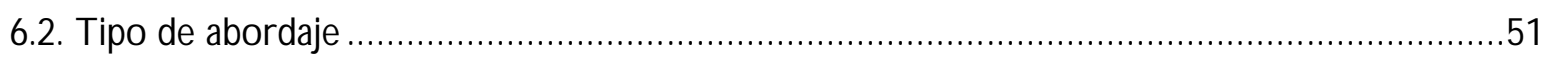

6.3. Universo

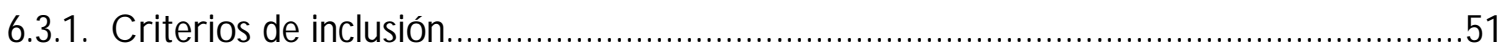

6.3.2. Criterios de exclusión..................................................................................

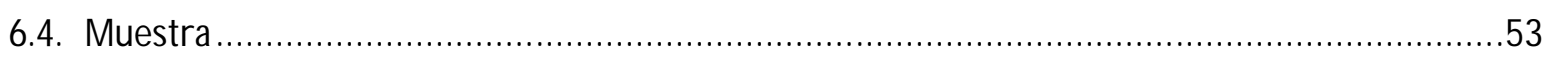

6.4.1. Tamaño muestral Subunidad publicaciones..........................................................53

6.4.2. Tameño muestral Subunidad proveedores y proveedoras del programa ..........................54

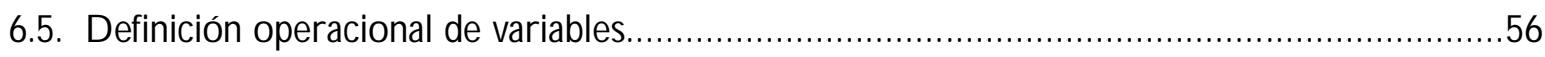

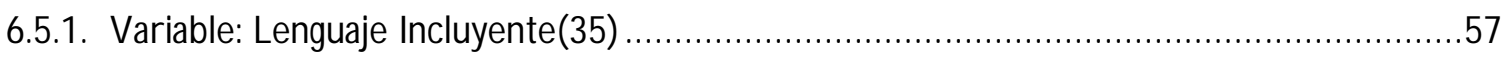

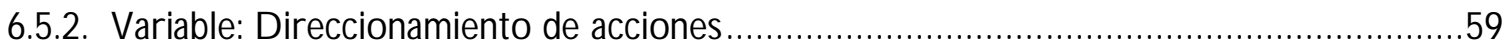

6.5.3. Variable: Disponibilidad de métodos anticonceptivos .................................................59

6.5.4. Variable: Promoción de la Vinculación del Varón en la Consejería de Planificación Familiar

6.5.5. Variable: Sensibilización de proveedores/as de consejería en planificación familiar en

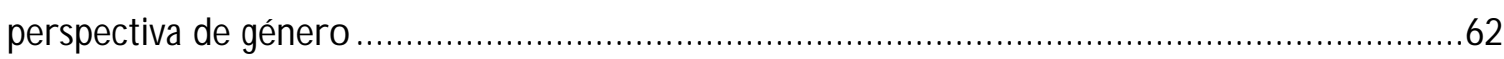

6.5.6. Variable: Reconocimiento de las estrategias de vinculación del varón en el PPSSyPR.......63

6.6. Dinámica de trabajo de campo ...................................................................................64

6.6.1. Preparación previa a las salidas de campo …….........................................................64

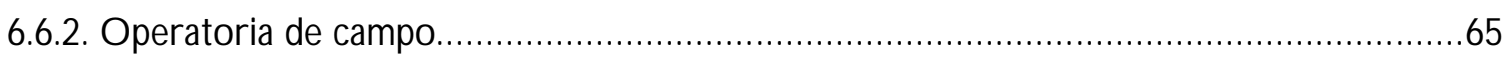

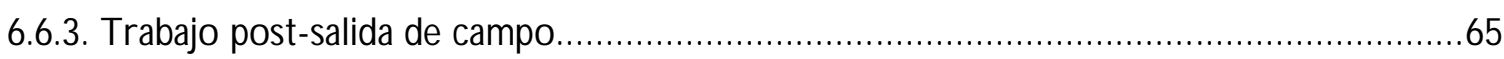

6.7. Técnicas de recolección de datos ................................................................................65

6.7.1. Instrumentos para la recolección de datos...............................................................65

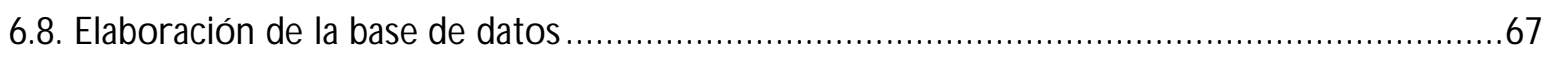

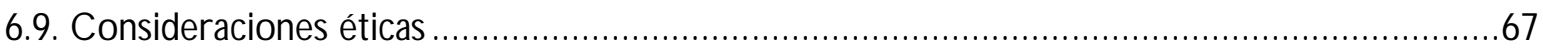

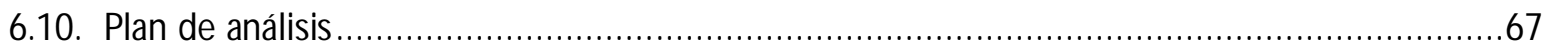

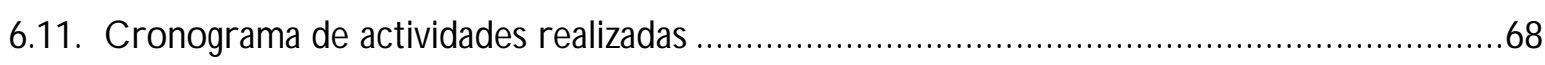

6.12. Financiación e infraestructura............................................................................. 


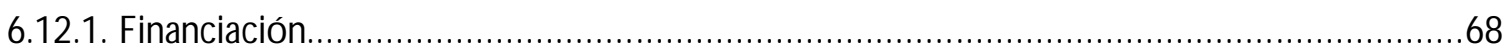

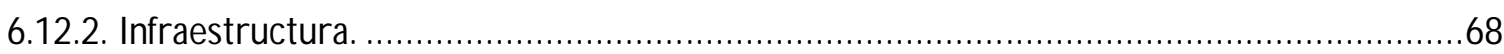

7. RESULTADOS

7.1. Análisis descriptivo de la variable lenguaje incluyente .....................................................69

7.1.1. Lenguaje induyente en publicaciones..............................................................70

7.1.2. Lenguaje incluyente en piezas publicitarias(53), (54), (55), (56), (57), (58), (59), (60)(61).75

7.2. Análisis descriptivo de la variable direccionamiento de acciones...........................................91

7.3. Análisis descriptivo de la variable disponibilidad de Métodos Anticonceptivos........................92

7.4. Análisis descriptivo de la variable promoción de la Vinculación del Varón en la Consejería de Planificación Familiar

7.5. Análisis descriptivo de la variable sensibilización de Proveedores de Consejería en Planificación Familiar en Perspectiva de Género.

7.6. Análisis descriptivo de la variable, reconocimiento de las estrategias de vinculación del varón en el PPSSyPR

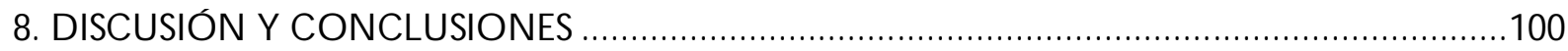

9. LA INCLUSIÓN DE LOSVARONESEN EL PPSSYPR. Premisas propuestas ..............................104

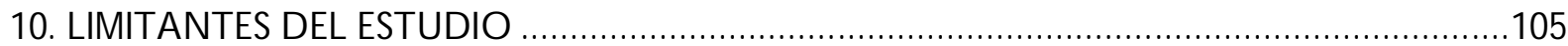

10. REFLEXIÓN Y RECOMENDACIONES

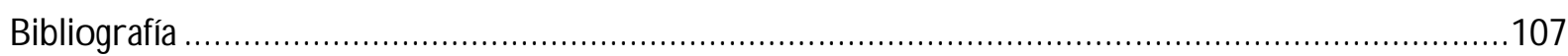

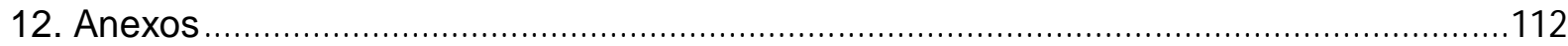


TABLA DE ANEXOS

Anexo 1. Ficha técnica de Indicadores de la variable lenguaje incluyente. 112

Anexo 2. Fichas técnicas de indicadores de la Variable Direccionalidad de Acciones

Anexo 3. Fichas técnicas de indicadores de la variable disponibilidad de métodos anticonceptivos

Anexo 4. Ficha técnica indicador de la variable promoción de la vinculación del varón en las acciones de salud sexual y reproductiva.

Anexo 5. Fichas técnicas de indicadores de la variable sensibilización de proveedores de consejería en planificación familiar en perspectiva de género

Anexo 6. Fichas técnicas de indicadores de la variable reconocimiento de las estrategias de vinculación del varón en las acciones del PSSRyPR

Anexo 7. Instrumento de verificación del lenguaje induyente en las publicaciones emitidas por el PPSSYPR

Anexo 8. Instrumento de análisis de piezas publicitarias emitidas por el PPSSyPR de la municipalidad de la plata.

Anexo 9. Instrumento determinación del direccionamiento de las acciones ofertadas por el PPSSYPR

Anexo 10. Instrumento de observación estructurada aplicable a los centros de atención primaria en salud que ofertan acciones del programa de salud sexual y procreación responsable de la Municipalidad de la Plata.

Anexo 11. Instrumento dirigido a usuarias y usuarios del Programa de salud Sexual y procreación responsable de la Municipalidad de La Plata.

Anexo 12. Instrumento dirigido a referentes del Programa de salud sexual y procreación responsable de la Municipalidad de La Plata.

Anexo 13. Instrumento dirigido a proveedoras y proveedores del Programa de salud sexual y procreación responsable de la Municipalidad de La Plata. 


\section{LISTADO DE TABLAS}

Tabla 1 Attemativas sugeridas para evitar el uso sistemático de genéico masalino............................42

Tabla 2. Categorías para el análisis de género en actividades, proyectos, programas y políticas...............44

Tabla 3. Matriz para análisis de género de las piezas publidtarias...............................................45

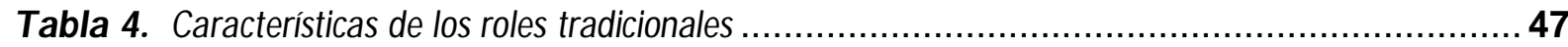

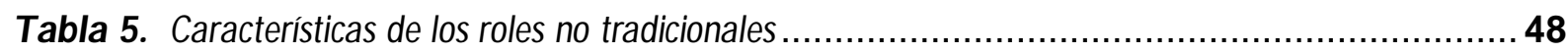

Tabla 6. Características de los mensajes tradicionales y no tradicionales ...........................................49

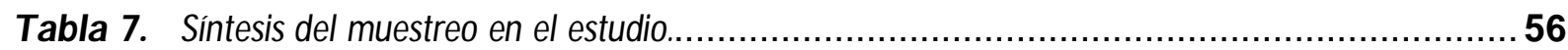

Tabla 8. Descripción de materiales publicados por el PPSSYPR, 2010 - 2012 ................................69

Tabla 9. Caracterización de las piezas publictarias utilizadas en los CAPS de la municipalidad de La Plata

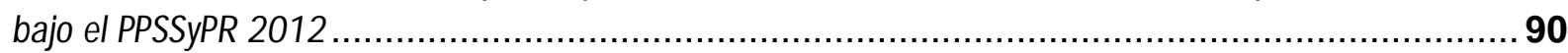

Tabla 10. Distribución porcentual de las características de lenguaje induyente y vinculación de los varones en las piezas publictarias del PPSSYPR usadas en los CAPS de la municipalidad de La Plata, 2012...........91

Tabla 11. Direccionamiento de acciones en el PPSSYPR. Municipalidad de La Plata, 2012 .................. 91

Tabla 12. Distribución de la variable edad en la población usuaria del PSSYPR de la munidpalidad de La

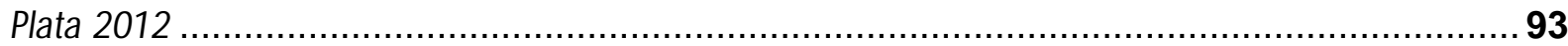

Tabla 13. Disponibilidad de MAC ofertados por el PPSSyPR en los CAPS de la munidipalidad de La Plata. 93

Tabla 14. Formas en que se informó sobre la importancia de la vinculación del varón en la consejería de planificacón familiar

Tabla 15. Distribución porcentual de las razones por las cuales la poblacón proveedora de la consejería en planificacón familiar considera importante la vinculación del varón en el PSSYPR 96

Tabla 16. Distribución porcentual de las razones por las cuales la población proveedora de la consejería en planificacón familiar no considera importante la vinaulación del varón en el PSSYPR.

Tabla 17. Distribución porcentual de proveedores/as de consejería en planificación familiar que refieren haber sido sensibilizados/as en la importancia de la perspectiva de género o importancia de la vinauladón del varón.

Tabla 18. Distribución porcentual del reconocimiento de las estrategias de vinaulacoón del varón en el PPSSYPR implementado en la Municipalidad de La Plata

Tabla 19 Distribución porcentual del reconocimiento de las estrategias de vinaulación del varón en el PPSSYPR de la Municipalidad de La Plata

Tabla 20. Distribución porcentual de las y los proveedores/as que consideran que las estrategias de vinaulacón del varón en el PPSSYPR de la Municipalidad de La Plata, son implementadas en su lugar de trabajo. 


\section{LISTADO DE SIGLAS}

\begin{tabular}{|c|c|}
\hline VIH & Virus de Inmunodeficiencia humana \\
\hline TMM & Tasa de mortalidad materna \\
\hline NV & Nacidos vivos \\
\hline PPSSyPR & Programa Provincial de Salud Sexual y Procreación Responsable \\
\hline MAC & Métodos Anticonceptivos \\
\hline PSSyPR & Programa de salud sexual y procreación responsable \\
\hline ONG & Organización no gubernamental \\
\hline APS & Atención primaria en salud \\
\hline OMS & Organización Mundial de la salud \\
\hline OPS & Organización Panamericana de la Salud \\
\hline CAPS & Centros de atención primaria en salud \\
\hline SSySR & Salud sexual y salud reproductiva \\
\hline DIU & Dispositivo intrauterino \\
\hline MAC & Métodos anticonceptivos \\
\hline AHM & Anticoncepción hormonal de emergencia \\
\hline PMO & Plan Obligatorio Medico \\
\hline AOC & Anticonceptivos orales combinados \\
\hline ACOLAC & Anticonceptivos orales en Lactancia \\
\hline ACI & Anticonceptivos Combinados Inyectables \\
\hline AHE & Anticoncepción Hormonal de Emergencia \\
\hline
\end{tabular}




\section{RESUMEN}

A partir de la Declaración de Teherán en 1968 la salud sexual y reproductiva comienza a formar parte de las agendas políticas de un gran número de países y gobiernos alrededor del mundo. Los movimientos sociales iniciaron paralelamente a esta decisión, un duro camino en pro de la consecución de herramientas que permitieran el ejercicio de los derechos sexuales y reproductivos con el fin de mejorar la salud de la población y prevenir enfermedad y muerte relacionadas con el ejercicio de la sexualidad. Si bien es cierto que se ha avanzado en múltiples escenarios en el proceso de posicionar la salud sexual y reproductiva de las poblaciones y que organizaciones internacionales movilizan recursos humanos, políticos y económicos alrededor del tema, los resultados aún siguen siendo preocupantes.

En el contexto mundial en el que se desarrolla la población joven, las mujeres y niñas especialmente son vulnerables a diversas problemáticas. Este grupo poblacional presenta riesgos de muerte y discapacidad que se relaciona directamente con la falta de métodos anticonceptivos y prácticas sexuales de riesgo, que finalmente generan embarazos no deseados, abortos peligrosos, complicaciones en el embarazo y parto e infecciones de transmisión sexual, con un mayor impacto en páses de bajos ingresos.

En la Argentina la salud sexual y reproductiva SSyR se incluye en la agenda la política en el año 2002 con la sanción de la Ley Nacional № 25.673 - "Por la aul se crea al Programa Nacional de Salud Sexual y Procreación Responsable en el ámbito del Ministerio de Salud", siendo esta la piedra angular para la estructuración de los programas en todo el territorio nacional. Sin embargo los indicadores para 2012 han empeorado, se reporta una tasa de mortalidad materna 5.5 x $\mathbf{1 0 . 0 0 0}$ nacidos vivos, y presentado grandes diferencias entre los datos de las diferentes provincias. La mayor cantidad de muertes maternas fueron atribuidas a causas obstétricas directas como las complicaciones en el puerperio, seguidas de aborto, que en el 2009 representó el 21,2\% del total de las defunciones, según los datos aportados por el Sistema Informático Perinatal. Este hecho indica que de cada 10 embarazos en la Argentina 6 son no deseados, calculándose por estimaciones indirectas una frecuencia de abortos que oscila entre 372.000 y 522.000 al año.

La responsabilidad de las decisiones en la salud sexual y reproductiva ha sido puesta en mayor parte sobre las mujeres, invisibilizando las relaciones de poder que se viven al interior de las parejas; por esta razón surge el interés de analizar las estrategias de vinculación de los varones que se implementan desde el Programa de Salud Sexual y Procreación Responsable PSSyPR. 
En este aspecto, este trabajo propuso estudiar la temática, con el fin de aportar elementos que permitan mejorar sus resultados. Se realizó pues un estudio descriptivo con una etapa analítica en el que se tomó como sujeto/objeto de estudio a la población usuaria y proveedora del servicio de consejería en planificación familiar de los Centros de Atención Primaria en Salud de la Municipalidad de La Plata y al Programa Provincial de Salud Sexual y Procreación Responsable PPSSyPR en sí con todos sus componentes documentales, publicaciones e insumos provistos por el programa Para el análisis de las estrategias de vinculación del varón utilizadas por el PPSSyPR en el Partido de La Plata, se definieron seis variables que permitieron analizar elementos determinantes en las acciones de salud sexual y reproductiva, entre las que se encuentran el uso de lenguaje incluyente en publicaciones, el direccionamiento de acciones, la disponibilidad de métodos anticonceptivos, la promoción de la vinculación del varón en la consejería de planificación familiar, la sensibilización de proveedores de consejería en planificación familiar en perspectiva de género y el reconocimiento de las estrategias de vinculación del varón en el PPSSyPR en sí con todos sus componentes documentales, publicaciones e insumos provistos por el programa.

Los resultados obtenidos mostraron que las publicaciones manejan una fuerte tendencia a empoderar a las mujeres en el ejercicio de la SSyR y a reconocer la vulneración de sus derechos, las acciones ofertadas por el programa son en gran mayoría dirigidas a las mujeres, la disponibilidad de los métodos anticonceptivos en los CAPS no representa un elemento determinante en la elección de estos por parte de la población usuaria, el mensaje que promueve la vinculación del varón en la salud sexual y reproductiva está enfocado en la responsabilidad compartida y no en el ejercicio del derecho a participar en el proceso. Además, se detectó dentro del programa la existencia de espacios potenciales de inclusión de los varones en la toma de decisiones en materia de salud sexual y reproductiva que no están siendo aprovechados, por lo que será necesario fortalecer los procesos de capacitación y sensibilización de la población proveedora de servicios de consejería en planificación familiar en relación a perspectiva de género y a la importancia de la vinculación del varón en la SSyR, para generar un mejor impacto en la población.

Con base en los resultados obtenidos en el presente trabajo, se propone vincular de manera más activa a los varones en el Programa de Salud Sexual y Procreación responsable, con el fin de optimizar los resultados a obtener por el programa e impactar de manera más efectiva en la salud de la población. 


\section{PLANTEAMIENTO DEL PROBlemA}

La situación de salud de las mujeres en el mundo y a través de la historia ha mantenido como elemento continuo la desigualdad frente a los hombres en cuanto a educación, ingresos y empleo, condiciones que finalmente se ven reflejadas en la capacidad de niñas y mujeres para proteger su propia salud. Las diferencias biológicas y de comportamiento generan expectativas de vida más prolongadas que las de los varones sin obviar que esto signifique mejor calidad de vida; así mismo ciertos estados de exclusividad femenina como el embarazo y el parto ponen a las mujeres frente a riesgos característicos, ante los cuales los servicios sanitarios deben acondicionar sus estructuras para minimizar los riesgos en salud (1).

Otras inequidades estructurales propias de los países que habitan, generan según el nivel de desarrollo diferentes riesgos, por ejemplo, en los países más pobres las tasas de mortalidad en la población infantil son más altas y la mayoría de las defunciones de mujeres corresponden a adolescentes y adultas jóvenes entre los 15 y 19 años a causa de complicaciones en el embarazo y el parto. La diferencia entre los páses ricos y los pobres se observa en la mortalidad materna: de las más de medio millón de defunciones maternas que ocurren en el mundo cada año 99\% corresponden a los páses en desarrollo. Por lo tanto, la máxima carga de morbilidad y mortalidad, particularmente durante los años reproductivos, se concentra en los países más pobres y a menudo con las instituciones más débiles, en particular los que afrontan crisis humanitarias (1).

La Organización Mundial de la Salud en su informe de 2009 “Las Mujeres y la Salud. Los datos de hoy, la agenda del mañana", manifiesta que las mujeres y las niñas se consideran entre toda la población como las más vulnerables frente a la epidemia de $\mathrm{VIH}$, esto, relacionado con una serie de factores biológicos y desigualdades de género, sobre todo en culturas que limitan el ejercicio de los derechos, la posibilidad de adquirir conocimientos frente a esta patología y su posibilidad de protegerse y negociar relaciones sexuales sin riesgo. De la misma manera informa que en los páses de ingresos bajos o medianos los riesgos de muerte y discapacidad en el grupo de las mujeres, se relaciona directamente con la falta de métodos anticonceptivos y prácticas sexuales de riesgo que, finalmente generan embarazos no deseados, abortos peligrosos, complicaciones en el embarazo y el parto, e infecciones de transmisión sexual (1).

En la Argentina la mortalidad materna a finales de la década del 80 era aproximadamente de 5x10.000 nacidos vivos, manteniendo una tendencia relativamente estable en el periodo 
1990-2008 y presentando fluctuaciones, en el año 2000 se reportó la cifra más baja con 3,5 muertes maternas por cada 10.000 nacidos vivos, para 2008 la Tasa de Mortalidad Materna TMM había descendido casi un punto y para 2009 alcanzó el máximo valor 5,5 x 10.000 nacidos vivos, (410 mujeres), 114 fallecimientos más que los atribuidos a esta causa en el año anterior (2). Se identificó que para el año 2008 la mayor cantidad de muertes maternas fueron atribuidas a causas obstétricas directas como las complicaciones en el puerperio, seguidas de trastornos hipertensivos; sin embargo, para el año 2012 se reportó que la principal causa de estas fue el aborto, que representó el 20,9\% del total de las defunciones (3) y para 2009 el $21,2 \%$ (2). La mayoría de las causas de los abortos realizados se atribuyen a embarazos no deseados, se considera, según los datos aportados por el Sistema Informático Perinatal, que de cada 10 embarazos en la Argentina 6 son no deseados (2), así mismo según estimaciones indirectas se calcula que la frecuencia de abortos, oscilan entre 372.000 y 522.000 al año (4).

Otra de las grandes problemáticas sociales relacionadas con este tema es el embarazo adolescente, considerado como aquel que se produce en mujeres menores de 19 años de edad. Con respecto al indicador de Tasa de Natalidad de las Adolescentes, en Argentina durante el año 2008, el 15\% de los nacimientos correspondieron a mujeres entre los 15 y los 19 años y el 0,4\% a adolescentes/niñas de 0 a 14 años (3). Al igual que se presentan diferencias entre los países del mundo según su grado de desarrollo, al interior de pás también se refleja esta situación, mientras que en la provincia de Buenos Aires el porcentaje de nacidos vivos de mujeres menores de 20 años es de 7,1\% del total, la provincia del Chaco reporta un 24,4\% Así mismo, para este grupo de edad, se reporta una tendencia ascendente en el número de egresos hospitalarios por embarazos terminados en abortos, para el año 2000 el $9 \%$ de las mujeres menores de 20 años egresaban con este diagnóstico y para 2007 las complicaciones por abortos atendidas a nivel hospitalarios había ascendido a 15\%(2).

En las cifras generales de la Nación se encuentra que aunque en la provincia de Buenos Aires se reportan cifras más positivas en los aspectos analizados anteriormente, la salud sexual y reproductiva de las mujeres en esta zona aún continua siendo un problema de salud pública; para el año 2012 la provincia de Buenos Aires reporta una tasa de mortalidad materna 3,0 por 10.000 nacidos vivos, mientras que Córdoba y La Rioja son reportadas como las provincias con menor TMM (1,6 x $10.000 \mathrm{NV})$, cifra muy por debajo de la Tasa Nacional que para este mismo año se encuentra en 3,5 y bastante alejada de los datos de la provincia con mayor TMM que es Formosa con 16,0 x $10.000 \mathrm{NV}$; reflejando el grado de desigualdad que tienen las mujeres en cuanto a su posibilidad de vivir o morir según las condiciones económicas y la región del pás que habiten. Por su parte, la Provincia de Buenos Aires en el año 2007 aportó el 5,33\% del total de egresos hospitalarios por abortos en hospitales públicos (5). 
Frente al panorama mundial, múltiples organismos internacionales y movimientos sociales han recomendado a los Estados a contribuir en el mejoramiento de las condiciones de salud de las mujeres, de esta manera se ha incorporado en el discurso una fuerte línea que inicialmente apuntaba a la igualdad de derechos civiles de estas frente a los hombres y que posteriormente, con su evolución, involucró elementos como la perspectiva de género, que se refiere a la "evaluación de las consecuencias para las mujeres y los hombres de aralquier adividad planificada". Es así, como elementos conceptuales fueron incorporándose en las agendas políticas de las Naciones; en materia de salud sexual y reproductiva, la Conferencia Internacional de Población y Desarrollo (CIPD) de El Cairo celebrada en 1994 aportó quizá, los elementos más contundentes para mejorar las condiciones de salud de las mujeres abordando, además de los elementos estructurales como la pobreza y la desigualdad en diversas áreas, su salud sexual y reproductiva como elemento fundamental. Se define entonces y hasta ahora, que la salud sexual y reproductiva debe ser un derecho y que para el ejercicio pleno de este, los gobiernos deben implementar una serie de estrategias que vinculan a todos los sectores de la sociedad así como a sus individuos, y hace hincapié en la importancia de la respuesta de los servicios sanitarios y la vinculación de los varones en las acciones de salud sexual y reproductiva (6).

Según el documento Objetivos de Desarrollo del Milenio. República de Argentina. Rendición de cuentas 2010, la Nación se ha incorporado en la última década al grupo de países que toman medidas para la promoción de la equidad de género; de esta manera las políticas implementadas en este tema han generado mayor equidad en la distribución de ingresos, inclusión social, equidad e igualdad de oportunidades; como parte de las estrategias diseñadas para esto, se ha procurado introducir la perspectiva de género a fin de remover estereotipos y se ha promovido la creación de leyes que conduzcan a mejorar la condición y posición de las mujeres en la sociedad. De esta manera se refleja un importante direccionamiento de acciones en diversos ministerios que contribuyen de manera directa e indirecta con la mejoría en las condiciones de las mujeres. Este documento es explicito además en concluir que "La incorporación de la perspectiva de género en proyectos, políticas y programas sociales y económicos fue primordial para asegurar el objetivo de la igualdad entre los géneros" (3).

En materia legislativa se ha generado un avance significativo con la Ley 26.485 que ofrece el marco integral para la atención, protección y prevención de la violencia de género, al incorporar nuevas formas de violencia, (simbólica, institucional, laboral, contra la libertad reproductiva, obstétrica y la mediática que se ejerce desde los medios de comunicación), pone al país a la vanguardia en el tema (3). 
En la provincia de Buenos Aires, en materia de salud sexual y reproductiva, se crea en 2003 el Programa Provincial de Salud Reproductiva y Procreación Responsable (PPSRyPR) con el propósito de garantizar las políticas orientadas a la promoción y desarrollo de la salud reproductiva y la procreación responsable dirigdas a toda la población sin discriminación alguna y su implementación en el ámbito del Ministerio de Salud de la Provincia de Buenos Aires. Desde su creación, el Programa funcionó como subprograma dentro del Área Materno Infantil. En mayo de 2010 mediante Resolución № 1395 el programa comienza a funcionar bajo la órbita del Área de Políticas de Género, dependiente de la Unidad del Ministro. Entre sus objetivos plantea promover la participación de los varones en el cuidado de la salud reproductiva (7).

Bajo esta argumentación surge el interés de hacer una revisión a la perspectiva de género implementada en el Programa de Salud Sexual y Reproductiva de municipalidad de La Plata a través del análisis de las estrategas de vinculación de los varones en las acciones de salud sexual y reproductiva, y de esta manera determinar si las estrategias utilizadas están enfocadas en la participación de estos para alcanzar el objetivo de mejorar la salud de las mujeres. Se seleccionó La Plata como área geográfica de este estudio, ya que, además de ser la capital de la provincia, es la municipalidad más representativa en cuanto a población en la provincia de Buenos Aires y a su vez adopta los lineamentos del Programa Provincial de Salud Sexual y Procreación Responsable.

\section{JUSTIFICACIÓN Y USO DE LOS RESULTADOS}

Luego del logro de la adquisición de los derechos civiles y políticos, y del derecho al voto, el Movimiento Feminista y los Estados inician un largo camino en la búsqueda de un mejor estado de bienestar de las mujeres en las sociedades, es así como a partir de 1968 con la declaración de Teherán (8), las Naciones Unidas instan a los gobiernos a garantizar los mínimos básicos en derechos relacionados con la reproducción, manifestando que la libertad de determinar el número de hijos y los intervalos entre los nacimientos es un derecho humano fundamental de los individuos; posteriormente múltiples tratados, conferencias y declaraciones se han proclamado con relación a este tema. En 1994 se celebra la Conferencia Internacional de Población y Desarrollo (CIPD) de El Cairo (6) este evento además de reivindicar los derechos de las mujeres como derechos humanos y de definir los derechos sexuales y reproductivos, define de manera explícita que solo con la vinculación de los hombres en temas como la planificación familiar y la salud reproductiva se podrían 
generar procesos de cambio de las condiciones de las mujeres y dedica en el capítulo IV una sección a "Las Responsabilidades y Participadón del Hombre". Posteriormente en la Cuarta Conferencia Mundial sobre la Mujer (9) celebrada en 1995 en Beijing se da vía al concepto de perspectiva de género definiéndolo como:

“La incorporación de la perspectiva de género es el proceso de evaluación de las consecuencias para las mujeres y los hombres de cualquier actividad planificada, inclusive las leyes, políticas o programas, en todos los sectores y a todos los niveles. Es una estrategia destinada a hacer que las preocupaciones y experiencias de las mujeres, así como de los hombres, sean un elemento integrante de la elaboración, la aplicación, la supervisión y la evaluación de las políticas y los programas en todas las esferas políticas, económicas y sociales, a fin de que las mujeres y los hombres se beneficien por igual y se impida que se perpetúe la desigual dad. El objetivo final es lograr la igualdad entre los géneros" (10).

De esta manera se refuerza aún más que el monitoreo de las acciones en favor del bienestar de la mujer incluye la vinculación del varón en todos los sectores.

En este contexto, se incluye en la agenda la política de Argentina la salud sexual y reproductiva por diferentes vías y se inicia la articulación del tema en las diferentes acciones del sistema de salud; de igual forma en el año 2002 se sanciona la Ley Nacional № 25.673 “Por la cual se crea al Programa Nacional de Salud Sexual y Procreación Responsable en el ámbito del Ministerio de Salud" y se define la responsabilidad de suscribir convenios con las provincias para que cada una organice sus programas en cada una de sus jurisdicciones, siendo esta un cimiento importante para la estructuración de los programas en todo el territorio nacional (11). Posteriormente en junio de 2003 mediante la Ley 13.066 se da el aval para la creación en el ámbito de la Provincia de Buenos Aires, del Programa Provincial que garantiza las políticas orientadas a la promoción, y desarrollo de la salud seproductiva y la procreación responsable, bajo la dirección del Ministerio de Salud de la provincia (12). En mayo de 2010 mediante la Resolución No. 1.395 el programa comienza a funcionar bajo la coordinación del Área de Políticas de Género (7).

La Ley 25.673 de 2002 y el Programa Nacional de Salud Sexual y Procreación Responsable aplican para todo el territorio nacional y este último define entre sus estrategias la articulación con los programas provinciales principalmente en las áreas de distribución de métodos anticonceptivos (MAC), oferta de consejerías en planificación familiar y atención especializada, capacitación al recurso humano y estrategias de comunicación (2). No obstante, a pesar de todos los esfuerzos realizados; no se ha logrado el impacto deseado con 
el PPSSyPR; tal vez este hecho radique en que estos esfuerzos parecieran focalizarse en las mujeres.

Bajo esta argumentación surge el interés por un estudio que permita analizar la realidad del PPSSyPR en un área testigo (Partido de La Plata). Con los resultados obtenidos, se podrá evaluar la vinculación de los varones en las acciones relacionadas con la salud sexual y reproductiva y eventualmente proponer estrategias para lograr una mayor eficacia en este tipo de políticas sanitarias. 


\section{MARCO TEÓRICO}

\subsection{La salud sexual y reproductiva en el marco normativo internacional}

El marco normativo internacional en materia de derechos relacionados con la salud sexual y reproductiva se ha desarrollado de manera articulada con el campo del desarrollo humano y la reivindicación de las mujeres como sujetos de derechos; es así como se identifica a lo largo de la historia que los avances en la materia no se encuentran propiamente vinculados a reuniones que traten el tema desde el sector salud, sino que por el contrario, la evolución de estos ha estado más impulsada por otros sectores como el económico, el poblacional y el de desarrollo social.

\subsubsection{Conferencia Internacional de Derechos Humanos, Teherán}

El deber del Estado como garante de derechos relacionados con la salud sexual tiene sus orígenes en 1968 cuando en la Conferencia Internacional de Derechos Humanos en Teherán (8) se describe como derecho humano fundamental de los individuos la libertad de determinar libremente el número de hijos y los intervalos entre los nacimientos.

\subsubsection{Primera Conferencia Internacional de la Mujer}

Posteriormente se declara 1975 como el año Internacional de la Mujer de las Naciones Unidas, se define que los siguientes diez años serían considerados como el decenio de las Naciones Unidas para la Mujer. En este mismo año se realiza la Primera Conferencia Internacional de la Mujer, México 1975, donde se trabajó sobre la condición jurídica y social de las mujeres, en el documento político final de dicho encuentro se expresa que:

\footnotetext{
"las mujeres y hombres de todos los países deben tener iguales derechos y deberes, y que incumbe a todos los Estados crear las condiciones necesarias para que aquéllas los alcancen y puedan ejercerlos, ya que la utilización insuficiente del potencial de aproximadamente la mitad de la población mundial es un grave obstáculo para el desarrollo económico y social" (13)
}

El contexto mundial de este tiempo permitía ver que era indispensable la vinculación de las mujeres en el desarrollo de los países por lo que el plan de acción de dicha conferencia apuntó a garantizar que las mujeres tuvieran mayores facilidades de acceso a recursos como 
la educación, el empleo, la política, los servicios de salud, la vivienda, la nutrición y la planificación familiar; de esta manera además de proponer acciones en el ámbito público, también se diriǵan la mirada hacia lo privado en donde se promovieran cambios que transformaran los roles de cada sexo al interior de la familia y la comunidad. Frente a estos compromisos los Estados se comprometen a reformar sus leyes, a crear dentro de cada gobierno un mecanismo que velara por el logro de la igualdad de oportunidades para las mujeres y su plena integración en la vida y el desarrollo de los países. Como resultado de los compromisos al finalizar el decenio 127 países habían reformado leyes y establecido el mecanismo para investigar y transformar la situación de las mujeres; adicionalmente se dio la creación del Instituto Internacional de Investigaciones y Capacitación para la Promoción de la Mujer (INSTRAW) y al Fondo de Desarrollo de las Naciones Unidas para la Mujer (UNIFEM), que tendrían como objetivo proporcionar el marco institucional para la investigación, capacitación y las actividades operacionales en la esfera de las mujeres y el desarrollo (13)

De esta manera se abre la puerta a una gran cantidad de conferencias, tratados y acuerdos internacionales que potenciados por el movimiento feminista buscaban adelantar la posición de la mujer en la sociedad.

\subsubsection{Convención sobre la Eliminación de Todas las Formas de Discriminación Contra la Mujer (14).}

La Convención sobre la Eliminación de todas las Formas de Discriminación contra la Mujer, CEDAW en 1979 retoma desde la discriminación la importancia de trabajar a partir de la escala cultural en la ruptura de roles que perpetúen la condición disciplinada de las mujeres, propone como estrategias de vinculación a las acciones de salud elementos como la eliminación de estereotipos y el acceso a la información.

Art. 10 - c) La eliminación de todo concepto estereotipado de los papeles masculino y femenino en todos los niveles y en todas las formas de enseñanza, mediante el estímulo de la educación mixta y de otros tipos de educación que contribuyan a lograr este objetivo y, en particular, mediante la modificación de los libros y programas escolares y la adaptación de los métodos de enseñanza (14);

Art. 10 - h) Acceso al material informativo específico que contribuya a asegurar la salud y el bienestar de la familia, incluida la información y el asesoramiento sobre planificación de la familia (14).

Art. 12 - 1) Los Estados Partes adoptarán todas las medidas apropiadas para eliminar la discriminación contra la mujer en la esfera de la atención médica a fin de asegurar, en condiciones de igualdad entre hombres y mujeres, el acceso a servicios de atención médica, inclusive los que se refieren a la planificación de la familia (14). 
Art. 16 - e) Hombres y Mujeres tienen los mismos derechos a decidir libre y responsablemente el número de sus hijos y el intervalo entre los nacimientos y a tener acceso a la información, la educación y los medios que les permitan ejercer estos derechos (14).

\subsection{Segunda Conferencia Internacional de la Mujer}

En 1980 Naciones Unidas realiza la Segunda Conferencia Internacional de la Mujer en Copenhague, con el fin de identificar los avances en los compromisos adquiridos en México, se concluyó entonces que existían factores importantes que limitaban el acceso igualitario de las mujeres a los espacios públicos y que finalmente generaban la dislocación entre los derechos jurídicos y la habilidad de las mujeres para su pleno ejercicio, entre estos factores se encontraban la falta de participación adecuada del hombre en el mejoramiento del papel de la mujer en la sociedad, una voluntad política insuficiente, falta de reconocimiento del valor de las contribuciones de la mujer a la sociedad, una escasez de mujeres en posiciones de adopción de decisiones, insuficientes servicios para apoyar el papel de la mujer en la vida nacional, como cooperativas, guarderías infantiles y facilidades de crédito; falta de los recursos financieros necesarios en general, falta de sensibilización entre las propias mujeres respecto de las oportunidades disponibles (15).

\subsubsection{Tercera Conferencia Internacional Sobre la Mujer}

La Tercera Conferencia Mundia Sobre la Mujer realizada en 1985 en Nairobi era el momento para realizar la evaluación de los compromisos asumidos para el decenio, fue considerada además como una expresión del feminismo a nivel mundial, se calcula que paralelamente asistieron $15 \mathrm{mil}$ representantes de diferentes ONG del mundo, se presentaron informes que revelaban que las mejoras en la situación jurídica y social de las mujeres y los esfuerzos para reducir la discriminación solo habían beneficiado a una pequeña parte de estas; por lo que se concluye que no se habían cumplido los objetivos del Decenio de las Naciones Unidas para La Mujer. Por esta razón, se consideró que se debían aumentar los esfuerzos en tres áreas para favorecer el empoderamiento de la mujer: medidas constitucionales y jurídicas, igualdad en la participación social e igualdad en la participación política y en la adopción de decisiones (15).

\subsubsection{Conferencia Internacional de Población y Desarrollo}

En 1994 se realiza en E Cairo, Egipto un evento con trascendencia en materia de salud sexual y reproductiva, se celebró la Conferencia Internacional de Población y Desarrollo (CIPD) (6) en la que se antepuso a los seres humanos como el centro del proceso de 
desarrollo; destacando que con la satisfacción de las necesidades en materia de planificación familiar y salud reproductiva, junto con otros servicios de salud y de educación, la estabilización de la población ocurrirá naturalmente.

El mejoramiento de la condición de la mujer favorece también su capacidad de adopción de decisiones a todos los niveles en todas las esferas de la vida, especialmente en el terreno de la sexualidad y la reproducción. Esto es esencial, a su vez, para el éxito a largo plazo de los programas de población (6).

La conferencia de El Cairo abarcó un gran número de posibles soluciones en materia de población y desarrollo haciendo énfasis en la importancia de favorecer a las mujeres frente a aspectos relacionados con desigualdades, representación política, educación, formas de discriminación, violencias e ingresos; además resaltó la importancia de ayudarlas a establecer y realizar sus derechos, incluidos los relativos a la salud sexual y reproductiva. Uno de los elementos interesantes en el abordaje que se dio desde población y desarrollo se encuentra en la nominación del varón como parte importante de los procesos de cambio de las condiciones de las mujeres; en el documento final, en el capítulo IV "Igualdad y equidad entre sexos y habilitación de la mujer" se dedica una sección a "las responsabilidades y participación del hombre" y describe como bases para la acción:

Los cambios de los conocimientos, las actitudes y el comportamiento de hombres y mujeres constituyen una condición necesaria para el logro de una colaboración armoniosa entre hombres y mujeres. El hombre desempeña un papel clave en el logro de la igualdad de los sexos, puesto que, en la mayoría de las sociedades, ejerce un poder preponderante en casi todas las esferas de la vida, que van de las decisiones personales respecto del tamaño de la familia hasta las decisiones sobre políticas y programas públicos a todos los niveles. Es fundamental mejorar la comunicación entre hombres y mujeres en lo que respecta a las cuestiones relativas a la sexualidad y a la salud reproductiva y la comprensión de sus responsabilidades conjuntas, de forma que unos y otras colaboren por igual en la vida pública y privada (6).

Reconoce de esta manera que los Estados deben incluir estrategias de vinculación de los varones si pretenden alcanzar los objetivos del plan de acción, de esta manera es objetivo de este apartado alentar a los hombres a que se responsabilicen de su comportamiento sexual y reproductivo, y asuman su función social y familiar. Como estrategias, entre otras, incluye la promoción de la participación de los hombres en todas las esferas de la vida incluida la planificación familiar mediante la información, la educación, la comunicación y las leyes; así mismo insta a favorecer la plena participación de los varones en la vida familiar y la plena integración de la mujer en la vida comunitaria. 
En el capítulo VII "Derechos reproductivos y salud reproductiva" se definen como base para la acción los conceptos, objetivos y estrategias en esta área. Uno de los grandes aportes del documento es la definición del concepto de la salud sexual y reproductiva.

La salud sexual y reproductiva es un estado general de bienestar físico, mental y social, y no de mera ausencia de enfermedades o dolencias, en todos los aspectos relacionados con el sistema reproductivo y sus funciones y procesos. En consecuencia la salud sexual y reproductiva entraña la capacidad de disfrutar de una vida sexual satisfactoria y de procrear sin riesgos, y la libertad para decidir hacerlo o no hacerlo, cuando y con qué frecuencia. Esta última condición lleva implícito el derecho del hombre y de la mujer a obtener información relacionada con la planificación familiar y de su elección de métodos para la regulación dela fecundidad que no estén legalmente prohibidos, y acceso a métodos seguros, eficaces, asequibles y aceptables, el derecho a recibir servicios adecuados de atención de la salud que permitan los embarazos y los partos sin riesgos y den a las parejas las máximas posibilidades de tener hijos sanos (6).

De esta manera se da apertura a una serie de elementos que darán argumento y cuerpo al marco de la salud sexual y reproductiva y articula el concepto con aquellas obligaciones que tienen los Estados en esta materia desde los diversos sectores. Como herramienta para la acción entrega una definición integra de la atención de la salud sexual y reproductiva.

... la atención de la salud reproductiva se define como el conjunto de métodos, técnicas y servicios que contribuyen a la salud y el bienestar reproductivos al evitar y resolver problemas relacionados con la salud reproductiva. Incluye también la salud sexual, cuyo objetivo es el desarrollo de la vida y de las relaciones personales y no meramente el asesoramiento y la atención en materia de reproducción y de enfermedades de transmisión sexual (6).

Como parte de las medidas de implementación, sugrió la estrategia de Atención Primaria en Salud, APS, como elemento que permitiría a todas las personas el acceso a la salud reproductiva abarcando el asesoramiento, información, educación, comunicaciones y servicios en materia de planificación familiar, atención prenatal y partos sin riesgos, atención materna infantil, interrupción del embarazo incluida la prevención del aborto ${ }^{1}$ y el tratamiento de sus consecuencias, entre otras. De la misma manera plantea la importancia de crear programas innovadores que favorezcan la incorporación en la cotidianidad de la

\footnotetext{
${ }^{1}$ Párrafo 8.25 En ningún caso se debe promover el aborto como método de planificación familiar. Se insta a los gobiernos y a las organizaciones intergubernamentales y no gubernamentales pertinentes a incrementar su compromiso con la salud de la mujer, a ocuparse de los efectos que en la salud tienen los abortos realizados en condiciones no adecuadas como un importante problema de salud pública y a reducir el recurso del aborto mediante la prestación de más amplios y mejores servicios de planificación familiar. Conferencia Internacional de Población y Desarrollo (CIPD) El Cairo 1994
} 
igualdad de responsabilidades en planificación familiar, labores domésticas, crianza de los hijos y las hijas, así como en la prevención de enfermedades de transmisión sexual, garantizando que dichos programas lleguen a los lugares de trabajo y esparcimiento, a las escuelas y organizaciones juveniles (6).

Siguiendo con la línea de planificación familiar, la CIPD 1994, plantea que los programas de planificación familiar deben reconocer los métodos de regulación de la fecundidad según las características de sus poblaciones y velar porque mujeres y hombres tengan información y acceso a la mayor gama posible de métodos inocuos y eficaces, y así puedan tomar decisiones bien informadas. De la misma manera considera que es indispensable que los servicios cuenten con sistemas logísticos que garanticen el suministro suficiente y continuo de productos anticonceptivos esenciales de alta calidad (6).

Aunque el documento no nomina como tal los derechos sexuales y reproductivos, en sus apartados se identifica las directrices que darían los recursos para su posterior construcción.

... los derechos reproductivos abarcan ciertos derechos humanos que ya están reconocidos en las leyes nacionales, en los documentos internacionales sobre derechos humanos y en otros documentos pertinentes de las Naciones Unidas aprobados por consenso. Esos derechos se basan en el reconocimiento básico de todas las parejas e individuos a decidir libre y responsablemente el número de hijos, el espaciamiento de los nacimientos y el intervalo entre estos y a disponer de la información y de los medios para ello y el derecho a alcanzar el nivel más elevado de salud sexual y reproductiva. También incluye su derecho a adoptar decisiones relativas a la reproducción sin sufrir discriminación, coacciones ni violencia, de conformidad con lo establecido en los documentos de derechos humanos (6).

\subsubsection{Cumbre Mundial Sobre Desarrollo Social}

En 1995 se desarrolló en Copenhague la Cumbre Mundial sobre Desarrollo Socia, en esta se refuerza la idea de que el ser humano se debe ubicar en el centro del desarrollo de los países y se logra transversalizar en el Plan de Acción la importancia de la posición social de las mujeres y las niñas dentro del conjunto de acciones programadas. Dentro de los compromisos pactados por los páses participantes se encuentra la creación de entornos que favorezcan el desarrollo social, la erradicación de la pobreza, el empleo y la preparación de las comunidades para su desarrollo sostenible, la integración socia como herramienta para construir sociedades estables, el respeto por la dignidad humana, la equidad entre hombres y mujeres, la educación y los servicios de salud incluyendo los de salud sexual y 
reproductiva, y los ajustes estructurales que favorecieran el desarrollo de África y los países menos desarrollados. (16)

\subsubsection{Cuarta Conferencia Mundial de la Mujer}

También en 1995 se realiza la Cuarta Conferencia Mundial de la Mujer en Beijing, en esta se reconocen y se respaldan nuevamente los compromisos adquiridos en las conferencias, convenciones y declaraciones anteriores; entre los que se encuentra el valor central del ser humano en el desarrollo; sin embargo, tras realizar un análisis de los avances dela situación de las mujeres desde la primera conferencia internacional en 1975 en Teherán, se concluye que si bien se han producido adelantos en varios sectores en diferentes páses, aún queda un camino arduo por recorrer, debido a que aún no se han generado cambios en la estructura básica de desigual dad entre hombres y mujeres.

Como precedente importante se encuentra la fuerza que en encuentros anteriores, organizaciones no gubernamentales habían generado en cuanto a la importancia de incorporar a las mujeres en las agendas políticas nacionales internacionales además de involucrarlas plenamente en los procesos de adopción de decisiones (15).

En Beijing 1995 surge como elemento trascendental el reconocimiento de la importancia de trasladar el centro de atención al concepto de género y no exclusivamente a la mujer; considerando a su vez, que toda la estructura de la sociedad y todas las relaciones entre hombres y mujeres en el interior de esa estructura debían ser reevaluadas. La reestructuración de la sociedad y sus instituciones permitiría potenciar el papel igualitario de la mujer frente al hombre en todos los aspectos de la vida; este abordaje reforzaría que los derechos de las mujeres también son derechos humanos y que la igualdad entre géneros era una cuestión de interés universal y de beneficio para todos y todas (15).

Como producto de este encuentro se presentó la Plataforma de Acción de Beijing, documento en el que se abordan doce esferas de especial preocupación que se consideraba que representaban el mayor obstáculo al adelanto de la mujer y que exiǵan la adopción de medidas concretas por parte de los gobiernos y la sociedad civil. Las esferas abordadas son las siguientes (9):

- La mujer y la pobreza;

- La educación y la capacitación de la mujer;

- La mujer y la salud;

- La violencia contra la mujer; 
- La mujer y los conflictos armados;

- La mujer y la economía;

- La participación de la mujer en el poder y la adopción de decisiones;

- Los mecanismos institucionales para el adelanto de la mujer;

- Los derechos humanos de la mujer;

- La mujer y los medios de comunicación;

- La mujer y el medio ambiente;

- La niña.

En el apartado Las Mujeres y la Salud se retoman los conceptos de salud reproductiva, atención en salud reproductiva y derechos sexuales y reproductivos, planteados en la Conferencia Internacional de Población y Desarrollo, El Cairo 1994 (6) (9). Se consideró además, entre otros aspectos, que las mujeres no suelen tener el poder necesario para insistir en que se adopten prácticas sexuales libres de riesgo, tienen un acceso reducido a la información y a los servicios de salud, y crecen en culturas donde es leǵtimo y aceptado el inicio de prácticas sexuales en edades tempranas; generando en consecuencia un riesgo superior en cuestiones de salud. En este sentido, frente al objetivo fortalecer los programas de prevencoón que promueven la salud de la mujer, los gobiernos de los países participantes se comprometen a:

Párrafo 107-d): Reforzar las leyes, reformar las instituciones y promover normas y prácticas que eliminen la discriminación contra las mujeres y dentar tanto a las mujeres como a los hombres a asumir la responsabilidad de su comportamiento sexual con respecto a la procreación...

Párrafo 108-1): Preparar programas espećficos para varones de todas las edades, y para los varones adolescentes, con objeto de proporcionar información completa y fidedigna sobre conducta sexual responsable y sin riesgo, que incluya métodos voluntarios pertinentes y eficaces adoptados por los varones para la prevención del VIH/SDA y otras enfermedades de transmisión sexual, mediante, entre otros, la abstinencia y el uso de preservativos;

En cada una de las esferas de la Plataforma de Acción Beijing 1995 se encuentra articulada la perspectiva de género como un concepto que engloba a toda la sociedad y no meramente a la mujer como centro de la atención en las acciones que lleven a mejorar su posición y condición social (9). La introducción de esta exiǵa que se examinara nuevamente la sociedad en su totalidad y su estructura básica de desigualdad. Por consiguiente, la atención no se centraba únicamente en la mujer y su condición jurídica y social, sino que se diriǵa a reestructurar las instituciones y la adopción de decisiones políticas y económicas en la sociedad en su conjunto (15). 
“La incorporación de la perspectiva de género es el proceso de evaluación de las consecuencias para las mujeres y los hombres de cualquier actividad planificada, inclusive las leyes, políticas o programas, en todos los sectores y a todos los niveles. Es una estrategia destinada a hacer que las preocupaciones y experiencias de las mujeres, así como de los hombres, sean un elemento integrante de la elaboración, la aplicación, la supervisión y la evaluación de las políticas y los programas en todas las esferas políticas, económicas y sociales, a fin de que las mujeres y los hombres se beneficien por igual y se impida que se perpetúe la desigual dad. El objetivo final es lograr la igualdad entre los géneros" (10).

Al respaldar el documento final de la conferencia, los 17 mil participantes, entre estos los representantes de 189 páses, se comprometieron a generar mecanismos que contribuyeran a la incorporación de la perspectiva de género en la corriente principal de la sociedad mediante la acción de todos los programas e instituciones (15).

El marco de los derechos y el acceso de las mujeres a estos con igualdad de oportunidades se han presentado desde diversas miradas que han permitido evolucionar en conceptos que garantizan su ejercicio pleno en toda la población. Como se ha mencionado con anterioridad, el movimiento feminista y el desarrollo de teorías y mecanismos en los años setentas y ochentas permitieron poner a las mujeres en primera fila y demostraron que el género no solamente se refería a las maneras en las cuales los roles, las actitudes, los valores y las relaciones con respecto a niños y niñas, mujeres y hombres se construyen en las sociedades; demostraron que el género también construye instituciones sociales, como el derecho, el control social, la religión, la familia, el imaginario, la ideología etc.; las cuales crean posiciones sociales distinguibles para una asignación desigual de derechos y responsabilidades (17).

La inclusión de la perspectiva de género permitió visibilizar las relaciones de poder entre los sexos; esto se desarrolló a finales del siglo XX cuando se criticó fuertemente el modelo humano de hombre, blanco, occidental, padre de familia, adinerado, heterosexual, sin discapacidades visibles etc.; y a su vez se develo la importancia de incorporar elementos de espacios públicos y privados, así como la posibilidad de incluir la diversidad de mujeres de todos los colores, edades, capacidades, religiones, orientaciones y prácticas en todas las esferas de la vida (17).

\subsubsection{Declaración de Derechos Sexuales}

En 1997 se proclamaría la Declaración de los Derechos Sexuales, en el XII Congreso Mundial de Sexología, Sexualidad y Derechos Humanos, partiendo de que la sexualidad es 
parte integral de la personalidad de todo ser humano y que su desarrollo depende de la satisfacción de necesidades humanas básicas como el deseo de contacto, intimidad, expresión emocional, placer, ternura y amor. Considerando que los derechos sexuales deben ser reconocidos, promovidos, respetados y defendidos por todas las sociedades con todo sus medios y que la salud sexual será el resultado de un ambiente que reconoce, respeta y ejerce dichos derechos. Describe nueve Derechos Sexuales (18):

- Derecho a la libertad, que excluye todas las formas de coerción, explotación y abusos sexuales en cualquier momento de la vida y en toda condición. La lucha contra la violencia constituye una prioridad.

- Derecho a la autonomía, integridad y seguridad corporal. Este derecho abarca el control y disfrute del propio cuerpo libre de torturas, mutilaciones y violencias de toda índole.

- Derecho a la igualdad sexual. Se refiere a estar libre de todas las formas de discriminación. Implica respeto a la multiplicidad y diversidad de las formas de expresión de la sexualidad humana, sea cual fuere el sexo, género, edad, etnia, clase social, religión y orientación sexual a la que pertenece.

- Derecho a la salud sexual. Incluyendo la disponibilidad de recursos suficientes para el desarrollo de la investigación y conocimientos necesarios para su promoción. El SIDA y las ETS (Enfermedades de transmisión sexual) requieren de más recursos para su diagnóstico, investigación y tratamiento.

- Derecho a la información amplia, objetiva y verídica sobre la sexualidad humana que permita tomar decisiones respecto a la propia vida sexual.

- Derecho a una educación sexual integral desde el nacimiento y a lo largo de toda la vida. En este proceso deben intervenir todas las instituciones sociales.

- Derecho a la libre asociación. Significa la posibilidad de contraer o no matrimonio, de disolver dicha unión y de establecer otras formas de convivencia sexual.

- Derecho a la decisión reproductiva libre y responsable. Tener o no hijos, el espaciamiento de los nacimientos y el acceso a las formas de regular la fecundidad. El niño tiene derecho a ser deseado y querido.

- Derecho a la vida privada, que implica la capacidad de tomar decisiones autónomes respecto a la propia vida sexual dentro de un contexto de ética personal y social. E ejercicio consciente racional y satisfactorio de la sexualidad es inviolable es insustituible. 


\subsubsection{Objetivos del Desarrollo del Milenio (19) (20)}

En el año 2000 los 189 páses miembros de las Naciones Unidas se reúnen para reafirmar la fe en la organización y su Carta, como pilares fundamentales para un mundo más pacífico, próspero y justo. En este evento la Asamblea General de las Naciones Unidas aprueba la Declaración del Milenio que define las líneas de acción y los Objetivos de Desarrollo del Milenio, incluidas 18 metas con plazos cronológicos delimitados.

Objetivo 1: Erradicar la pobreza extrema y el hambre.

Objetivo 2: Lograr la enseñanza primeria universal.

Objetivo 3: Promover la igualdad entre los géneros y la autonomía de la mujer.

Objetivo 4: Reducir la mortalidad infantil.

Objetivo 5: Mejorar la salud materna.

Objetivo 6: Combatir el VIH/SIDA, el paludismo y otras enfermedades.

Objetivo 7: Garantizar la sostenibilidad del medio ambiente.

Objetivo 8: Fomentar una asociación mundial para el desarrollo.

Como parte de la consolidación del proceso se presentaron 48 indicadores, cada uno con orientaciones sobre su definición, justificación, conceptos y fuentes de datos, estas herramientas permiten la supervención de las metas. De acuerdo a los fines de este documento, se contemplarán los objetivos e indicadores relacionados con la perspectiva de género y la salud sexual y reproductiva (20).

El objetivo número 3: Promover la igualdad entre los géneros y el empoderamiento de la mujer, se propone como meta eliminar las desigualdades entre los géneros en la enseñanza primaria y secundaria, preferiblemente para el año 2005, y en todos los niveles de enseñanza antes de fines de 2015. Con indicadores que apuntan a determinar la relación entre los sexos, en cuanto a vinculación en los diferentes grados de enseñanza, relación de alfabetización, proporción de mujeres en empleos remunerados en el sector no agrícola y proporción de escaños ocupados por mujeres en los parlamentos nacionales; considerando los elementos eje de mediciones como esenciales en la emancipación de la mujer dentro de la sociedad (20).

En el objetivo número 5 "Mejorar la salud materna" se referencia como meta la reducción de la mortalidad materna en tres cuartas partes, siendo indicadores para la supervisión de la meta la tasa de mortalidad materna y el porcentaje de partos con asistencia de personal sanitario especializado. 
Combatir el VIH/SIDA, el paludismo y otras enfermedades, es el objetivo número 6 y en relación a la salud sexual y reproductiva plantea como meta la detección y reducción de la propagación del VIH/SIDA para el año 2015. Este objetivo será analizado a la luz de indicadores como la prevalencia de VIH entre las mujeres embarazadas de 15 a 24 años; porcentaje de uso de preservativo dentro de la tasa de uso de anticonceptivos, uso de preservativos en la última relación sexual, porcentaje de población con conocimientos amplios y correctos sobre el VIH/SIDA, tasa de prevalencia de uso de anticonceptivos.

Todos los indicadores planteados cuentan en sus orientaciones con un apartado denominado arestiones de género, que permite resaltar la importancia de la perspectiva de género en la medición de las variables a supervisar en el proceso del logro de los Objetivos de Desarrollo del Milenio; de esta manera devela que los problemas sociales que se muestran como problemas de salud, afectan de manera diferente a hombres y a mujeres.

Cada año se hace publicación oficial sobre los avances de los páses en materia del logro de los objetivos del milenio. Por su parte La Misión Permanente Argentina ante Naciones Unidas trabaja desde 1945diversos temas de relevancia, desde la promoción de la democracia, los derechos humanos, la igualdad de género, la gobernanza, el desarrollo económico y social, la salud internacional, medio ambiente y desarrollo sostenible, hasta la protección de refugados, socorro en casos de desastre, la lucha contra el terrorismo y el desarme, entre otros; por lo que sus compromisos son de carácter jurídico vinculante (21).

\subsubsection{Política de Igualdad de Género - Organización Panamericana de la Salud.}

Consciente de que en la actualidad se evidencian de manera significativa las diferencias entre hombres y mujeres en relación a los factores determinantes de la salud, reconociendo que la dinámica de las relaciones de género en el campo sanitario es trascendental en el logro de un estado óptimo de salud y que no se ha brindado, hasta ese momento, la importancia y la atención que requiere; en el año 2002 la Organización Mundial de la Salud emite la "Política en Materia de Género. Integración de la perspectiva de género en la labor de la OMS". Esta iniciativa se fundamenta en la intencionalidad de dar respuesta a la inequidad entre hombres y mujeres en materia de salud mediante la incorporación de la perspectiva de género en todas las facetas de su labor: investigación, planificación, ejecución, vigilancia y evaluación de programas, gestión de recursos humanos y preparación de presupuestos. Así mismo define que las oficinas regionales deberán disponer de los recursos necesarios para la creación de políticas aplicables a sus características poblacionales (22). 
Las oficinas regionales y en los países habrán de poner en pie sus propios mecanismos, con el personal y los recursos apropiados, y colaborar con la Sede en la elaboración de estrategias para promover la integración de los asuntos de género en los sistemas de salud, trabajando principalmente con los ministerios de salud, otros sectores, organizaciones no gubernamentales y la sociedad civil.

Siguiendo los lineamientos emitidos por la OMS en este documento, en 2005 se lanza la Política de Igualdad de Género- OPS, en esta se plantea la necesidad de trabajar con los diferentes gobiernos y la sociedad civil para eliminar las desigualdades en materia de salud entre hombres y mujeres. De esta manera como meta de la Política se plantea el generar aportes en el logro de la igualdad de género mediante la investigación, la creación de políticas y programas y la identificación de factores determinantes de la igualdad de género en materia de salud. En este documento es posible identificar una línea que apunta a definir la transversalización de la perspectiva de género hasta el punto de institucionalizar el término.

Los objetivos establecidos para el sector salud desde la Política de Igualdad de Género son (23):

- Logro de un estado óptimo de salud y de bienestar para las mujeres y los hombres, durante todo su ciclo de vida y en los diversos grupos de población. Un componente integral de este logro es la eliminación de todas las formas de violencia contra la mujer, incluido el tráfico de mujeres.

- Asignación equitativa de los recursos a fin de asegurar que las mujeres y los hombres tengan acceso a atención de salud adecuada de acuerdo con sus necesidades especiales a lo largo de todo el ciclo de vida, incluidas sin carácter limitativo las relacionadas con la salud sexual y reproductiva. La equidad supone dar más a quienes tienen menos, con miras a corregir desequilibrios en los resultados.

- Participación igualitaria de las mujeres y los hombres en la toma de decisiones relacionadas con su propia salud, el bienestar de sus familias y sus comunidades y la definición de programas de política sanitaria. El empoderamiento individual y colectivo de las mujeres es visto como un fin altamente importante en sí mismo y como una condición esencial para lograr la igualdad de género y el desarrollo sostenible.

- Distribución justa entre las mujeres y los hombres de la carga y las retribuciones asociadas con el trabajo para el desarrollo de la salud, tanto en el ámbito público como en el doméstico de la familia. 
Un elemento importante de la Política es que incorpora, con un enfoque de salud, una serie de conceptos antes descritos desde otros sectores como el social, el económico y el político (23):

La igualdad de género en la salud significa que las mujeres y los hombres se encuentran en igualdad de condiciones para ejercer plenamente sus derechos y su potencial para estar sanos, contribuir al desarrollo sanitario y beneficiarse de los resultados. El logro de la igualdad de género exige medidas concretas destinadas a eliminar las inequidades por razón de género.

La equidad de género significa una distribución justa de los beneficios, el poder, los recursos y las responsabilidades entre las mujeres y los hombres. El concepto reconoce que entre hombres y mujeres hay diferencias en cuanto a las necesidades en materia de salud, al acceso y al control de los recursos, y que estas diferencias deben abordarse con el fin de corregir desequilibrios entre hombres y mujeres. La inequidad de género en el ámbito de la salud se refiere a las desigualdades injustas, innecesarias y prevenibles que existen entre las mujeres y los hombres en el estado de la salud, la atención de salud y la participación en el trabajo sanitario. Las estrategas de equidad de género se utilizan para finalmente lograrla igualdad. La equidad es el medio, la igualdad es el resultado.

La transuersalizacón de la perspectiva de género es "...el proceso de evaluar las consecuencias que tiene para los hombres y las mujeres cualquier acción planeada, incluidas la legislación, las políticas y los programas, en cualquier sector y en todos los niveles. Es una estrategia para hacer de los problemas y experiencias de las mujeres y los hombres una dimensión integral del diseño, la ejecución, la vigilancia y la evaluación de las políticas y programas en todas las esferas políticas, económicas y sociales, de tal manera que no se perpetúe la desigualdad. El objetivo último es conseguir la igualdad de género". Una estratega para transversalizar la perspectiva de género puede incluir iniciativas afirmativas dirigidas bien sea a las mujeres 0 a los hombres.

En documentos emitidos con anterioridad por otros sectores, se identificaba la importancia de implementar el concepto de perspectiva de género en todas las acciones dirigidas a la población incluidas las de salud, esta política abre, de manera oficial, la puerta para la incorporación de esta importante temática en todas las acciones de salud. 


\subsection{La salud sexual y reproductiva en el marco normativo nacional de la Argentina}

Las conferencias internacionales han ayudado a elaborar el marco jurídico y las metas de política para la aplicación del derecho a la salud sexual y reproductiva. En Argentina los avances en la materia han evolucionado paralelamente con el contexto sociopolítico del pás, de esta manera, según las corrientes ideológicas de los gobiernos se ha determinado el papel de la salud sexual y la reproducción en el marco legal y en las políticas dirigidas a garantizar el derecho a gozar de una plena salud sexual.

\subsubsection{Marco normativo nacional de la salud sexual y reproductiva}

En 1949 el ministro de Salud Publica Dr. Ramón Carrillo creó un plan de Protección a la Madre y al Niño, propulsó la denuncia obligatoria del embarazo y el aborto, y prohibió las propagandas anticoncepcionales. Posteriormente, en 1974 mediante el decreto 959 el ministro de Bienestar Social José López Rega, prohibió las prácticas de control de la natalidad en hospitales públicos y se restringió la comercialización de anticonceptivos; bajo el gobierno militar tras el decreto 3938 en 1977 se eliminarían todas las actividades de control de la natalidad (24) (25).

En 1986 con el gobierno democrático del Dr. Raúl Alfonsín, a través del decreto 2274 se derogan las restricciones en materia de salud reproductiva, se realizan tareas de difusión y asesoramiento necesarios para que el derecho a decidir en materia reproductiva pueda ser ejercido por la población con libertad y responsabilidad (25).

Dado el estado federal de la República de Argentina, que permite la adopción de normatividad con cierta autonomía por parte de las provincias, en 1988 se crea el primer Programa de Salud Reproductiva en la Ciudad de Buenos Aires y en 1991 en La Pampa la primera Ley de Salud Sexual y Reproductiva.

El contexto internacional orientado por los tratados internacionales, la reforma constitucional de 1994, el debate público de Cairo y Beijing y los movimientos sociales de mujeres influirían en la inclusión del tema de la salud sexual y reproductiva en la normatividad, de este modo entre 1994 y 2001, catorce jurisdicciones habían sancionado leyes de salud sexual y reproductiva. 


\subsubsection{Programa Nacional de Salud Sexual y Procreación Responsable}

En el año 2003 se sanciona la Ley Nacional 25.673 mediante al cual se crea el Programa Nacional de Salud Sexual y Procreación Responsable en el ámbito del Ministerio de Salud. Se contempla entre sus objetivos (11):

- Alcanzar para la población el nivel más elevado de salud sexual y procreación responsable con el fin de que pueda adoptar decisiones libres de discriminación, coacciones o violencia;

- Disminuir la morbimortalidad materno-infantil;

- Prevenir embarazos no deseados;

- Promover la salud sexual de los adolescentes;

- Contribuir a la prevención y detección precoz de enfermedades de transmisión sexual, de $\mathrm{VIH} /$ sida y patologías genital y mamaria;

- Garantizar a toda la población el acceso a la información, orientación, métodos y prestaciones de servicios referidos a la salud sexual y procreación responsable;

- Potenciar la participación femenina en la toma de decisiones relativas a su salud sexual y procreación responsable.

Definido explícitamente mediante sus artículos el Programa Nacional de Salud Sexual y Procreación Responsable será destinado a la población general sin discriminación alguna y su ejercicio será en un marco de derechos; así mismo los Ministerios de Educación y Desarrollo Social y Medio Ambiente serán responsables de las acciones de capacitación a educadores, trabajadores sociales y demás agentes comunitarios en temas que favorezcan el logro de los objetivos. Adicionalmente define su responsabilidad en la creación de convenios con las provincias para que cada una organice sus programas en cada una de sus jurisdicciones; siendo esta la piedra angular para la estructuración de los programas en todo el territorio nacional.

Se considera, entonces que la Ley 25.673 de 2002 fue el primer paso para la construcción del programa a nivel de nación desde el Ministerio de Salud en 2003, dando vía a una serie de avances en el campo de los derechos en materia de salud sexual y reproductiva. En 2006 se sancionó la Ley Nacional 26.130 de Anticoncepción Quirúrgica que reconocería la ligadura de trompas y la vasectomía como métodos anticonceptivos; posteriormente se sancionaría la Ley Nacional 25.929 de Derechos de Padres e Hijos durante el Proceso de Nacimiento, donde se establecen los derechos de las mujeres en el embarazo, trabajo de parto, parto y post parto. Otras acciones como la sanción de las leyes nacionales de 
Régimen Especial de Alumnas Embarazadas, de Acciones contra Alumnas Embarazadas y la Ley Nacional de Educación Sexual Integral, permiten analizar que los avances en el tema no solo pretendían el control de la natalidad sino que además buscaban garantizar los derechos (2).

Es así como desde su creación en el años 2002, en el desarrollo del programa se pueden visualizar tres etapas; una etapa inicial (2003 a 2006), en donde el programa se encontraba bajo la Dirección Nacional de Maternidad e Infancia, una etapa de institucionalización (2006 a 2010), donde adquiere autonomía administrativa y aborda el enfoque de las mujeres como sujetos de derechos alejándola del su rol exclusivamente materno; entre los años de 2010 a la fecha el programa se encuentra, así, en una etapa de consolidación, en la que se garantiza la provisión de anticonceptivos, se integra diversas identidades sexuales, se implementan políticas dirigidas a varones y a grupos específicos y un abordaje integral de la salud sexual y la salud reproductiva con elementos relacionados pero independientes (2)

Inicialmente el Programa Nacional de Salud Sexual y Procreación Responsable establece como objetivo central la disminución de las desigualdades que afectan la salud sexual y reproductiva de la población argentina a partir del mejoramiento del acceso y la calidad de los servicios de salud, dentro de su estructura se priorizaron cuatro ejes:

- Acceso universal y gratuito a servicios de salud sexual y reproductiva.

- Igualdad de oportunidades.

- Calidad de la atención.

- Redistribución de recursos materiales y simbólicos

Esto se desarrollaría mediante la articulación del programa nacional con los diferentes programas provinciales, la consolidación de un sistema de aseguramiento de insumos anticonceptivos, los recursos humanos atamente capacitados y la implementación de estrategias de comunicación y difusión de los derechos sexuales y reproductivos (2).

En 2010 se platea una estratega integral que refuerza la difusión y capacitación a los distintos actores del sistema de salud en derechos sexuales y reproductivos desde una perspectiva de género y derechos humanos; se garantizó la provisión de anticonceptivos en 2011 y se creó un sistema de información y monitoreo para identificar los resultados de la política de salud sexual y reproductiva. Adicionalmente se readecuaron los ejes programáticos en el marco del Plan de Reducción de la Mortalidad Materno Infantil, de la Mujer y la Adolescente, de la Subsecretaria de Salud Comunitaria del Ministerio de la Nación; es así como se implementan estrategias de fortalecimiento de los Programas de Salud Sexual y reproductiva a nivel nacional y provincial con el fin de mejorar la cobertura y 
la calidad de la atención, de promoción de los derechos sexuales y reproductivos y de distribución de distintos métodos anticonceptivos y campañas de difusión con el fin de garantizar el acceso igualitario a la salud sexual y reproductiva (2).

Frente a los avances que se iban presentando, el programa organizó sus equipos de trabajo en función de los objetivos propuestos. En 2006 conformó el Área de Capacitación y comunicación, así como el Sistema de Información y el Sistema de Aseguramiento de Insumos Anticonceptivos; en este último se definieron además los criterios de provisión de anticonceptivos para mujeres y distribución de preservativos masculinos (2).

En el 2007 se creó el Consejo Asesor del Programa Nacional de Salud Sexual y Procreación Responsable, estableciendo que estaría integrado por la unidad de coordinación del programa, organizaciones sociales, referentes académicos y organismos de cooperación. Como resultado de la implementación de esta estrategia junto con los aportes finales de las Mesas de Trabajo sobre Diversidad Sexual, se consideró como de vital importancia desarrollar acciones específicas que permitieran remover las barreras que obstaculizan el ejercicio de los derechos sexuales y reproductivos. Posteriormente Mediante la aprobación de la Ley de Matrimonio Igualitario en el 2010, se amplió el reconocimiento de los derechos humanos, cívicos económicos y sexuales y reproductivos de la comunidad de lesbianas, gays, bisexuales y trans; la sanción de la ley potencializa la posibilidad de inclusión socia (2).

\subsubsection{Marco normativo provincial de la salud sexual y reproductiva}

A través de la Ley Provincia 13066 de 2003, se crea en el ámbito de la Provincia de Buenos Aires, el programa provincia que garantiza las políticas orientadas a la promoción y desarrollo de la salud reproductiva y procreación responsable; con la premisa esencial del respeto al derecho del hombre y la mujer a tomar decisiones basadas en información veraz, en materia de salud sexual y reproductiva, a tener acceso a servicios y métodos anticonceptivos de calidad y a prevenir y tratar enfermedades de transmisión sexual y patologías sexuales y mamarias. Se establece mediante esta ley la Atención Primaria en Salud y la creación de espacios de asesoramiento y consejería como estrategias esencial para el cumplimiento de los objetivos (12). Posteriormente la resolución No. 1395 de 2010 entrega la potestad del programa al área de Políticas de Género (7). 


\subsubsection{Programa de Salud Sexual y Procreación Responsable de la provincia de Buenos Aires (7)}

El Programa Provincial de Salud Reproductiva y Procreación Responsable (PPSRyPR) se crea a partir de la Ley 13.066 sancionada en Mayo de 2003 con el propósito de garantizar las políticas orientadas a la promoción y desarrollo de la salud reproductiva y la procreación responsable, para toda la población sin discriminación alguna. En Noviembre de 2003 el Decreto Reglamentario 2327 establece su implementación en el ámbito del Ministerio de Salud de la Provincia de Buenos Aires. En el año 2007 mediante el Decreto 4559 del Ministerio de Salud se agregan las prácticas denominadas Ligadura de Trompas de Falopio y Ligadura de Conductos Deferentes o Vasectomía, como métodos de anticoncepción, en concordancia con la Ley Nacional Nro. 26.130 de anticoncepción quirúrgica. A su vez, en el año 2006 (Resolución № 1245) el Instituto de Obra Médico Asistencial (IOMA) de la provincia de Buenos Aires aprueba el Plan SER de Salud Sexual y Reproductiva El mismo tiene como objetivo la prevención, diagnóstico temprano y tratamiento oportuno de las enfermedades de transmisión sexual y cáncer génito - mamario, y busca garantizar el acceso a la información sobre salud sexual y reproductiva, encuadrándose en las obligaciones emanadas de la Ley 13.066.

Desde su creación, el Programa funcionó como subprograma dentro del Área Materno Infantil. En mayo de 2010 mediante Resolución № 1395 el programa comienza a funcionar bajo la órbita del Área de Políticas de Género, dependiente de la Unidad Ministro. A partir de esta iniciativa, se intenta dar respuesta a los compromisos adquiridos por el pás con vistas a adoptar medidas tendientes a mejorar la calidad de vida de la población a través de la adopción de un enfoque de derechos y de género en los servicios de la salud.

La perspectiva de género resulta fundamental en un abordaje tendiente a la promoción de los derechos y la construcción de una perspectiva que denuncia situaciones de desigualdad, discriminación y violencia y que intenta promover relaciones más igualitarias. Ela implica:

- La participación y el protagonismo de todos y todas en el cuidado de la salud en general y de la salud sexual y reproductiva en particular.

- La consolidación de una mirada crítica tendiente a desnaturalizar ciertas percepciones y estereotipos que, a negar las singularidades, pueden conducir a situaciones de discriminación y violencia.

- La identificación de obstáculos para el ejercicio pleno de los derechos.

- La construcción de estrategias conjuntas tendientes a atenuar desigual dades materiales y simbólicas y a promover relaciones más igualitarias. 
Desde esta perspectiva, la promoción de los derechos sexuales y reproductivos de varones y mujeres es una de las acciones que desde el enfoque de género favorecen la mejora de la calidad y equidad del sistema de salud, contribuyendo así a disminuir las desigualdades.

El Programa Provincial de Salud Reproductiva y Procreación Responsable (PSR y PR) cuenta en cada una de las Regiones Sanitarias con un Referente de Salud Reproductiva y PR del área que tiene a su cargo las acciones concernientes a su difusión e implementación.

\section{Objetivos del PPSSyPR}

- Reconocer el derecho a la salud y a la dignidad de la vida humana.

- Respetar las pautas culturales, éticas y religiosas del demandante.

- Disminuir la morbi-mortalidad materno infantil.

- Contribuir en la educación sexual de la población y en especial de los adolescentes, prevenir y detectar las enfermedades de transmisión sexual, patologías genitales y mamarias.

- Prevenir mediante información y educación, los abortos.

- Brindar información respecto de las edades y los intervalos intergenésicos considerados más adecuados para la reproducción.

- Promover la participación de los varones en el cuidado de la salud reproductiva y la paternidad responsable.

- Otorgar prioridad a la atención de la salud reproductiva de las adolescentes.

- Capacitar a docentes, profesionales y personal específico en educación sexual.

- Informar, otorgar y prescribir por parte del profesional médico, de los conceptivos y anticonceptivos, aprobados por la ANMAT, de carácter transitorios y reversibles a ser elegidos libremente por parte de los beneficiarios del Programa, los que serán otorgados respetando las convicciones y criterios de los destinados.

\section{Líneas de Acción del PPSSyPR}

- Fortalecimiento de la gestión integral del Programa Provincial

$\checkmark$ Diseño e implementación del Programa desde un enfoque de derechos y de género y atendiendo a la promoción de la APS.

$\checkmark$ Conformación del equipo de trabajo y de las áreas de trabajo en función de las múltiples dimensiones de la problemática de la Salud Sexual y Reproductiva.

$\checkmark$ Confección del presupuesto del Programa Provincial. 


\section{- Conformación del Sistema de Aseguramiento de insumos anticonceptivos}

$\checkmark$ Distribución de Insumos anticonceptivos a través del Programa Remediar + REDES.

$\checkmark$ Compra de Insumos por parte del Programa Provincial: Realización de la 10 licitación Pública realizada por el Ministerio de Salud de la Provincia de Buenos Aires e inclusión en el Presupuesto Provincial.

$\checkmark$ Promoción del acceso gratuito a métodos anticonceptivos hormonales (orales combinados, orales para lactancia e inyectables), dispositivos intrauterinos (Diu) AHE, ligadura tubárica, vasectomía y preservativos. Cobertura para usuarias del sistema de Obras Sociales y Medicina Prepaga.

\section{- Fortalecimiento de los Programas Regionales y Municipales de Salud Reproductiva y Procreación Responsable}

Implementación de proyectos de capacitación y asistencia técnica que apunten a fortalecimiento de la gestión de los Programas Regionales y Municipales en las 12 Regiones Sanitarias. Dichos proyectos configuran las "buenas prácticas" en salud sexual y reproductiva, desde una perspectiva de derechos y de género y se realizan con el apoyo de distintos organismos nacionales e internacionales (Programa Nacional de Salud Sexual y Procreación Responsable; Fondo de Población de Naciones Unidas - UNFPA; OPS; FLACSO; IPPF; FUSA).

El proceso de definición de ejes temáticos, lineamientos y focalización territorial de las acciones de capacitación y asistencia técnica se apoya en el análisis de los objetivos de gestión del Programa, dirigidos a la disminución de las brechas en salud sexual y reproductiva que afectan a la población enfocándose en dos dimensiones clave: accesibilidad y calidad de atención

Los ejes temáticos de las actividades de capacitación son los siguientes:

$\checkmark$ Género y Derechos sexuales y reproductivos.

$\checkmark$ Consejerías en salud sexual y reproductiva destinada a jóvenes y adultos/as.

$\checkmark$ Consejerías posaborto.

$\checkmark$ Sexualidad adolescente.

$\checkmark$ Violencia de género y violencia sexual. 


\section{- Implementación programas de formación continua y capacitación de los recursos humanos del Programa}

Calificación del recurso humano de los servicios de SRyPR y promoción del enfoque de derechos y de género. Promoción y extensión de servicios y modalidades de consejerías para adolescentes y jóvenes.

$\checkmark \quad$ Capaditadón en senvido. En el marco de las supervisiones de servicios, se propone también la capacitación de los efectores, promoviendo la comprensión y reflexión sobre las prácticas profesionales para su mejoramiento permanente.

$\checkmark \quad$ Encuentros Regionales Intersectoriales. Este dispositivo busca generar un espacio de trabajo e intercambio a nivel regional entre el PPSRyPR, los Programas Regionales y Municipales, efectores y otros sectores vinculados con la temática (educación, desarrollo social, cultura, juventud, universidad), con la finalidad de articular estrategias conjuntas que fortalezcan las acciones de promoción integral de la salud sexual y reproductiva que se estén implementando a nivel local y regional.

\section{- Visitas de Supervisión de Servicios de SS y PR}

En el marco del proyecto de mejora de la calidad de servicios de Salud Sexual y Procreación Responsable (PPSRyPR y Programa Funciones Esenciales de Salud Pública-FESP) se apunta al fortalecimiento de los actores a nivel del territorio en aspectos clave a la gestión de los programas regionales de SRyPR. El propósito consiste en articular y profundizar los ejes programáticos llevados adelante por los equipos locales en cada jurisdicción y detectar información relevante para la toma de decisiones en el marco de la mejora de la atención y calidad de servicios de SSyR.

\section{- Comunicación Social}

$\checkmark$ Convenios de cooperación con otras áreas de gobierno y diversos organismos gubernamentales y no gubernamentales que promuevan la difusión de los Derechos sexuales y Derechos reproductivos en el marco de los Derechos Humanos. (Sec. De Derechos Humanos, Universidades).

$\checkmark$ Campañas de comunicación: esta acción es fundamental para el fortalecimiento del Programa Provincial, así como lo es también en la difusión de los Derechos sexuales y Derechos reproductivos.

$\checkmark$ Ĺnea telefónica gratuita 0800 Salud Sexual. Acciones de apoyo y difusión del 0800 del Ministerio de Salud de la Nación que brinda información en salud sexual y reproductiva a toda la población a fin de promover la accesibilidad a los servicios de salud sexual y reproductiva y a la información. 
$\checkmark$ Consultas en línea. Acceso a consultas y contenidos del Programa Provincial a través de la WEB del Ministerio de Salud.

$\checkmark$ Distribución de materiales de difusión del Programa en lugares estratégicos.

$\checkmark$ Acciones comunicacionales diversas a través de micromedios y medios de alcance comunitario, incluyendo actividades de comunicación y educación.

\section{- Desarrollo Comunitario y participación social}

$\checkmark$ Construcción de un espacio institucional y sistemático para monitorear las políticas públicas en salud sexual y salud reproductiva desde la perspectiva de la población usuaria

$\checkmark$ Articulación y diálogo con referentes de instituciones de la sociedad civil, organizaciones comunitarias y movimientos sociales que permita promover los derechos sexuales y reproductivos, la difusión de derechos, la sensibilización e incidencia en el espacio público, el incremento, mejoramiento y efectivo acceso a los servicios.

$\checkmark$ Acompañamiento y asistencia técnica en proyectos de SSyPR en el espacio comunitario y social mediante la realización de reuniones destinadas a trabajar en el diseño, planeamiento, organización y fortalecimiento de acciones de promoción de los derechos sexuales y reproductivos.

\section{- Articulaciones interministeriales e intersectoriales}

$\checkmark$ Construcción de un espacio de articulación y reflexión y análisis de la problemática de la educación sexual (marco conceptual, perspectivas y abordaje) desde el enfoque de los derechos sexuales y reproductivos en el campo de la educación formal y no formal.

$\checkmark$ Generar investigaciones desde una perspectiva multidisciplinaria

$\checkmark$ Construir un espacio de trabajo conjunto entre los Programas de los distintos ministerios (Salud, Educación, Desarrollo Socia).

\section{- Consejo Asesor del PPSSyPR}

Construir un espacio de diálogo y cooperación entre el Programa Provincial, integrantes de agencias de Naciones Unidas, asociaciones científicas y profesionales, sector educativo y organizaciones no gubernamentales especializadas en la temática, con el objetivo de analizar y debatir los principales temas que competen al área, como también, elaborar líneas de acción posibles. 


\subsection{Salud Sexual y Reproductiva. Conceptualización.}

En 1994 la conferencia de El Cairo abarcó un gran número de posibles soluciones en materia de población y desarrollo haciendo énfasis en la importancia de favorecer a las mujeres frente a aspectos relacionados con desigualdades, representación política, educación, formas de discriminación, violencias e ingresos; además resaltó la importancia de ayudarlas a establecer y ejercer sus derechos, incluidos los relativos a la salud sexual y reproductiva.

En el documento final de esta conferencia, capítulo VII "Derechos reproductivos y salud reproductiva" se definen como base para la acción los conceptos, objetivos y estrategias en esta área Uno de los grandes aportes del documento es la definición del concepto de la salud sexual y reproductiva.

La salud sexual y reproductiva es un estado general de bienestar físico, mental y social, y no de mera ausencia de enfermedades o dolencias, en todos los aspectos relacionados con el sistema reproductivo y sus funciones y procesos. En consecuencia la salud sexual y reproductiva entraña la capacidad de disfrutar de una vida sexual satisfactoria y de procrear sin riesgos, y la libertad para decidir hacerlo o no hacerlo, cuando y con qué frecuencia. Esta última condición lleva implícito el derecho del hombre y de la mujer a obtener información relacionada con la planificación familiar y de su elección de métodos para la regulación de la fecundidad que no estén legalmente prohibidos, y acceso a métodos seguros, eficaces, asequibles y aceptables, el derecho a recibir servicios adecuados de atención de la salud que permitan los embarazos y los partos sin riesgos y den a las parejas las máximas posibilidades de tener hijos sanos (6).

De esta manera se da apertura a una serie de elementos que darán argumento y cuerpo a marco de la salud sexual y reproductiva y articula el concepto con aquellas obligaciones que tienen los Estados en esta materia desde los diversos sectores. Como herramienta para la acción entrega una definición integral de la atención de la salud sexual y reproductiva.

... la atención de la salud reproductiva se define como el conjunto de métodos, técnicas y servicios que contribuyen a la salud y el bienestar reproductivos al evitar y resolver problemes relacionados con la salud reproductiva. Incluye también la salud sexual, cuyo objetivo es el desarrollo de la vida y de las relaciones personales y no meramente el asesoramiento y la atención en materia de reproducción y de enfermedades de transmisión sexual (6).

Como parte de las medidas de implementación se sugirió la estrategia de atención primaria en salud, APS, como elemento que permitiría a todas las personas el acceso a la salud 
reproductiva abarcando el asesoramiento, información, educación, comunicaciones y servicios en materia de planificación familiar, atención prenata y partos sin riesgos, atención materna infantil, interrupción del embarazo incluida la prevención del aborto ${ }^{2}$ y el tratamiento de sus consecuencias, entre otras. De la misma manera plantea la importancia de crear programas innovadores que favorezcan la incorporación en la cotidianidad de la igualdad de responsabilidades en planificación familiar, labores domésticas, crianza de los hijos y las hijas así como en la prevención de enfermedades de transmisión sexual, garantizando que dichos programas lleguen a los lugares de trabajo y esparcimiento, a las escuelas y organizaciones juveniles (6).

No alejada de un tema de tan vita importancia, la Organización Panamericana de la Salud ha promovido entre sus Estados miembros, la relevancia de la intervención integral de la salud sexual y reproductiva y con el mismo evolucionar en el tiempo plantea nuevos abordajes de esta, así pues, para esta organización, la sexualidad es considerada por como una dimensión esencial de la vida de las personas, las familias y las comunidades, que sin lugar a dudas, vistas como expresiones sexuales gratificantes, responsables y libres de riesgo, proporciona el bienestar y la plenitud necesarios para el pleno goce de una salud integral (26).

Como complemento a las múltiples declaraciones internacionales y nacionales que dan el marco normativo al tema de salud sexual y reproductiva, aparecen en el escenario los Estados y los sistemas de salud dando argumentos de peso ante la necesidad de generar acciones integrales en esta materia, y siguiendo la lógica planteada, han iniciado la implementación de planes y programas encaminados a promover comportamientos saludables frente a los factores de riesgo relacionados con la salud sexual y reproductiva; no obstante en el camino se han presentado dificultades para el logro de esta en las poblaciones: puntos de intersección con causas estructurales como las inequidades de género y otras asimetrías de poder limitan el pleno goce de los derechos. fraccionamiento al interior de la organización de los sistemas de salud ha llevado a una parcelación de las problemáticas, (patologías como VIH están cargo de profesionales en epidemiología e infectología, la salud materna a cargo de profesionales en ginecología y las ITS en manos de la dermatología), adicionalmente existe una integración insuficiente con temas de género, interculturalidad, diversidad sexual y necesidades específicas como discapacidad; a todo esto se suman los mecanismos de financiamiento, siendo en conjunto elementos limitantes ante el logro del objetivo (26).

\footnotetext{
${ }^{2}$ Párrafo 8.25 En ningún caso se debe promover el aborto como método de planificación familiar. Se insta a los gobiernos y a las organizaciones intergubernamentales y no gubernamentales pertinentes a incrementar su compromiso con la salud de la mujer, a ocuparse de los efectos que en la salud tienen los abortos realizados en condiciones no adecuadas como un importante problema de salud pública y a reducir el recurso del aborto mediante la prestación de más amplios y mejores servicios de planificación familiar. Conferencia Internacional de Población y Desarrollo (CIPD) El Cairo 1994
} 
Frente a esta compleja problemática solo resta intervenir con estrategias integrales que orienten acciones de coordinación, colaboración y participación efectivas que generen abordajes articulados entre la salud sexual y reproductiva, la prevención de VIH y de ITS y la perspectiva de género, donde se establezcan verdaderas interacciones sinérgicas partiendo de una amplia participación comunitaria (26).

Múltiples investigaciones han surgido alrededor de la importancia de la salud sexual y reproductiva dentro de las agendas políticas de los países, algunas han promovido un enfoque poblacional en las políticas públicas en este tema, otras se basan en un enfoque de riesgo y otras, por fortuna han abogado por enfoques de derechos que en las que se articulan varias dimensiones dando vía al pleno goce de derechos en torno a la diversidad.

\subsection{Importancia de la vinculación del varón en la salud sexual y reproductiva. Conceptualización.}

Elementos interesantes se han dado en torno al tema del rol del varón en la salud sexual y reproductiva, como aquellos que se han identificado al abordar los contenidos de las diferentes declaraciones internacionales que dan marco normativo al tema; en gran número se incorpora la nominación del varón como parte importante de los procesos de cambio de las condiciones de las mujeres.

Los cambios de los conocimientos, las actitudes y el comportamiento de hombres y mujeres constituyen una condición necesaria para el logro de una colaboración armoniosa entre hombres y mujeres. El hombre desempeña un papel clave en el logro de la igualdad de los sexos, puesto que, en la mayoría de las sociedades, ejerce un poder preponderante en casi todas las esferas de la vida, que van de las decisiones personales respecto del tamaño de la familia hasta las decisiones sobre políticas y programas públicos a todos los niveles. Es fundamental mejorar la comunicación entre hombre y mujeres en lo que respecta a las cuestiones relativas a la sexualidad y a la salud reproductiva y la comprensión de sus responsabilidades conjuntas, de forma que unos y otras colaboren por igual en la vida pública y privada (6).

Se reconoce de esta manera la importancia de alentar a los hombres a que se responsabilicen de su comportamiento sexual y reproductivo, y asuman su función social y familiar.

En diversas publicaciones de organizaciones internacionales empoderadas de la salud sexual y reproductiva de las poblaciones se identifica que sin duda, los patrones de salud de hombres 
y mujeres no se relacionan exclusivamente con sus diferencias bilógicas sino que están fuertemente determinadas por la posición social desigual entre estos y estas (27).

Específicamente en materia de salud sexual y reproductiva, se siguen creando e implementando políticas y programas de salud dirigidos de forma aislada y casi exclusiva a la población de mujeres, donde sus líneas de acción aún guardan estrecha relación con sus características biológicas y su rol reproductivo pasando por alto el papel influyente que los hombres desempeñan en la salud sexual y reproductiva de sus familias y de sus parejas sexuales. La no incorporación de los varones en los programas de promoción, prevención y atención de la salud sexual y reproductiva ha tenido repercusiones negativas en su salud, la salud de las mujeres y en el éxito de los programas (27) (28).

Los temes de salud sexual y reproductiva no son solo tema de mujeres. El papel de los hombres en esta área, en cuanto su disposición y ejercicio de sus responsabilidades, es fundamental para llegar relaciones de igualdad que posibiliten el un goce equitativo del derecho a la salud... las estrategias para lograr cambios sostenibles deben tener en cuenta a los hombres, potenciando su responsabilidad y revisando las relaciones de poder existentes entre ambos sexos. Se reivindican aś los "derechos sexuales y reproductivos" de hombre y mujeres (27).

Como producto de su experiencia en investigación, la Dra Julia Espinosa Fajardo refiere que es habitual que la información y servicios de salud sexual y reproductiva se dirijan a las mujeres dejando a un lado a los hombres, desatendiendo las consecuencias que tienen ciertos comportamientos de los estos en la salud, como sucede en el caso de la epidemia de VIH - SIDA. No obstante manifiesta que múltiples investigaciones revelan que los hombres se encuentran más interesados en la salud sexual y reproductiva de lo que se supone; adiciona que los hombres pueden aportar en la movilización y redistribución de recursos de manera equitativa entre hombres y mujeres, pueden a su vez contribuir al cambio de la rigidez de ciertas instituciones culturales reduciendo las desigualdades en patrones de salud sexual y reproductiva existentes entre ambos sexos y así fortalecer el rol de las mujeres y la igualdad de género (27).

Por su parte la Organización Panamericana de la Salud desde la Oficina de Diversidad, Género y Derechos Humanos considera que la vinculación de los varones en la salud sexual y reproductiva, no solo mejora la salud de las mujeres, además es esencial para su propia salud y bienestar y determina las razones por la cuales es creciente el interés en la participación de éstos en este tema (28): 
- E reconocimiento del rol influyente de los hombres en la sexualidad y la reproducción;

- El reconocimiento que los hombres tienen sus propias necesidades y demandas de SSR ;

- Concientización de que las relaciones de género desiguales afectan a la SSR de mujeres y hombres ;

- Mayor evidencia de los efectos negativos, principalmente sobre las mujeres y los niños/as, comportamiento riesgoso de los hombres;

- Preocupación por el aumento de las tasas de ITSe infección por el VIH/SDA;

- El deseo de prevenir los embarazos no deseados o no planificados mediante el mayor uso de métodos més eficaces de planificación familiar;

- Solicitudes de las mismas mujeres para incorporar a sus parejas en la promoción, la educación y la prestación de servicios de SSR, en particular el embarazo y parto.

Además identifica diversos factores que limitan la participación de los hombres en la salud sexual y reproductiva (28):

- Los roles de género - masculinidad y feminidad - se asimilan en la niñez, cuando los niños/as aprenden que la sociedad tiene diferentes expectativas para cada uno de ellos. La masculinidad incluye un conjunto estricto de normas que influyen en el comportamiento y las actitudes de los hombres respecto a la SSR;

- La virilidad de un hombre es medida por sus conquistas sexuales, el número de sus hijos, y por el comportamiento de las mujeres en su círculo familiar/social (la esposa, las novias, las hijas, la madre etc.);

- En América Latina y el Caribe, la iniciación sexual en general empieza más temprano para los hombres que para las mujeres, y los adolescentes varones tienen que probar constantemente su virilidad mediante su actividad sexual. Los hombres jóvenes y adultos frecuentemente ven la iniciación y las relaciones sexuales como una manera de demostrar que son "hombres" y para ganar estatus en su grupo social, en lugar de verlas como una oportunidad para la intimidad;

- Se espera que los hombres estén sexualmente informados. En realidad, tanto los niños como los hombres están generalmente no informados o mal informados, pero no buscan información por el temor de parecer sin experiencia;

- La mayoría de los hombres conocen los métodos anticonceptivos, aunque este conocimiento no siempre se traduce en el uso práctico o consistente de los mismos ;

Frente a este contexto, en el que los varones adquieren características y actitudes especiales frente a la salud sexual y reproductiva, la OPS sugiere que las personas que formulan políticas y programas, pasen de ver a esta población como un limitante e inicien su abordaje integran, partiendo de que los hombres ya están participando como parejas sexuales, esposos y padres, y a partir de estas funciones involucrarlos en los programas y servicios de 
salud sexual y reproductiva desde una perspectiva de igualdad de género. Propone también como estrategia una perspectiva de asociación, en la que hombre y mujeres toman decisiones en conjunto, desde posiciones iguales de poder; considera además que se debe promover la comunicación y la negociación dentro y fuera de la pareja de manera que se generen acuerdos en planificación familiar, prevención de infecciones de transmisión sexual e igualada de géneros (28).

Como parte limitante de la comunicación de estos temas entre hombres y mujeres se encuentran los tabúes y normas culturales, las desiguales relaciones de poder que finalmente imposibilitarán mayores grados de igualdad entre géneros; por lo tanto se plantea como objetivo generar vías de comunicación y espacios para la construcción de la igualdad mediante intervenciones dirigidas a (27):

- La participación de los hombres en salud sexual y reproductiva.

- Llegar al público masculino con mensajes apropiados utilizando los medios de difusión pública disponibles y haciendo hincapié en la población adolescente y juvenil.

- Incitar a los hombres a asumir mayor responsabilidad en su comportamiento sexual.

- Informar sobre las identidades de género y los valores asociados a la masculinidad que implican conductas sexuales de riesgo.

- Informar sobre los preservativos y la vasectomía así como ofrecer una variedad de servicios de salud.

- Facilitar el acceso de los hombres a servicios de salud sexual y reproductiva.

- Sensibilizar a los hombres a comunicarse con la pareja y decidir juntos respecto de los anticonceptivos y las prácticas sexuales subrayando la importancia de la influencia del género.

- Abordar las necesidades de salud reproductiva tanto de los individuos como de las parejas.

Por su parte el PPSSyPR platea entre las directrices para el acceso sin barrearas a los servicios de salud sexual y reproductiva que las limitaciones que se imponen a los varones 0 a las mujeres para el integral uso de los servicios de salud sexual y reproductiva, son una vulneración de derechos y esta situación se verá reflejada en el aumento de la morbimortalidad materna. Define como criterios clave en este proceso de acceso a servicios (29):

- La negativa a entregar métodos anticonceptivos es una vilneración de derechos y constituye violencia contra las mujeres.

- El acceso a todos los métodos anticonceptivos sin restricciones es necesario para asegurar que mujeres y varones se encuentren en igualdad de condiciones para decidir con autonomía sobre su vida reproductiva. 
- Las personas destinatarias de las acciones e insumos del PNSSyPR son varones y mujeres de todas las edades.

- Especialmente las personas adolescentes deben tener acceso sin restricciones a los métodos anticonceptivos, ya que muchas se ven sometidas a situaciones que ponen en peligro su salud sexual y reproductiva.

Define además una serie de responsabilidades de los y las profesionales proveedores de servicios de salud sexual y reproductiva

- Los profesionales de la salud deben brindar información clara, precisa y adecuada sobre los diferentes métodos anticonceptivos existentes y sus posibilidades a toda mujer $u$ hombre que lo solicita, cualquiera sea su edad.

- Es deber del profesional proveer el método anticonceptivo en forma inmediata.

- Debe explicar a quién consulta de todos los métodos disponibles y proveer del método que la persona decida para sí.

- El secreto médico profesional es una obligación de confidencialidad que garantiza a quien consulta al sistema de salud que puedan hablar con entera libertad de sus síntomas, hábitos y actividades. La ley 26.569 sobre Derechos de Paciente establece en su Artículo 2 inciso D el deber de confidencialidad por parte del profesional de la salud.

- Es necesario asegurar a toda persona que nada de lo conversado, ni el método suministrado será revelado sin su consentimiento. Así se garantiza el derecho a la intimidad de las personas consagrado en los artículos 18 y 19 de la Constitución Nacional.

\subsection{Importancia del uso del lenguaje incluyente.}

\subsubsection{Lenguaje incluyente escrito. Conceptualización.}

La Convención sobre la Eliminación de Todas las Formas de Discriminación contra la Mujer, CEDAW en 1979 retoma desde la discriminación, la importancia de trabajar desde la escala cultural en la ruptura de roles que perpetúen la condición disciplinada de las mujeres, propone como estrategias de vinculación a las acciones de salud elementos como la eliminación de estereotipos y acceso a la información (14).

Art. 10 - c) La eliminación de todo concepto estereotipado de los papeles masculino y femenino en todos los niveles y en todas las formas de enseñanza, mediante el estímulo de la educación mixta y de otros tipos de educación que contribuyan a lograr este objetivo y, en particular, mediante la modificación de los libros y programas escolares y la adaptación de los métodos de enseñanza; 
La hipótesis del lenguaje como creador de realidades y no sólo como herramienta netamente descriptiva surge en la década de 40 con Edward Sapir y Benjamin Lee Whorf; posteriormente Michell Foucault desde la crítica contempla que los discursos son conjuntos de enunciados y términos que circulan sobre un determinado fenómeno, situación o práctica social y que dan sentido a las realidades. Desde esta perspectiva, el uso del lenguaje se ha convertido en un campo de batalla en el que el movimiento feminista reclama la adopción de un lenguaje incluyente que evite la concepción de grupos integrados por hombre y mujeres usando el "masculino genérico", y que busca el reconocimiento de algunos grupos que padecen algún tipo de subordinación socio cultural por razones de género, raza etnia u orientación sexual (30).

El concepto de "lenguaje incluyente" pretende diferenciarse del término "políticamente incorrecto"; este último, que se refiere al uso del vocabulario encaminado a no ofender a grupos discriminados por razones étnicas, religiosas, raciales, de nacionalidad, de género o de orientación sexual, hace referencia a un esfuerzo por evitar ofender o eliminar frases denigrantes y es entendida como una acción tímida por no parecer un agente discriminador. Por su parte el término "lenguaje incluyente" pretende ir más allá de prescindir mecánicamente de la discriminación, para buscar de manera activa y positiva formas de expresión que reconozcan la presencia de muchos sujetos cuya participación y existencia pareciera seriamente limitada o invisibilizada (30).

Desde los planteamientos de la Doctora en análisis del discurso, Gabriela Castellanos, las lesiones causadas por el uso del lenguaje excluyente se relacionan con el insulto, la inferiorización y la invisibilización.

El insulto por su parte se considera como aquella tendencia que ofende a alguien por razones de su identidad, se traduce en la tendencia de asignarles sobrenombres a grupos raciales, sociales o étnicos, elemento que se hace más complejo aun cuando suele mezclarse en la cotidianidad con apuntes humorísticos aparentemente ingenuos.

La inferiorización busca impedir a las personas participar en un intercambio lingüístico en un plano de igualdad; desde el uso del lenguaje, la asignación de adjetivos (negis, mina, flaco) aparentemente cariñosos llevan al interlocutor/a a ubicarse en un posición inferior, se encuentra frecuentemente en contextos de relaciones de poder como profesor/a y estudiante, médico y paciente o entre personas de diferentes clases sociales, este tipo de desigualdad debe ser abordado desde el contexto en el que se desarrolle.

La invisibilización por medio del lenguaje se ve reflejada en el uso del "masculino genérico", asumiendo que al utilizarlo se incluye de manera vinculante a la población femenina. Otra de las estrategias de invisibilización es el uso de sustantivos masculinos frente a grupos donde hay hombre y mujeres (30). 
Otros tipos de discriminación desde el lenguaje se alejan de los conceptos mencionados anteriormente, en estos no se explicita propiamente el insulto, la inferiorización o la invisibilización, se alejan de lo netamente léxico y semántico para situarse en modos discursivos de subordinación; el androcentrismo se concibe entonces como la focalización hacia el varón, empleada en narraciones donde intervienen hombres y mujeres.

Frente a este complejo elemento del lenguaje como herramienta de inclusión o exclusión, múltiples pensadores y pensadoras, gobernantes y dirigentes de instituciones nacionales e internacionales, desde diversos sectores, han abogado por el uso del lenguajes no sexistas o incluyentes, de esta manera surgen en diferentes páses manuales que instan a la utilización de lenguaje incluyente en todos los sectores del accionar de la agenda política; este tipo de estrategias pretenden generar aportes hacia la construcción de sociedades equitativas e igualitarias frente a hombre y mujeres.

Los manuales de recomendaciones relacionadas con el lenguaje incluyente coinciden en considerar que la lengua es una realidad en continuo cambio, que está continuamente en evolución y que está determinada por la época respondiendo a necesidades de la comunidad que la utiliza; por ende, la lengua como un producto social y su uso en una sociedad con mayor igualdad entre los sexos, deberá reflejar esta realidad y además contribuir a ella Así mismo los manuales estudiados en la construcción del marco teórico de esta investigación, confluyen en afirmar que existen múltiples posibilidades para que, sin agredir las normas gramaticales, no se produzca ningún tipo de discriminación en el uso del idioma (31) (32) (33).

La causa de la discriminación desde el lenguaje no se encuentra en la propia lengua, sino en el uso discriminatorio que los hablantes hacen de ella, frente a esto, es común que la mujer quede relegada a un segundo plano o en un primer plano como lo es en el caso de los programas relacionados con la salud sexual y reproductiva, a causa de la función que los miembros de la comunidad confieren al género.

Entre las estrategas sugeridas para hacer del lenguaje una herramienta para incluir de manera igualitaria tanto a hombres como a mujeres aparece (31):

- La utilización de sustantivos según la variación formal del género gramatical. El género es una categoría gramatical que permite clasificar los nombres en masculinos y femeninos, permitiendo establecer la concordancia con los demás elementos de la oración. Como herramienta de inclusión desde el lenguaje se debe tener en cuenta que la forma de las palabras se refiere a lo masculino en las terminaciones en -o, -e o en consonante; en algunos casos son palabras de distinta ráz frente a las de la pareja en femenino. Por su parte los sustantivos femeninos tiene terminaciones en -a o en 
consonante (espedialmente en -do en -z) y otras de número reducido forman el sustantivo femenino con terminaciones en -isa, esa, o -ina. Sin embargo, existen situaciones donde el género gramatical no corresponde a uno u otro sexo, es decir, el femenino no corresponde exclusivamente a la mujer ni el masculino exclusivamente al hombre, por lo tanto es un error identificar el género gramatical con el sexo biológico, (pronombre él/ella: "vivo en una casa en la playa, en ella me siento a gusto").

- E uso del masalino genérico. En español el género masculino posee un doble valor, como especifico (referido exclusivamente a los varones) y como genérico (referido a ambos sexos), este doble valor produce ambigüedades y confusiones y puede dar lugar a la discriminación y a la ocultación de la mujer.

- Los adjetivos: en español los adjetivos, al igual que los sustantivos se dividen en dos gupos, los adjetivos de doble forma que son aquellos que terminan en consonante 0 en vocal -o para el masculino y en vocal -a para el femenino (campeón - campeona), y aquellos de forma única que son aquellos que se mantienen invariables tanto para el género masculino como para el femenino (feliz, agradable). Partiendo de que los adjetivos serán usados en concordancia con los sustantivos, en el caso en el que un adjetivo acompañe a un sustantivo este se usará en femenino o en masculino según sea el género de este (Las alumas y ex-alumnas), si por el contrario los sustantivos son de distinto género, según las normas gramaticales, se deberá utilizar el masculino genérico en los adjetivos(Los alumos y alumas). Si no se desea usar el masculino genérico se deberá recurrir a desdoblar el adjetivo en femenino y en masculino con las implicaciones estilísticas que esto conlleva(los alumos y las alumnas); o bien utilizar sinónimos invariables en cuanto al género.

- Los artículos. Según las normas de concordancia gramatical, el articulo deberá adoptar el género del nombre al que acompaña (el niño / la niña) y es determinante en las situaciones en las que acompaña a sustantivos de forma única, ya que este será el que marque el género. Sin embargo, debido a la reciente incorporación de las mujeres en ámbitos en los que se encontraban vetadas ha obligado al uso de estructuras gramaticales intermedias en las que se una un artículo femenino a un sustantivo masculino (la abogado).También y con el fin de generar discursos incluyentes, podrán ser remplazados por el genérico persona o se puede desdoblar el término a femenino y masculino (-los -las - unos -unas, o las personas).

- Los pronombres. Partiendo de que son aquellas palabras que sustituyen a los nombres, que tienen variación genérica en todas sus formas y que adoptan distinta 
terminación para cada uno de los géneros según el que desee sustituir (excepto yo, tú, que, aral, quien, alguien, nadie y cualquier, que manejan una sola forma para referirse a masculino y al femenino). Estos pronombres mencionados como excepciones serán de gran utilidad para inclusiones lingüísticas independientes del sexo.

- E termino hombre. En la cotidianidad funciona como genérico (con el sentido de persona) o como específico (en el sentido de varón), este doble uso genera ambigüedades, por lo que se recomienda el uso de este solo cuando se hace referencia al sexo masculino, de la misma manera se sugiere utilizar para ambos sexos genéricos del tipo persona, humanidad, o gente 0 bien aplicar los desdoblamientos para femenino y masculino.

- Uso sistemático del masculino. Esta estrategia no siempre consigue representar de manera vinculante a hombre y a mujeres, pues genera ambigüedades. Con el fin de disminuir un sobreuso del masculino se sugiere:

Tabla 1 Altemativas sugeridas para evitar el uso sistemático del genérico masculino.

\begin{tabular}{|c|c|}
\hline Figura & Ejemplo \\
\hline $\begin{array}{c}\text { Sustantivos genéricos y } \\
\text { colectivos }\end{array}$ & $\begin{array}{l}\text { Personaje colectivo, grupo, pueblo, equipo, persona, criatura, gente, } \\
\text { colectividad, asociación, juventud, ciudadanía, humanidad, profesorado }\end{array}$ \\
\hline Perífrasis & $\begin{array}{l}\text { Personal sanitario, las personas que ejercen, el personal docente, la } \\
\text { comunidad, el ser humano }\end{array}$ \\
\hline $\begin{array}{l}\text { Construcciones metonímicas } \\
\text { (alusión al cargo) }\end{array}$ & Gerencia, dirección, jefatura, secretaria, presidencia \\
\hline $\begin{array}{l}\text { Desdoblamientos (alternado } \\
\text { el orden de presentación) }\end{array}$ & Las y los, propietario y propietaria, niños y niñas \\
\hline Barra & E/la, cliente/a, trabajadores/ras, las/los \\
\hline Aposiciones explicativas & Tanto mujeres como hombres, de uno y otro sexo, \\
\hline $\begin{array}{l}\text { Omisión del determínate } \\
\text { (eliminar el articulo) }\end{array}$ & Profesionales, titular \\
\hline $\begin{array}{c}\text { Determinantes si marca de } \\
\text { género }\end{array}$ & Cada, cada contribuyente, cada estudiante \\
\hline
\end{tabular}


Dentro de las recomendaciones frente a los problemas de estilo generados por la necesidad de un lenguaje incluyente, los manuales concuerdan en que el uso de las barras, si bien es una estrategia valida y útil, por cuestiones de estética del texto debe utilizarse lo menos posible; de la misma manera no se recomienda el uso del signo @ ya que no es un signo lingüístico y además es impronunciable. Se sugiere también tener especial cuidado con el abuso de los desdoblamientos (31) (10) (32).

\subsubsection{Lenguaje incluyente visual. Conceptualización}

Como parte de la implementación de la Política de Igualdad de Género - OPS en 2005, se identificó el papel determinante de la comunicación en los procesos de inserción y adquisición de nuevos valores y roles entre la población y su contribución en la transversalización efectiva del enfoque de género, no solo en las políticas sino también en la creación de materiales de comunicación. Como parte de este proceso y de innumerables intencionalidades a nivel de los y las profesionales que trabajan en este tema, se da inicio al análisis de género en los contenidos de las campañas publicitarias; por su parte OPS en el documento "La perspectiva de género en las auñas televisivas sobre $\mathrm{VH}$ " proporciona los elementos de análisis de género en las campañas de prevención de $\mathrm{VIH}$ y promoción de salud sexual y reproductiva (33).

Los cambios de conducta necesarios para frenar la epidemia son complejos porque el VIH implica comportamientos que son placenteros, íntimos, moldeados por tradiciones culturales sólidas y que involucran interacción entre partes no siempre igualitarias. En síntesis, son comportamientos que se relacionan con la sexualidad humana y las relaciones de género. (33)

Si bien es cierto que el documento centra su objetivo general en el análisis de género en campañas publicitarias de prevención de $\mathrm{VIH}$, se consideró relevante para esta investigación el objetivo que apunta a elaborar una metodología que permita desarrollar campañas de salud con enfoque de equidad de género; de esta manera aporta elementos, que como bien se menciona en dicho documento, son aplicables y adaptables en la identificación de la perspectiva de género en los programas de salud sexual y reproductiva (33).

Una de las premisas de esta estrategia consiste en que "ninguna iniciativa será exitosa si no está basada en la equidad de género y en la realización efectiva de los derechos humanos de todas las personas"; para lo cual plantea como prioridad la promoción de cambios en los comportamientos que lleven no solo a la equidad de género, sino también a promover y mejorar las relaciones sociales y el respeto por las distintas orientaciones sexuales e identidades de género al interior de las poblaciones (33). 
La comunicación juega un papel determinante para la inserción y adquisición de nuevos valores y roles entre la población, contribuyendo así a la transversalización efectiva del enfoque de género no solo en las políticas y programas, sino también en el desarrollo de materiales de comunicación que generen esa igualdad de género tan necesaria en nuestra sociedad (33).

El estudio que presentó OPS contribuye al análisis de la perspectiva de género en las cuñas publicitarias tomando como punto de partida la forma en que se presenta en cada pieza publicitaria la relación entre hombres, mujeres y personas con diferentes orientaciones sexuales e identidades de género. De esta manera construyó categorías para evaluar desde el enfoque de género y así determinar el grado en que se refuerza la desigualdad de género o se desarrolla un rol transformador.

\section{Tabla 2. Categońas para e análisis de género en actividades, proyectos, programas y políticas.}

\begin{tabular}{|c|c|}
\hline Concepto & Características \\
\hline Desigual & $\begin{array}{l}\text { Favorecen a un género sobre el otro, actividades o políticas en las que } \\
\text { las desigualdades están claras y se transmiten como "hechos de la } \\
\text { naturaleza”, y en las que se reconocen los derechos y oportunidades } \\
\text { de los hombres sobre los de las mujeres. }\end{array}$ \\
\hline Sensible & $\begin{array}{l}\text { Reconocen y toman en cuenta las diferencias de género en los roles y } \\
\text { en el acceso a los recursos. Sin embargo no tratan de cambian las } \\
\text { causas profundas de la desigualdad de género, buscan de forma } \\
\text { específica empoderar a las mujeres como el polo más débil de la } \\
\text { relación. }\end{array}$ \\
\hline Transformadora & $\begin{array}{l}\text { Reconocen y toman en cuenta las diferencias de género en los roles y } \\
\text { en el acceso a los recursos. Busca cambiar las causas que originan la } \\
\text { desigualdad y tratan de generar equidad de género mediante la } \\
\text { renegociación del status quo y las relaciones de poder. }\end{array}$ \\
\hline
\end{tabular}

Fuente: Elaboración de la investigadora, basada en el documento La perspectiva de género en las cuñas televisivas sobre $\mathrm{MH}$. OPS. 2010 (33) 
El análisis de género en las campañas publicitarias se considera relevante ya que estas frecuentemente transmiten mensajes con estereotipos de roles de género y de los roles sexuales, alejándolas de su objetivo de modificar comportamientos. Como marco metodológico el documento de OPS, propone la siguiente matriz de análisis de cuñas publicitarias.

Tabla 3. Matriz para análisis de género de las piezas publicitarias

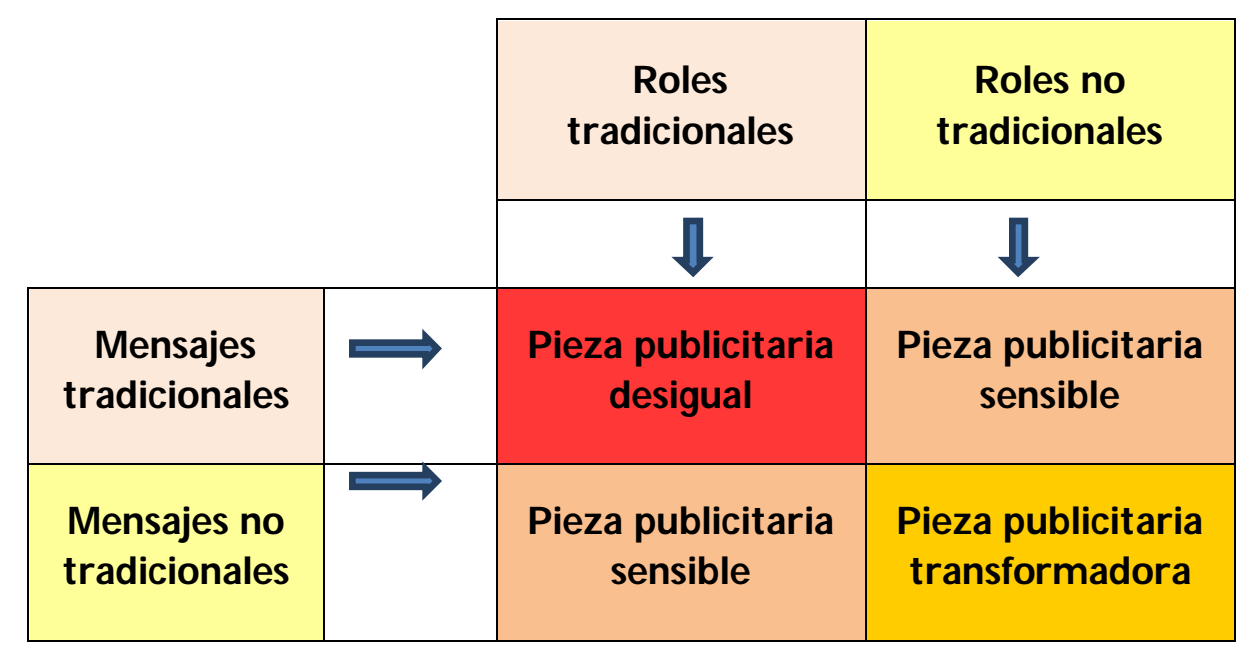

Fuente: OPS 2010 (33)

Como parte introductoria desde el componente teórico previo al desarrollo de la matriz presentada en la tabla 3, se describen una serie de conceptos empleados por los psicólogos que analizan la afectividad del proceso persuasión-comunicación: La fuente, el mensaje, el receptor, el canal y el contexto. (33)

- La fuente se refiere a la persona que transmite el mensaje y puede variar dependiendo de los aspectos relevantes del proceso de persuasión, ya que se puede tratar de una persona similar, un experto, etc. ... la persuasión aumenta cuando la fuente del mensaje es una persona experta, atractiva o similar al receptor.

- El mensaje es la información que se presenta, que puede ser emocional o lógica, entre otros. ....incrementa la persuasión en función del número de argumentos relevantes.

- El mensaje se transmite por medio de un canal de comunicación como televisión, radio, cara a cara, etc. 
- El receptor del mensaje también presenta determinadas características que pueden variar, como el nivel de educación, el nivel de ingreso o la autoestima, por nombrar algunas, al igual que el contexto en el que se produce la comunicación ya que el receptor puede estar en casa, en la escuela etc.

Como parte de la metodología propuesta para el análisis de género en las piezas publicitarias se describen los elementos utilizados desde la fuente (roles tradicionales y no tradicionales, de género y sexuales), y desde el contenido del mensaje (mensaje tradicional y no tradicional).

$\checkmark$ Roles tradicionales (33). Desde los roles de género, suelen encontrarse estereotipos ligados a las emociones, las mujeres suelen mostrarse como seres más expresivos, con emociones centradas en los demás; los estereotipos masculinos muestran hombres que controlan y suprimen sus emociones o muestra emociones mayoritariamente poderosas como el enfado y el orgullo; también suelen encontrarse características estereotípicas ligadas a los espacios predominantemente domésticos para las mujeres y laborales en el caso de los hombres. Se considera que estas características estereotípicas están directamente relacionadas con el proceso de socialización de los roles de género. De la misma manera es posible identificar los roles de género en las relaciones sexuales que para fines de la estrategia planteada son aquellas pautas de interacción entre hombres y mujeres en el marco de las relaciones sexuales y/o amorosas, definidas socialmente e influenciadas por las relaciones de género. Para el análisis de las piezas publicitarias se consideraran roles tradicionales cuando se presentan hombres y mujeres basados en estereotipos. 
Tabla 4. Características de los roles tradicionales

\begin{tabular}{|l|l|l|}
\cline { 2 - 3 } & \multicolumn{1}{|c|}{ Mujeres } & \multicolumn{1}{c|}{ Hombres } \\
\hline $\begin{array}{l}\text { Rol de } \\
\text { género } \\
\text { tradicional }\end{array}$ & $\begin{array}{l}\text { Mas comunitaric } \\
\text { Menos ejecutiva } \\
\text { Expresa emociones centradas en los } \\
\text { demás } \\
\text { Ocupa espacios domésticos y de } \\
\text { cuidado de los hijos }\end{array}$ & $\begin{array}{l}\text { Menos comunitario } \\
\text { Mas ejecutivo } \\
\text { Expresa emociones poderosas como el } \\
\text { orgullo y el enfado } \\
\text { Ocupa espacios de trabajo profesional o } \\
\text { fuera de la casa }\end{array}$ \\
\hline Rol sexual \\
tradicional & $\begin{array}{l}\text { Pasiva } \\
\text { Expresa menos deseo sexual } \\
\text { Tiene control personal } \\
\text { Desempeña el rol de “portera” } \\
\text { (pone limitantes) } \\
\text { Relaciona el sexo con miedo o } \\
\text { riesgo } \\
\text { Mantiene relaciones sexuales con } \\
\text { pareja estable }\end{array}$ & $\begin{array}{l}\text { Activo } \\
\text { Expresa mayor deseo sexual } \\
\text { Tiene falta de control } \\
\text { Desempeña el rol de conquistador } \\
\text { Relaciona el sexo con placer y deseo } \\
\text { Mantiene relaciones sexuales con } \\
\text { múltiples parejas }\end{array}$ \\
\hline \multicolumn{2}{|c|}{ Fuente: Creación de la investigadora basada en OPS 2010 (33) }
\end{tabular}

Fuente: Creación de la investigadora basada en OPS 2010 (33)

$\checkmark$ Roles no tradicionales (33). Debido a las modificación que se han presentado en los últimos 30 años en las relaciones de género, es posible pensar negociaciones en las actividades tradicionalmente desempeñadas por hombres o mujeres y que en la actualidad son valoradas positivamente, desatacado; por ejemplo, que los hombres ahora son más participativos en las funciones domésticas y las mujeres más destacadas en las actividades laborales. Desde los roles sexuales se analizan los abordajes de la sexualidad segura, el disfrute de ambas partes de su sexualidad, la responsabilidad del hombre de cuidarse dentro de la relación sexual y la consideración de diversas orientaciones sexuales. Se considerara como roles de género no tradiciones aquellas alternativas a los roles tradicionales. 
Tabla 5. Características de los roles no tradicionales

\begin{tabular}{|c|c|c|}
\hline & Mujeres & Hombres \\
\hline $\begin{array}{l}\text { Rol de } \\
\text { género no } \\
\text { tradicional }\end{array}$ & $\begin{array}{l}\text { Es económicamente independiente } \\
\text { Participa en actividades públicas } \\
\text { Participa activamente en el mercado } \\
\text { laboral } \\
\text { Adquiere un nivel educativo alto }\end{array}$ & $\begin{array}{l}\text { Apoya la diversidad de género en los } \\
\text { espacios políticos y laborales } \\
\text { Coopera en las tareas domesticas } \\
\text { Adquiere mayor responsabilidad en el } \\
\text { rol paterno } \\
\text { Posee mayor libertad para expresar } \\
\text { emociones }\end{array}$ \\
\hline $\begin{array}{l}\text { Rol } \\
\text { sexual no } \\
\text { tradicional }\end{array}$ & $\begin{array}{l}\text { Activa } \\
\text { Expresa su deseo sexual } \\
\text { Comunica abiertamente su } \\
\text { sexualidad } \\
\text { Asocia sexo a placer } \\
\text { Está abierta a otras orientaciones } \\
\text { sexuales }\end{array}$ & $\begin{array}{l}\text { Es sensible a los requerimientos } \\
\text { sexuales de su pareja } \\
\text { Se distancia de la concepción } \\
\text { “machista” de la sexualidad como } \\
\text { expresión de su virilidad } \\
\text { Es abierto para negociar con su pareja } \\
\text { Es responsable en la protección } \\
\text { Está abierto a otras orientaciones } \\
\text { sexuales }\end{array}$ \\
\hline
\end{tabular}

Fuente: Creación de la investigadora basada en OPS 2010 (33)

- Mensaje no tradicional (33).Es aquel que promueve alternativas como la negociación del uso de métodos anticonceptivos en la cotidianidad, en forma visible o explicita en los diálogos, la utilización de la consejería en planificación familiar, el control del individuo sobre la situación, la responsabilidad compartida, la comunicación intrafamiliar, el respeto por la diversidad de orientaciones sexuales y por identidades de género de otros individuos. Se trata de mensajes que presentan roles de género más igualitarios y en los que ambas partes pueden gozar de su sexualidad.

- Mensaje tradicional (33). Es aquel que promueve roles de género desiguales, donde la abstinencia o la fidelidad son indispensables como responsabilidad de uno de los dos géneros, se expresa el sexo y la prevención como tabúes, donde se reconoce solo la heterosexualidad o donde se presenta un doble estándar de conducta representado en el amor y la procreación para la mujer y en impulso y deseo para el hombre. 
Tabla 6 Características de los mensajes tradicionales y no tradicionales

\begin{tabular}{|c|c|}
\hline Mensaje tradicional & Mensaje no tradicional \\
\hline $\begin{array}{l}\text { Roles de género desiguales } \\
\text { Abstinencia o fidelidad } \\
\text { Sexo y prevención como tabúes } \\
\text { Sexo únicamente heterosexual } \\
\text { Doble estándar de conducta: amor y } \\
\text { procreación para las mujeres y deseo e } \\
\text { impulso para el hombre }\end{array}$ & $\begin{array}{l}\text { Roles de género igualitarios } \\
\text { Uso de métodos anticonceptivos } \\
\text { Comunicación franca sobre prevención } \\
\text { Otras orientaciones sexuales } \\
\text { Disfrute mutuo de la sexualidad } \\
\text { Empoderamiento y control personal }\end{array}$ \\
\hline
\end{tabular}

Fuente: Creación de la investigadora basada en OPS 2010 (33)

El análisis se plantea exclusivamente desde la perspectiva de género, desde el contenido de los mensajes y los roles representado en las piezas, no pretende llegar determinar la eficacia de las campañas. 


\section{OBJETIVOS DE LA INVESTIGACIÓN}

\subsection{Objetivo general}

Analizar las estrategias que promueven la vinculación de los varones y las mujeres en el Programa de Salud Sexual y Procreación Responsable de la municipalidad de La Plata.

\subsection{Objetivos específicos}

- Identificar la presencia del lenguaje incluyente en las publicaciones y campañas publicitarias del PPSSyPR de la municipalidad de La Plata.

- Analizar según población objetivo, el direccionamiento de las acciones del PPSSyPR de la municipalidad de La Plata.

- Determinar la disponibilidad de métodos anticonceptivos en el PPSSyPR de la municipalidad de La Plata, como estrategia de vinculación del varón a la salud sexual y reproductiva.

- Identificar las acciones dirigdas a la promoción de la vinculación de los varones en el PPSSyPR de la municipalidad de La Plata.

- Analizar la capacitación y la sensibilización de los proveedores (profesionales a cargo de la consejería en planificación familiar)en la importancia de la vinculación del varón en el PPSSyPR de la municipalidad de La Plata.

- Identificar el reconocimiento de las estrategas de vinculación de los varones por parte de los proveedores del PPSSyPR de la municipalidad de La Plata.

- Generar una propuesta que permita operativizar el discurso incluyente de los varones en el PPSSyPR, a través de los hallazgos identificados en el estudio.

\subsection{Hipótesis}

El Programa de Salud Sexual y Procreación Responsable implementado en el municipio de La Plata dirige sus acciones en su mayor proporción hacia las mujeres y no hacia los hombres, limitándose así a la mitad de los destinatarios involucrados con la temática, aspecto éste que puede tener un papel negativo en los resultados finales obtenidos por el programa. 


\section{METODOLOGÍA}

\subsection{Tipo de estudio}

Investigación observacional de tipo descriptivo explicativo con una etapa analítica.

\subsection{Tipo de abordaje}

La investigación se realizó con un enfoque cualitativo y se integraron en ella técnicas de recolección de datos cuantitativas y cualitativas.

\subsection{Universo}

Se consideró como sujeto/objeto de estudio la población usuaria y proveedora del servicio de consejería en planificación familiar de los Centros de Atención Primaria en Salud de la Municipalidad de La Plata - Argentina y al PPSSyPR en sí con todos sus componentes documentales, publicaciones e insumos provistos por el programa.

\subsubsection{Criterios de inclusión.}

- Criterios de indusión subunidad lineamentos y publicaciones.

$\checkmark$ Publicaciones y lineamientos emitidos por el programa de Salud Sexual y Procreación Responsable de la municipalidad de La Plata.

$\checkmark$ Publicaciones y lineamientos emitidos por el Programa Nacional de Salud Sexual y Procreación Responsable que sean manejados por el programa municipal.

$\checkmark$ Publicaciones y lineamientos emitidos en el periodo comprendido entre 2010 y 2012

$\checkmark$ Publicaciones y lineamientos dirigidos a proveedores y proveedoras de servicios de consejería de planificación familiar.

$\checkmark$ Publicaciones y lineamientos dirigidos a la población usuaria del programa de Salud Sexual y Procreación Responsable de la Municipalidad de La Plata. 
- Criterios de indusión subunidad Proveedores y proveedoras del Programa.

$\checkmark$ Para fines de este estudio se consideraron proveedores y proveedoras del servicio de consejería en planificación familiar a los y las profesionales en enfermería y ginecología

$\checkmark$ Proveedoras y proveedores del servicio de consejería en planificación familiar de los CAPS de la Municipalidad de La Plata.

$\checkmark$ Proveedoras y proveedores del servicio de consejería en planificación familiar, que se encontraban en los CAPS de la Municipalidad de La Plata en el momento de la aplicación de la encuesta.

$\checkmark$ Proveedoras y proveedores del servicio de consejería en planificación familiar que aceptaron participar en la investigación.

- Criterios de indusión subunidad de usuarios y usuarias.

$\checkmark$ Usuarias y usuarios del servicio de Consejería en planificación familiar de los CAPS de la Municipalidad de La Plata.

$\checkmark$ Usuarias y usuarios que acudieron al servicio de Consejería en planificación familiar en el momento de aplicar la encuesta.

$\checkmark$ Usuarias y usuarios del servicio de Consejería en planificación familiar que aceptaron participar en el estudio.

\subsubsection{Criterios de exclusión.}

- Criterios de exdusión subunidad Lineamentos y publicadiones.

$\checkmark$ Publicaciones y lineamientos emitidos por instituciones $u$ organizaciones no gubernamentales o gubernamentales diferentes al programa de Salud Sexual y Procreación Responsable de la municipalidad de La Plata.

$\checkmark$ Publicaciones y lineamientos emitidos por instituciones $u$ organizaciones no gubernamentales o gubernamentales diferentes al Programa Nacional de Salud Sexual y Procreación Responsable que sean manejados por el programa municipal.

$\checkmark$ Publicaciones y lineamientos emitidos en periodos diferentes al comprendido entre 2010 y 2012

$\checkmark$ Publicaciones y lineamientos dirigidos a proveedores de servicios de consejería de planificación familiar. 
$\checkmark$ Publicaciones y lineamientos dirigidos a la población diferente a la usuaria del programa de Salud Sexual y Procreación Responsable de la Municipalidad de LaPlata.

- Criterios de exdusión subunidad Proveedores y proveedoras del Programa.

$\checkmark$ No se tuvieron en cuenta proveedores ni proveedoras del servicio de consejería en planificación familiar diferentes a los y las profesionales en enfermería y ginecología

$\checkmark$ Proveedoras y proveedores del servicio de consejería en planificación familiar de las obras sociales de la Municipalidad de La Plata.

$\checkmark$ Proveedoras y proveedores del servicio de consejería en planificación familiar, que se encontraban ausentes en el momento de la aplicación de la encuesta.

$\checkmark$ Proveedoras y proveedores del servicio de consejería en planificación familiar que no aceptaron participar en la investigación.

- Criterios de exdusión subunidad de usuarios y usuarias.

$\checkmark$ Usuarias y usuarios de servicios diferentes al de Consejería en planificación familiar de los CAPS de la Municipalidad de La Plata

$\checkmark$ Usuarias y usuarios del servicio de Consejería en planificación familiar que no se encontraban presentes en el momento de aplicar la encuesta

$\checkmark$ Usuarias y usuarios del servicio de Consejería en planificación familiar que no aceptaron participar en el estudio

\subsection{Muestra}

Se consideró como unidad de análisis general del estudio al Programa Provincial de Salud Sexual y Procreación Responsable de la municipalidad de La Plata En éste se identificaron a su vez, subunidades de análisis población usuaria, población proveedora, documentos, publicaciones y herramientas de comunicación que permitieron el estudio de seis variables en cada una de sus dimensiones.

\subsubsection{Tamaño muestral Subunidad publicaciones}

En este nivel se analizaron 12 publicaciones que corresponden al total de lineamientos de las acciones relacionadas con la Consejería en Planificación Familiar y suministro de métodos anticonceptivos y 8 piezas publicitarias que son las utilizadas en el programa. 


\subsubsection{Tamaño muestral Subunidad proveedores y proveedoras del programa} En este nivel se determinó una muestra representativa de los y las proveedoras encargadas de dar la asesoría en planificación familiar en los Centros de Atención Primaria de la Salud (CAPS). La muestra de esta subunidad fue seleccionada a través de un muestreo aleatorio simple. Previo a esta selección se realizó un muestreo aleatorio simple de los CAPS de la municipalidad de La Plata.

- Muestreo de CAPS

El tamaño de la muestra $n=41$ de los CAPS se determinó para un error $\beta$ del $5 \%$ con un 95\% de confianza y un 5 \% de precisión. Mediante la fórmula:

$$
n=\frac{\left(Z^{2}\right)(p)(q)(N)}{(N)\left(e^{2}\right)+\left(Z^{2}\right)(p)(q)}
$$

Dónde:

$Z=$ Nivel de confianza (95)

$\mathrm{p}=$ Probabilidad a favor de que ocurra el evento $(0,5$ partiendo de que no existen estudios anteriores que nos definan la probabilidad de ocurrencia del evento)

$q=$ Probabilidad en contra de la ocurrencia del evento $(0,5$ partiendo de que no existen estudios anteriores que nos definan la probabilidad en contra de la ocurrencia del evento)

$\mathrm{N}=$ Universo de CAPS de la municipalidad de La Plata (46)

$\mathrm{e}=$ Error estimado (5)

$\mathrm{n}=$ Tamaño de la muestra

$\checkmark$ Muestreo de proveedores y proveedoras

El tamaño de la muestra es $n=122$ se determinó para un error $\beta$ del $5 \%$ con un $95 \%$ de confianza y un $5 \%$ de precisión. Mediante la fórmula:

$$
n=\frac{\left(Z^{2}\right)(p)(q)(N)}{\overline{(N)\left(e^{2}\right)+\left(Z^{2}\right)(p)(q)}}
$$


Dónde:

$Z=$ Nivel de confianza (95)

$\mathrm{p}=$ Probabilidad a favor de que ocurra el evento $(0,5$ partiendo de que no existen estudios anteriores que nos definan la probabilidad de ocurrencia del evento)

$q=$ Probabilidad en contra de la ocurrencia del evento $(0,5$ partiendo de que no existen estudios anteriores que nos definan la probabilidad en contra de la ocurrencia del evento)

$\mathrm{N}=$ Universo de proveedores y proveedoras de la consejería de planificación familiar en la Municipalidad de La Plata (179).

$\mathrm{e}=$ Error estimado (5)

$\mathrm{n}=$ Tamaño de la muestra

\subsubsection{Tamaño muestral subunidad usuarios y usuarias}

Se determinó una muestra representativa de la población usuaria de la consejería en planificación familiar de los CAPS de la Municipalidad de La Plata, se realizó un muestreo aleatorio simple de los CAPS, de la muestra resultante se tomó el n de los proveedores y los usuarios.

El tamaño de la muestra $n=312$ se determinó para un error $\beta$ del $5 \%$ con un $95 \%$ de confianza y un $5 \%$ de precisión. Mediante la fórmula:

$$
n=\frac{\left(Z^{2}\right)(p)(q)(N)}{(\bar{N})\left(e^{2}\right)+\left(Z^{2}\right)(p)(q)}
$$

Dónde:

$Z=$ Nivel de confianza (95)

$\mathrm{p}=$ Probabilidad a favor de que ocurra el evento $(0,5$ partiendo de que no existen estudios anteriores que nos definan la probabilidad de ocurrencia del evento).

$q=$ Probabilidad en contra de la ocurrencia del evento $(0,5$ partiendo de que no existen estudios anteriores que nos definan la probabilidad en contra de la ocurrencia de evento).

$\mathrm{N}=$ Universo de usuarios y usuarias que acuden a la consejería de planificación familiar en la Municipalidad de La Plata en un mes (1669)

$\mathrm{e}=$ Error estimado (5)

$\mathrm{n}=$ Tamaño de la muestra 
Tabla 7. Síntesis del muestreo en el estudio.

\begin{tabular}{|c|c|l|}
\hline Sub Unidad & $\begin{array}{c}\text { Tipo de } \\
\text { muestreo }\end{array}$ & \multicolumn{1}{|c|}{ Tamaño muestral } \\
\hline Publicaciones & Censo & $\begin{array}{c}12 \text { publicaciones y lineamientos } \\
8 \text { piezas publicitarias }\end{array}$ \\
\hline $\begin{array}{c}\text { Proveedores y } \\
\text { Proveedoras del } \\
\text { PPSSyPR }\end{array}$ & $\begin{array}{c}\text { Muestreo } \\
\text { deatorio simple }\end{array}$ & 122 Profesionales \\
\hline $\begin{array}{c}\text { Usuarios y usuarios del } \\
\text { PPSSyPR }\end{array}$ & $\begin{array}{c}\text { Muestreo } \\
\text { deatorio simple }\end{array}$ & 312 Usuarios y Usuarias \\
\hline
\end{tabular}

Fuente: Diseño de la investigadora.

\subsection{Definición operacional de variables}

Para el análisis de las estrategias de vinculación del varón utilizadas por el PPSSyPR en el Partido de La Plata, se crearon seis variables que permitieron analizar elementos determinantes en las acciones de salud sexual y reproductiva.

- Uso de lenguaje incluyente en publicaciones.

- Direccionamiento de acciones.

- Disponibilidad de Métodos Anticonceptivos

- Promoción de la vinculación del varón en la consejería de planificación familiar

- Sensibilización de proveedores de consejería en planificación familiar en perspectiva de género

- Reconocimiento de las estrategias de vinculación del varón en el PPSSyPR

Cada variable se analizó a partir de una serie de indicadores que entregaron la información necesaria para su abordaje; las técnicas cualitativas y cuantitativas de recolección de datos utilizadas para alimentar cada uno de los indicadores, se direccionaron a los tres niveles de la prestación del servicio: referentes, población proveedora de consejería en planificación familiar y población usuaria del programa.

Con el fin de dar estructura a cada uno de los 16 indicadores usados en la investigación, se realizaron las fichas técnicas de estos según las recomendaciones del Manual de Indicadores - DANE (34). 


\subsubsection{Variable: Lenguaje Incluyente (35)}

Esta implica la medición de la inclusión tanto de las mujeres como de los varones en el uso de palabras e imágenes e identifica las acciones que realizan mujeres y hombres como partes equilibradas, sin predominio de alguna sobre la otra

La identificación del lenguaje incluyente en los lineamientos y publicaciones se realizó teniendo en cuenta las oportunidades de inclusión de los dos géneros en los textos, se contó con el apoyo técnico de un Licenciado de Lenguas Modernas de la Universidad del Tolima en Colombia

Para el análisis de las piezas publicitarias se contó con el apoyo de un docente de la Facultad de Diseño Gráfico y Comunicación Visual de la Universidad Nacional de La Plata y con un estudiante de último año Diseño Gráfico de la Universidad Nacional de Colombia, en el proceso se analizaron todos los materiales elaborados y distribuidos por el Programa de Salud Sexual y Procreación Responsable.

A partir de los hallazgos identificados se realizó un análisis de acuerdo con los siguientes indicadores (ver anexo 1 Ficha técnica de Indicadores de la variable lenguaje induyente):

- Porcentaje de publicaciones que usan el lenguaje incluyente en su contenido

$$
\mathrm{PPCLI}=\frac{\text { Número de publicaciones analizadas en las que se identificó el lenguaje incluyente }}{\text { Número de publicaciones andizadas }} \times 100
$$

Se consideró como una publicación con lenguaje incluyente aquella que utiliza en mayor porcentaje la inclusión de elementos gramaticales incluyentes según formato de análisis.

\section{- Porcentaje de piezas publicitarias con carácter desigual}

$$
\mathrm{PPPCD}=\frac{\text { Número de piezas publicitarias analizadas en las que se identificó carácter desigual }}{\text { Número de piezas publicitarias analizadas }} \times 100
$$

Se consideró como pieza publicitaria con carácter desigual aquella que favorecen a un género sobre el otro, actividades o políticas en las que las desigualdades están claras y se transmiten como "hechos de la naturaleza", y en las que se reconocen los derechos y oportunidades de los hombres sobre los de las mujeres. 


\title{
- Porcentaje de piezas publicitarias con carácter sensible
}

\author{
Número de piezas publicitarias analizadas en las que se identificó carácter sensible \\ PPPCS= \\ Número de piezas publicitarias analizadas \\ $\mathrm{X} 100$
}

Se consideró como pieza publicitaria con carácter sensible aquella que reconoce y toma en cuenta las diferencias de género en los roles y en el acceso a los recursos. Sin embargo no trata de cambiar las causas profundas de la desigualdad de género, busca de forma específica empoderar a las mujeres como el polo más débil de la relación.

\section{- Porcentaje de piezas publicitarias con carácter transformador}

$$
\mathrm{PPPCT}=\stackrel{\text { Número de piezas publicitarias analizadas en las que se identificó carácter transformador }}{\text { Número de piezas publicitarias analizadas }} \times 100
$$

Se consideró como pieza publicitaria con carácter transformador aquella que reconoce y toma en cuenta las diferencias de género en los roles y en el acceso a los recursos. Busca cambiar las causas que subyacen la desigualdad y tratan de generar equidad de género mediante la renegociación del status quo y las relaciones de poder.

\section{- Porcentaje de piezas publicitarias dirigidas exclusivamente a varones}

\author{
Número de piezas publicitarias analizadas en las que se \\ identificó una direccionalidad exclusivamente masculina \\ PPPDV $=\overline{\text { Número de piezas publicitarias analizadas }}$ \\ $\times 100$
}

Se consideró como pieza publicitaria con direccionalidad exclusivamente masculina, aquella que, tanto en su contenido visual, como en su contenido lingüístico se enfoca específicamente en el varón.

\section{- Porcentaje de piezas publicitarias usadas en los CAPS, que fomentan la vinculación del varón en el PPSSyPR}

\author{
Número de piezas publicitarias usadas en los CAPS, \\ $\mathrm{PPPU}=$ \\ que fomentan la vinculación del varón en el PPSSyPR \\ Número de piezas publicitarias usadas en los CAPS \\ $\mathrm{X} 100$
}

Se consideró como pieza publicitaria utilizada en los CAPS, aquellas que fueron entregadas a los usuarios - que se encontraron expuestas en áreas comunes y consultorios de consejería en planificación familiar y que están dirigidas a varones y a mujeres en conjunto o exclusivamente a varones. 


\subsubsection{Variable: Direccionamiento de acciones}

A partir del análisis de los documentos "Métodos Anticonceptivos. Una guía para el acceso sin barreras" y "Consejerías en salud sexual y reproductiva" emitidos por el Programa Nacional de Salud Sexual y Procreación Responsable y adoptados por el PPSSYPR de la Municipalidad de La Plata, se determinó el direccionamiento de cada una de las acciones que se ofertan, en cuanto a la población objetivo desde la categoría de sexo varones y mujeres; a partir de esta información se analizaron los resultados por medio de los siguientes indicadores (ver anexo 2. Fichas técnicas de Indicadores variable direcionamiento de acciones):

\section{- Porcentaje de acciones dirigidas a mujeres dentro del PPSSyPR}

$$
\begin{aligned}
& \text { Número de acciones ofertadas en el programa dirigidas a mujeres } \\
& \text { PADM }=\overline{\text { Número de acciones ofertadas en el programa }}
\end{aligned}
$$

Se consideró como una acción dirigida a mujeres aquella que defina su acceso a las mujeres.

- Porcentaje de acciones dirigidas a varones dentro del PPSSyPR

$$
\mathrm{PADV}=\frac{\text { Número de acciones dirigidas a mujeres }}{\text { Número de acciones ofertadas en el programa }}
$$

Se consideró como una acción dirigida a varones aquella que defina su acceso a los varones.

\subsubsection{Variable: Disponibilidad de métodos anticonceptivos}

Esta variable pretende abordar el acceso a los métodos anticonceptivos ofertados por el programa partiendo de la disponibilidad del sistema para su entrega; para esto se realizó una encuesta a usuarios y usuarias de la consejería en planificación familiar. E análisis de los resultados se hizo a través de los siguientes indicadores (ver anexo 3. Fichas técnicas de indicadores de la variable disponibilidad de anticonceptivos): 
- Porcentaje de mujeres que solicitaron preservativos dentro del PPSSyPR

\author{
Número de mujeres encuestadas que solicitaron \\ preservativos en la consejería de planificación familiar \\ $\mathrm{PMSP}=$ \\ Número de mujeres encuestadas que acudieron a la consejería \\ en planificación familiar.
}

Se consideró como aquella mujer que solicitó preservativos dentro de la consejería en planificación familiar.

- Porcentaje de mujeres que solicitaron preservativos y les fueron entregados dentro del PPSSyPR

$$
\mathrm{PMEP}=\begin{aligned}
& \begin{array}{l}
\text { Número de mujeres encuestadas que solicitaron preservativos en } \\
\text { la consejería de planificación familiar y que les fue entregado }
\end{array} \\
& \begin{array}{l}
\text { Número de mujeres encuestadas que acudieron a la consejería en } \\
\text { planificación familiar y solicitaron preservativos. }
\end{array}
\end{aligned}
$$

Se consideró como aquella mujer que solicitó preservativos dentro de la consejería en planificación familiar y le fueron entregados en esta.

- Porcentaje de varones que solicitaron preservativos dentro del PPSSyPR

$$
\begin{aligned}
& \text { Número de varones encuestados que solicitaron preservativos en } \\
& \text { la consejería de planificación familiar } \\
& \mathrm{PVSP}= \\
& \text { Número de varones encuestados que acudieron a la consejería en }
\end{aligned}
$$

Se consideró como aquel varón que solicitó preservativos dentro de la consejería en planificación familiar.

- Porcentaje de varones que solicitaron preservativos y les fueron entregados dentro del PPSSyPR

$$
\begin{aligned}
& \text { Número de varones encuestados que solicitaron preservativos en } \\
& \text { la consejería de planificación familiar y que les fue entregados. } \\
& \text { PVEP }= \\
& \text { Número de varones encuestados que acudieron a } \\
& \times 100 \\
& \text { la consejería en planificación familiar y solicitaron preservativos. }
\end{aligned}
$$

Se consideró como aquel varón que solicitó preservativos dentro de la consejería en planificación familiar y le fueron entregados en esta. 
- Porcentaje de mujeres que solicitaron métodos anticonceptivos diferentes a preservativos y vasectomía.

$$
\mathrm{PMMAC}=\frac{\begin{array}{l}
\text { Número de mujeres encuestadas que solicitaron MAC diferentes a la } \\
\text { vasectomía y a preservativos en la consejería de planificación familiar }
\end{array}}{\begin{array}{l}
\text { Número de mujeres encuestadas que acudieron a la } \\
\text { consejería en planificación familiar. }
\end{array}}
$$

Se consideró como métodos diferentes a preservativos y vasectomía a los anticonceptivos hormonales, ligadura tubárica o dispositivo intrauterino dentro de la consejería en planificación familiar.

- Porcentaje de mujeres que solicitaron MAC diferentes a vasectomía y preservativos y les fueron entregados dentro del PPSSYPR

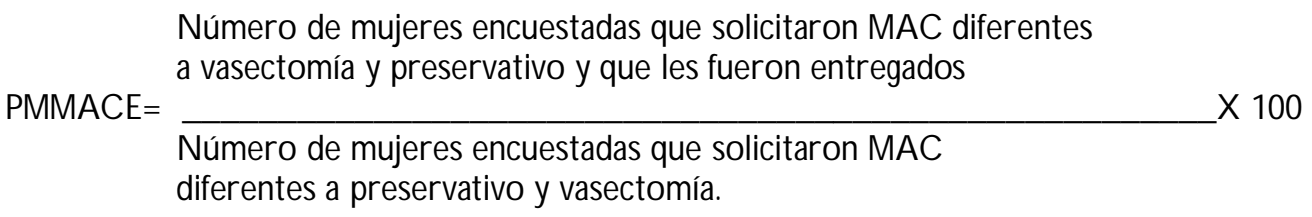

Se consideró como entrega métodos diferentes a preservativos y vasectomía dentro del programa a los anticonceptivos hormonales entregados en la consejería, a la inserción de dispositivo intrauterino o realización de ligadura tubárica en el siguiente mes posterior a la consulta; en estos dos últimos casos se realizó seguimiento telefónico como estrategia de verificación.

- Porcentaje de varones que solicitaron vasectomía y les fue realizada dentro del PPSSyPR en un tiempo inferior a un mes.

$$
\begin{aligned}
& \text { Número de varones encuestados que solicitaron la vasectomía y les } \\
& \text { fue realizada dentro del programa en un tiempo inferior a un mes }
\end{aligned}
$$

Se consideró aquel varón que solicitó la vasectomía dentro de la consejería en planificación familiar y que fue intervenido en el siguiente mes, en este caso se realizó seguimiento telefónico como estrategia de verificación. 


\subsubsection{Variable: Promoción de la Vinculación del Varón en la Consejería de Planificación Familiar}

Mediante la aplicación de una encuesta anónima dirigida se determinó la percepción de la población usuaria frente a las estrategias que usan los y las proveedoras como herramientas para la vinculación del varón en el PPSSyPR, teniendo en cuenta el fortalecimiento de la participación a través de material escrito o de manera verbal, difusión de los derechos sexuales y reproductivos, invitación a formar parte del programa y la entrega de material de comunicación. Los hallazgos identificados se analizaron a partir de los siguientes indicadores (ver anexo 4 Ficha técnica del Indicador de la variable Promoción de la Vinculación del Varón en la Consejería de Planificacón Familiar):

\section{- Porcentaje de población usuaria que refiere haber recibido información sobre vinculación del varón en la SSR durante la consejería en planificación familiar.}

$$
\text { PPPW }=\frac{\begin{array}{l}
\text { Número de usuarios/as que refieren haber recibido información sobre la } \\
\text { vinculación del varón en la SSR durante la consejería en planificación familiar }
\end{array}}{\text { Número de usuarias/os de la consejería en planificación familiar encuestados/as. }}
$$

Se consideró como informadón sobre vinculación del varón en la SSR, al refuerzo positivo de la importancia de la participación del varón en la salud sexual y reproductiva a través de material escrito o de manera verbal durante la consejería en planificación familiar.

\subsubsection{Variable: Sensibilización de proveedores/as de consejería en planificación familiar en perspectiva de género}

Esta variable pretende determinar las herramientas de sensibilización en perspectiva de género y vinculación del varón que ha ofertado el PPSSyPR a los proveedores y proveedoras de la consejería en planificación familiar, así como la percepción de estos sobre la importancia de estas en las acciones de salud sexual y reproductiva.

La información fue recolectada a través de la aplicación de una encuesta anónima autoadministrada en la que se buscó identificar si la población proveedora ha recibido capacitación o sensibilización en perspectiva de género o importancia de vinculación del varón a las acciones de salud sexual y reproductiva; así como la percepción de estos ante la importancia del tema. Los hallazgos fueron abordados a través de los siguientes indicadores (ver anexo 5 Fichas técnicas de Indicadores de la variable sensibilización de proveedores de consejería en planificación familiar en perspectiva de género): 
- Porcentaje de proveedores de consejería en planificación familiar que refieren haber sido sensibilizados en la importancia de la perspectiva de género.

\author{
Número de proveedores encuestados que refieren \\ haber sido sensibilizados en perspectiva de género \\ PPSPG = \\ Número de proveedores encuestados. \\ $\mathrm{X} 100$
}

Se consideró como estrategia de sensibilización o capacitaciones a: jornadas de actualización o reflexión sobre derechos sexuales y reproductivos, perspectiva de género o vinculación del varón en la salud sexual y reproductiva.

- Porcentaje de proveedores y proveedoras de consejería en planificación familiar que consideran importante la vinculación del varón en la salud sexual y reproductiva.

\author{
Número de proveedores de la consejería en planificación que \\ $\mathrm{PPIW}=$ \\ consideran importante la vinculación del verón en la SSR \\ Número de total de proveedores. \\ $\mathrm{X} 100$
}

\title{
6.5.6. Variable: Reconocimiento de las estrategias de vinculación del varón en el PPSSyPR
}

Partiendo de que uno de los objetivos del PPSSyPR incorpora la vinculación del varón como un elemento importante para el logro de la salud sexual y reproductiva de la población, esta variable permite identificar el reconocimiento si la población proveedora reconoce las estrategas diseñadas por el programa para favorecer tal fin; así como su percepción frente al uso de estas en cada uno de sus lugares de trabajo. Las tres estrategias de vinculación fueron determinadas a partir de la parametrización de las respuestas encontradas en entrevistas a las referentes del programa: la entrega de folletería y material publicitario que promueve la participación del varón, la consejería integral en planificación familiar y las capacitaciones en derechos sexuales y reproductivos a los profesionales de los CAPS.

Para la identificación del estado de esta variable en el PPSSyPR de la Municipalidad de La Plata se aplicó a la muestra seleccionada de proveedores y proveedoras de la consejería en planificación familiar una encuesta anónima autoadministrada. Los resultados encontrados fueron analizados mediante los siguientes indicadores. Ver anexo 6 Fichas técnicas de indicadores de la variable reconocimiento de las estrategias de vinculación del varón en el PPSSYPR: 
- Porcentaje de proveedores que reconocen las estrategias de vinculación del varón en las acciones del PPSSyPR.

\author{
Número de proveedores encuestados que reconocen las \\ estrategias de vinculación del varón en el PPSSyPR. \\ PRREV $=$ \\ Número de total de profesionales proveedores encuestadas/os

Se consideraron como estrategias de vinculación del varón en el PPSSyPR: la entrega de folletería y material publicitario que promueve la participación del varón, la consejería integral en planificación familiar y las capacitaciones en derechos sexuales y reproductivos a los profesionales de los CAPS.

- Porcentaje de proveedores que consideran que en su lugar de trabajo se implementan las estrategias de vinculación del varón en las acciones del PPSSYPR.

\author{
Número de proveedores encuestados/as que consideran que en su lugar de \\ PRIEV= \\ trabajo se implementan las estrategias de vinculación del varón en el PPSSyPR \\ Número de total de referentes encuestados/as que reconocen las \\ $\times 100$ \\ estrategias de vinculación del varón
}

\title{
6.6. Dinámica de trabajo de campo
}

\subsubsection{Preparación previa a las salidas de campo}

Una vez planteada la estructura de la investigación, como parte de la fase preparatoria a la recolección de datos, se gestionó desde la Secretaria de Salud y Medicina Social y desde el PPSSyPR de la Municipalidad de La Plata la autorización para el ingreso a las instalaciones de cada uno de los CAPS;

Las actividades de esta etapa iniciaron en cada uno de los CAPS a partir de encuentros con la dirección de cada unidad sanitaria, donde se explicó la dinámica de la investigación, se mostraron los instrumentos a utilizar y se definieron los horarios en los que se aplicarían las encuestas y observaciones estructuradas. En los lugares que fue posible la presentación inmediata con los y las proveedoras se realizó. Es importante resaltar que en la fase previa a la recolección de datos se realizó la prueba piloto de los instrumentos. 


\subsubsection{Operatoria de campo}

Las encuestas a usuarios y usuarias del programa y a los y las proveedoras se aplicaron teniendo en cuenta los horarios en los que la población proveedora de la consejería en planificación familiar ofrecía la consulta se aplicaban. Se visitaron los servicios en días hábiles de la semana y a diferentes horas del día.

La comunidad usuaria de los CAPS fue abordada al finalizar la consulta, la encuestadora se presentaba, explicaba el trabajo que se estaba realizando, posteriormente se solicitaba el consentimiento para la participación en la investigación y finalmente se diligenciaba la encuesta.

Las observaciones estructuradas se realizaron durante la primera visita a cada CAPS, una vez fuera aceptada la intervención por parte de la dirección de este.

\subsubsection{Trabajo post-salida de campo}

Al culminar cada jornada de recolección de datos se verificó el total diligenciamiento de los instrumentos usados; posteriormente fueron digitados en las bases de datos diseñadas para tal propósito. Los instrumentos diligenciados fueron archivados.

\subsection{Técnicas de recolección de datos}

\subsubsection{Instrumentos para la recolección de datos}

- Instrumento de verificación del lenguaje incluyente en las publicaciones emitidas por el PPSSyPR. La información documental para el estudio de la variable uso de lenguaje induyente se obtuvo de fuentes secundarias provenientes del Programa de Salud Sexual y Procreación Responsable implementado en la Municipalidad de La Plata, de esta manera se utilizaron publicaciones y campañas publicitarias como material de análisis teniendo en cuenta los criterios de inclusión y exclusión para esta subunidad. instrumento fue diseñado para esta investigación partiendo del componente teórico; pretende identificar y cuantificar las oportunidades de uso del lenguaje incluyente en la redacción de textos, identifica entonces como criterio de lenguaje excluyente, el uso del masculino genérico y el uso del término hombre desde el sentido genérico y como criterio de uso de lenguaje incluyente figuras gramaticales como el manejo de sinónimos 
invariables de género, desdoblamientos, barras, aposiciones explicativas, determinantes sin marca de género y omisión del determinante.(ver Anexo 7. Instrumento de análisis de las publicaciones emitidas desde el PPSSyPR de la municipalidad de la plata, periodo 2010-2013 y Anexo 8. Instrumento de análisis de piezas publictarias).

- Instrumento de determinación del direccionamiento de las acciones ofertadas por el PPSSyPR. Al igual que en el caso de la variable lenguaje incluyente, el direccionamiento de acciones se obtuvo de fuentes secundarias del PPSSyPR implementado en la Municipalidad de La Plata, se analizaron los documentos "Métodos Anticonceptivos. Una guía para el acceso sin barreras" y "Consejerías en salud sexual y reproductiva" emitidos por el Programa Nacional de Salud Sexual y Procreación Responsable y adoptados por el PPSSyPR de la Municipalidad de La Plata, se determinó el direccionamiento de cada una de las acciones que se ofertan, en cuanto a la posibilidad de acceso como varones 0 mujeres (ver anexo 9. Instrumento determinación del direcionamiento de las acciones ofertadas por el PPSSYPR de la munidipalidad de la plata).

- Instrumento de observación estructurada aplicable a los CAPS que ofertan acciones del PPSSyPR de la Municipalidad de la Plata. La técnica de observación estructurada permitió determinar la accesibilidad de la población a las piezas publicitarias. Se usó un instrumento en el que en cada CAPS se revisaron las piezas expuestas, la institución que las emitió, el lugar de ubicación y la disponibilidad de entrega en el caso de folletos postales y autoadhesivos (ver anexo 10 Instrumento de observación estructurada aplicable a los centros de atención primaria en salud que ofertan acciones del PPSSYPR ).

- Instrumento dirigido a usuarias y usuarios del PPSSyPR de la Municipalidad de La Plata. Para la unidad de análisis de usuarios y usuarias del PPSSyPR, la información se obtuvo en terreno a partir de la aplicación de una encuesta anónima dirigida, mediante esta se identificaron elementos relacionados con la promoción de la vinculación del varón en las acciones de salud sexual y reproductiva, el acceso a los métodos de anticoncepción seleccionados en la consulta y la asistencia de ambos miembros de la pareja. (Ver anexo 11 Instrumento dirigido a usuarias y usuarios del programa de salud sexual y procreación responsable de la municipalidad de la plata

- Instrumento dirigido a referentes del PPSSyPR de la Municipalidad de La Plata. Como base para la estrategia de triangulación utilizada en el análisis de la subunidad de proveedores y proveedoras de la consejería en planificación familiar, se diseñó y aplicó una entrevista semi-estructurada dirigida a los referentes del programa, que permitió identificar algunos conceptos y el abordaje de estos en el interior del programa, de esta manera se indagó por la concepción de elementos como género, 
perspectiva de género e importancia del varón en la salud sexual y reproductiva, así como por las estrategias utilizadas en el programa para la vinculación del varón y su difusión. (ver anexo 12 Instrumento dirigido a referentes del PPSSYPR de la Municipalidad de La Plata.)

- Instrumento dirigido a proveedoras y proveedores del PPSSyPR de la Municipalidad de La Plata. La unidad de análisis de proveedores y proveedoras de la consejería en planificación familiar se abordó a partir de la estrategia de triangulación, donde inicialmente se realizó la entrevista a las referentes del programa y según la parametrización de sus respuestas, se elaboró una encuesta con preguntas cerradas que posteriormente se aplicó anónima autoadministrada al grupo de profesionales proveedores de la consejería; a través de esta se identificó su percepción acerca de la importancia de la perspectiva de género y la vinculación de los varones en la SSyR, las acciones que el programa ha realizado enfocadas a la sensibilización en este tema, el reconocimiento de las acciones de promoción de la vinculación del varón a la salud sexual y reproductiva y su percepción sobre la implementación de estas en las unidades sanitarias.(Ver anexo 13 Instrumento dirigido a proveedoras y proveedores del PPSSyPR de la Municipalidad de La Plata)

\subsection{Elaboración de la base de datos}

Se creó una base de datos en Excel para la consolidación de los datos recolectados en esta investigación. Se utilizaron diferentes archivos permitiendo el análisis de cada uno de los instrumentos utilizados en la identificación del estado de las variables.

\subsection{Consideraciones éticas}

Todos los instrumentos tipo encuesta y entrevista contienen en su enunciado el texto alusivo al consentimiento informado, de tal manera que este fue expuesto en cada una de los encuentros con proveedores/as y usuarias/os. La información recolectada en la investigación fue utilizada exclusivamente en este estudio.

\subsection{Plan de análisis}

El análisis de datos a evaluar se realizó teniendo en cuenta las variables propuestas en el estudio. Los datos cuantitativos se recolectaron en hojas de cálculo de Excel, se expresaron 
en promedio, seguidos de un desvío estándar. Las variables cualitativas se determinaron según la repetición de patrones de respuesta de las mismas. Las variables cuantitativas se expresaron en porcentuales.

\subsection{Cronograma de actividades realizadas}

\begin{tabular}{|l|c|c|c|c|c|c|c|c|}
\hline \multirow{2}{*}{ Actividad } & \multicolumn{5}{c|}{2012} & \multicolumn{2}{c|}{2013} & 2014 \\
\cline { 2 - 9 } & $\begin{array}{c}\text { Jun - } \\
\text { Ago }\end{array}$ & Sep & Oct & $\begin{array}{c}\text { Nov- } \\
\text { Dic }\end{array}$ & $\begin{array}{c}\text { Ene - } \\
\text { Abr }\end{array}$ & $\begin{array}{c}\text { May- } \\
\text { Jun }\end{array}$ & Jul & Jul \\
\hline Construcción de Plan de Tesis & $\mathbf{X}$ & & & & & & & \\
\hline $\begin{array}{l}\text { Presentación de Plan para } \\
\text { aprobación }\end{array}$ & & $\mathbf{X}$ & & & & & & \\
\hline Construcción de Marco teórico & & $\mathbf{X}$ & & & & & & \\
\hline Construcción de Instrumentos & & $\mathbf{X}$ & $\mathbf{X}$ & & & & & \\
\hline Recolección de datos & & & & $\mathbf{X}$ & & & & \\
\hline Análisis de información & & & & & $\mathbf{X}$ & & & \\
\hline Elaboración de informe & & & & & & $\mathbf{X}$ & $\mathbf{X}$ & $\mathbf{X}$ \\
\hline Defensa de tesis & & & & & & & & $\mathbf{X}$ \\
\hline
\end{tabular}

\subsection{Financiación e infraestructura}

\subsubsection{Financiación.}

La financiación del trabajo de investigación se dio de manera exclusiva por parte de la investigadora, en éste se incluyeron los recursos humanos y físicos (papelería y útiles de oficina)

\subsubsection{Infraestructura.}

La recolección de datos se realizó en cada uno de las unidades sanitarias de la municipalidad de La Plata 


\section{RESULTADOS}

\subsection{Análisis descriptivo de la variable lenguaje incluyente}

Dentro de la implementación del PPSSyPR se identificó el manejo de cuatro líneas editoriales (2):

- Institucional: Para los materiales sobre información de gestión y campañas institucionales de comunicación. La identifica el color violeta.

- Actualización profesional: Para temas médicos, técnicos y de investigación. La identifica el color celeste.

- Promoción de derechos y accesibilidad: Para los materiales de difusión masiva orientados a población general y publicaciones orientadas a remover barreras culturales e institucionales en el acceso a los servicios de salud. La identifica el color verde.

- Participación y acción comunitaria: Para los materiales destinados al trabajo territorial y equipos de salud de atención primaria en promoción barrial de derechos. La identifica el color rojo

Tabla 8. Descripción de materiales publicados por el PPSSyPR, 2010 - 2012

\begin{tabular}{|c|c|c|c|}
\hline Institucional. & $\begin{array}{l}\text { Actualización } \\
\text { profesional. }\end{array}$ & $\begin{array}{l}\text { Promoción de } \\
\text { derechosy } \\
\text { accesibilidad }\end{array}$ & $\begin{array}{l}\text { Participación y } \\
\text { acción comunitaria: }\end{array}$ \\
\hline $\begin{array}{l}\text { Identidades diversas los } \\
\text { mismos derechos. (36) } \\
\text { (Cuadernillo) }\end{array}$ & $\begin{array}{l}\text { Consejerías en Salud } \\
\text { sexual y salud } \\
\text { reproductiva. } \\
\text { (Cuadernillo) }\end{array}$ & $\begin{array}{l}\text { Métodos } \\
\text { anticonceptivos. Guía } \\
\text { para un acceso sin } \\
\text { barrearas. } \\
\text { (Cuadernillo) }\end{array}$ & $\begin{array}{l}\text { Serie Participación } \\
\text { comunitaria, modulo } 1 . \\
\text { Derechos sexuales y } \\
\text { reproductivos. (38) } \\
\text { (Cuadernillo) }\end{array}$ \\
\hline $\begin{array}{l}\text { ¿Cuál es tu pregunta? } \\
\text { (39) (Revista) }\end{array}$ & $\begin{array}{l}\text { Guía técnica para la } \\
\text { đtención integral de } \\
\text { abortos no punibles. } \\
\text { (40) (Cuadernillo) }\end{array}$ & & $\begin{array}{l}\text { Serie Participación } \\
\text { comunitaria, modulo } 2 . \\
\text { Sexualidad y acceso a } \\
\text { métodos } \\
\text { anticonceptivos (41) } \\
\text { (Cuadernillo) }\end{array}$ \\
\hline $\begin{array}{l}\text { Políticas de salud sexual } \\
\text { y salud reproductiva. } \\
\text { Avances y desafíos. } \\
\text { Balance 2003-2011 (2). } \\
\text { (Cuadernillo) }\end{array}$ & $\begin{array}{l}\text { Protocolo de atención } \\
\text { integral de personas } \\
\text { víctimas de violaciones } \\
\text { sexuales (42) } \\
\text { (Cuadernillo) }\end{array}$ & & $\begin{array}{l}\text { Serie Participación } \\
\text { comunitaria, modulo } 3 . \\
\text { Conocernos, divertirnos } \\
\text { y cuidarnos. } \\
\text { (43) (Cuadernillo) }\end{array}$ \\
\hline
\end{tabular}




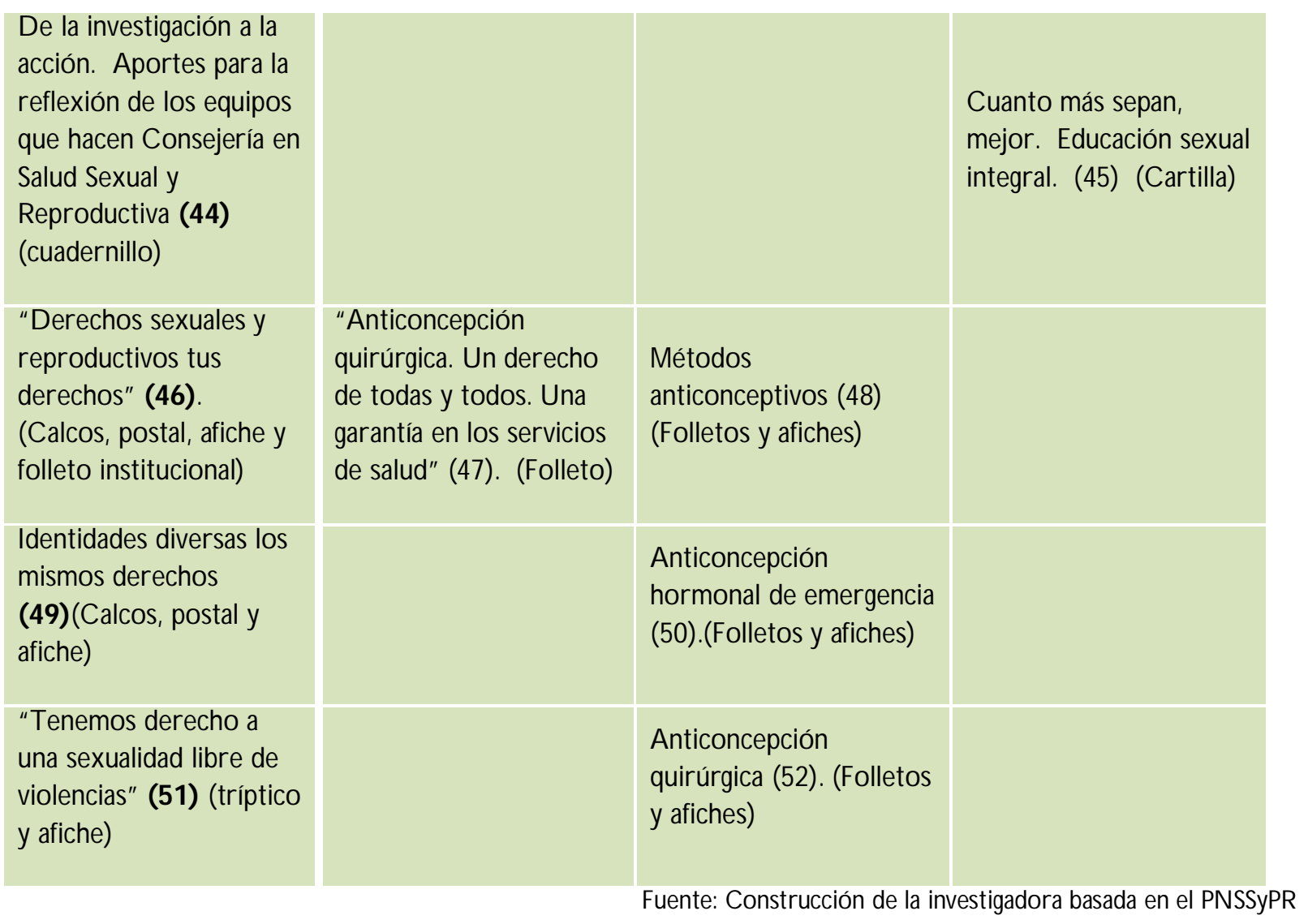

A partir de la identificación de los materiales publicitarios manejados por el PSSyPR en el periodo 2010- 2012 se realizaron los análisis correspondientes teniendo en cuenta los indicadores planteados.

Las publicaciones tipo cuadernillo, revista o cartilla fueron analizadas en la variable de lenguaje incluyente en publicaciones y aquellas como folletos, afiches, calcos y postales fueron analizados desde los indicadores de lenguaje incluyente en piezas publicitarias.

\subsubsection{Lenguaje incluyente en publicaciones.}

La metodología utilizada para la obtención de estos indicadores se basó en la aplicación del "Instrumento de análisis de las publicadiones emitidas desde el PPSSYPR de la municipalidad de La Plata, periodo 2010-2012". Con su implementación se identificaron aquellas oportunidades de inclusión que fueron o no aprovechadas en la construcción de los textos de dichas publicaciones.

Se leyeron 12 documentos de manera completa y se tabularon los criterios excluyentes y criterios incluyentes, a partir de su cuantificación se determinó el peso mayoritario del lenguaje desde la inclusión o no inclusión del varón. 


\title{
Indicador: Porcentaje de publicaciones que usan el lenguaje incluyente en su contenido
}

\author{
PPCLI $=\frac{\text { Número de publicaciones analizadas en las que se identificó el lenguaje incluyente }}{\text { Número de publicaciones analizadas }} \times 100$
}

Se consideró una publicación con lenguaje incluyente aquella que utilice en mayor porcentaje la inclusión de elementos gramaticales incluyentes según formato de análisis.

\section{Publicaciones con lenguaje mayoritariamente incluyente}

De las 12 publicaciones estudiadas siguiendo los criterios del instrumento, se determinó que 10 de estas, el $83.3 \%$ utilizan un lenguaje incluyente siendo adherentes a las recomendaciones gramaticales sugeridas para este fin. Los documentos del PPSSyPR implementado en la municipalidad de La Plata en el periodo 2010-2013 son:

- Identidades diversas los mismos derechos. (36) (Cuadernillo)

- Consejerías en Salud sexual y salud reproductiva. (37) (Cuadernillo)

- Métodos anticonceptivos. Guía para un acceso sin barrearas. (29)(Cuadernillo)

- Serie Participación comunitaria, Modulo 1. Derechos sexuales y reproductivos. (Cuadernillo) ¿Cuál es tu pregunta? (39) (Revista)

- Serie Participación comunitaria, Modulo 2. Sexualidad y acceso a métodos anticonceptivos (41) (Cuadernillo)

- Protocolo de atención integral de personas víctimas de violaciones sexuales (42) (Cuadernillo)

- Serie Participación comunitaria, Modulo 3. Conocernos, divertirnos y cuidarnos. (43) (Cuadernillo) De a investigación a la acción. Aportes para la reflexión de los equipos que hacen Consejería en Salud Sexual y Reproductiva (44) (cuadernillo)

- Cuanto más sepan, mejor. Educación sexual integral. (45) (Cartilla)

Al inicio de esta investigación se pretendió realizar un análisis cuantitativo aterrizado en indicadores, sin embargo durante la implementación del instrumento fue posible identificar una serie de características cualitativas que permiten advertir connotaciones que el mero uso de formalismos gramaticales no visualiza; de esta manera, se identifican a la luz del mensaje de las publicaciones:

Documentos completamente incluyentes. Se identificaron documentos con completas coherencias entre el lenguaje induyente y sus mensajes. En muchos de estos es posible encontrar apartados que hacen referencia a la perspectiva de género, en dichas secciones se expresa de manera más especifica la vinculación de los varones en las relaciones existentes en una pareja, se describen patrones socioculturales determinantes en el desarrollo de una vida sexual y reproductiva plena. Cabe resaltar que en uno de los documentos se plantea la socialización de las preguntas que 
realiza la población usuaria del programa, en este aparece: ¿Cómo hacen los varones para acceder a los servicios de salud sexual y reproductiva si no van al ginecólogo?; como respuesta: las consejerías en SSYSR

Violencias exclusivas contra las mujeres. Es más sencillo identificar en el discurso mensajes mayoritariamente alusivos a las violencias de las que son víctimas mujeres, adolescentes, niños y niñas:

"Se considera como un tipo de violencia contra las mujeres la no entrega de MAC".

Además, se pudo identificar que algunos documentos hacen referencia a que cualquier persona, de cualquier edad puede ser víctima de múltiples violencias sexuales, pero desde el uso del lenguaje, apela a calificativos como "el violador", "el agresor", atribuyendo de manera exclusiva este tipo de violencias al varón como único generador y excluyéndolo de la posibilidad de ser víctima $Y$ aunque se da el argumento cuantitativo de que las principales víctimas de las violaciones sexuales son las mujeres, las niñas y los niños, de esta manera se invisibilizan las agresiones generadas por mujeres y se perpetúan estereotipos nocivos en la percepción social de que solo esta población puede ser víctima.

Solo en un documento, como pie de página, se encontró una nota adaratoria en la que se considera la violencia sexual sobre los varones y por lo tanto su consulta a los servicios de salud, como eventos extraños, que de suceder serán manejados como eventos aislados de los procesos planteados.

"Adultos y niños varones también son víctimas de violaciones perpetradas por otros hombres"

"Las consultas de varones adultos que hayan sido víctimas de violación serán evaluadas por los equipos de salud a fin de determinar las derivaciones pertinentes."

Este tipo de mensajes generan una ambigua postura: el uso de genéricos masculinos criticados en el objetivo de empoderar a las mujeres, pero aceptado frente a estigmatización de los varones.

Exclusión del vínculo de pareja. Muchos de los documentos clasificados como incluyentes por el uso de sugerencias gramaticales, utilizan en su contenido el sustantivo de "pareja" para advertir que no es necesaria su vinculación en la toma de decisiones, como lo es en el caso de la inserción de DIU, la ligadura tubárica, vasectomía y en el caso de la interrupción voluntaria del embarazo la participación de varón se deja exclusivamente determinada a la voluntad de la mujer; estas concepciones, como se ha justificado en el marco teórico, invisibilizan las relaciones de poder existentes en las parejas y limitan el trabajo colectivo en el cambio de estructuras sociales en el espacio privado.

Múltiples segregaciones. Al manejar componentes como el acceso a los derechos sexuales y reproductivos, se hacen visibles una serie segregaciones sociales de que son víctimas las usuarias de 
los servicios de SSySR, los casos expuestos reflejan solo la vulneración de los derechos de las mujeres, múltiples segregaciones por la condición de pobreza o de migrante y el maltrato por parte de los equipos de salud; situaciones en las que aparentemente el varón es completamente invisible, no se muestra igualmente inmerso en estas interacciones sociales.

Lenguaje incluyente selectivo. En algunas publicaciones el lenguaje incluyente se hace visible especialmente para referirse a los y las integrantes del equipo proveedor de servicios de SSySR, pero expresa de manera clara el direccionamiento de las acciones que le apuntan prioritariamente al empoderamiento de las mujeres frente a la vulneración de sus derechos. En otras oportunidades los documentos muestran un lenguaje induyente en toda su construcción desde el punto de vista gramatical, pero es posible observar que usan las herramientas gramaticales de inclusión para referirse a todas las diversas orientaciones sexuales e identidades de género que hacen parte de la población LGTBI, dejando visible un tipo de jerarquía en la direccionalidad de las acciones de SSYSR: Mujeres, adolescentes, población LGTBI y finalmente los varones heterosexuales.

Exclusión del varón. En ocasiones la construcción del texto es completamente excluyente en el direccionamiento de los servicios SSySR, se identificaron apartados de documentos de trabajo que giraban en torno a preguntas y firmaciones orientadoras como:

¿Qué incorporar en la dimensión comunicacional para lograr un verdadero diálogo con las usuarias?

“... entendemos que la violacón de los derechos humanos de las personas, en este caso de las mujeres que concurren a los servicios públicos de salud reproductiva, es una arestión de suma importanda que debe ser pensada como una realidad a ser transformada"

Los mensajes construidos con herramientas incluyentes entran en contradicción con la presentación de formatos sin determinación de género, se identificó un documento donde se presentan esquemas de examen clínico físico para la valoración del abuso sexual, donde no se hace referencia a los genitales masculinos.

Se percibe además la manera en que los varones heterosexuales son excluidos incluso de mensajes que promueven y fortalecen la diversidad de género y las orientaciones sexuales. En este tipo de documentosse menciona la construcción de masculinidades de las personas transgénero pero no es posible identificar en el documento cual es la función social de los varones heterosexuales en el proceso de inclusión de esta población; sin embargo se reconoce continuamente la importancia de la construcción social de ciudadanías en conjunto con el colectivo de mujeres.

\section{Publicaciones con lenguaje mayoritariamente excluyente.}

Como documentos que usan un lenguaje mayoritariamente excluyentes de los varones, se identificaron dos; es decir, el $16.7 \%$ de los documentos publicados por el PNSSyPR en el periodo comprendido entre el años 2010 y 2012, no manejan un lenguaje incluyente. 
$\checkmark$ Guía técnica para la atención integral de abortos no punibles. (40) (Cuadernillo)

$\checkmark$ Políticas de salud sexual y salud reproductiva. Avances y desafíos. Balance 2003-2011 (2). (Cuadernillo)

Al igual que en el apartado anterior, adicional al análisis cuantitativo se identificaron elementos importantes que van más allá de los criterios de incluyente o no incluyente y que podrán convertirse en un aporte importante para el logro del objetivo de la salud sexual y la salud reproductiva de la población.

El documento Guía técrica para la atención integral de abortos no punibles, presenta un abordaje completamente excluyente del varón. La vinculación de este en el proceso de la toma de la decisión de interrumpir el embarazo en el contexto de una pareja se hace a merced de la voluntad de la mujer y en ningún caso se hace visible como derecho.

"salvo en los casos en los que la mujer consienta explíitamente la consulta del profesional con el esposo, compañero/a, padre, madre o a aalquier otra persona así sea para asegurar una atendón segura y apropiada, constituirá una vidación de la confidencialidad"

De esta manera el argumento es que por ser una decisión personal, el acceso a esta práctica no requiere de ningún tipo de negociación de pareja y nuevamente en la formalidad, la participación del varón pasa a ser meramente pasiva y por esto susceptible de no ser tenida en cuenta por el equipo de salud. Además de esto, como prueba de la direccionalidad de este accionar, se pudo observar que el termino mujer es utilizado en el documento 277 veces, mientras que el termino varón no aparece, el termino hombre es utilizado en cinco oportunidades articulado en la forma "hombres y mujeres" y lo hace en el contexto de igualdad de derechos humanos o bajo la cita de dedaraciones internacionales. Los sustantivos relacionados con el ciclo vital como adolescentes y niñas son abordados exclusivamente desde el género femenino y al utilizar los desdoblamientos estos hacen referencia exclusivamente a los y las profesionales que realizan el proceso. Nuevamente el varón es excluido.

En el segundo documento Políticas de salud sexual y salud reproductiva. Avances y desafíos. Balance 20032011 (2) es posible identificar desde su introducción, los logros obtenidos en materia de acceso de las mujeres a los MAC, es enfático en que uno de los objetivos del programa es empoderar a las mujeres en la toma de decisiones en su salud sexual y reproductiva y alejar el programa de los estereotipos que encasilla a la mujer en el rol reproductivo. Se hace mayor relevancia en la salud sexual de las mujeres y en impacto de desigualdades en materia de SSYSR y se resaltan fuertemente los grupos de mujeres y sus logros en esta materia.

Se menciona a los varones ocasionalmente en relación al acceso a la vasectomía, al suministro de preservativos y la AHE, y en contadas oportunidades en relación a la vinculación en el parto. Como iniciativa se describe la vinculación de los adolescentes varones a los CAPS,

No se encuentran indicadores disgregados por género en relación al acceso de servicios de Salud sexual y reproductiva, pero es posible encontrar un dato general de entrega de preservativos, vasectomías y uso de la línea 0800. 
Se define como un primer intento en el tema la creación de un afiche que invita a modificar los roles de género estereotipados Sexualidad orientada a varones: "Anímate a cambiar. Por una sexualidad con decisiones compartidas". Esta herramienta de comunicación no se encontró expuesta en ningún de los CAPS vinculados a este estudio.

\subsubsection{Lenguaje incluyente en piezas publicitarias (53), (54), (55), (56), (57), (58), (59), (60) (61).}

Los resultados que se exponen a continuación son el producto de la exploración en terreno de la región capital de la provincia de Buenos Aires, de la observación estructurada de todas las piezas publicitarias presentes en los CAPS y del análisis del experto en diseño de comunicación visual de la UNLP Lic. Martin V. Samudio. Algunos de los elementos que se tomaron en cuenta, además del lugar de aplicación de la pieza gráfica fueron: el receptor de la misma; forma de emisión del mensaje, códigos y lenguajes del mismo. Adicional al análisis cualitativo del experto se aplicó la metodología de análisis de género en piezas publicitarias propuesto por la OPS en el documento "La perspectiva de género en las añas televisivas sobre $\mathrm{MH}^{\prime \prime}$.

Se identificaron y analizaron ocho piezas publicitarias que al interior del programa se presentaban en diferentes formatos: afiches, folletos, postales y autoadhesivos. 


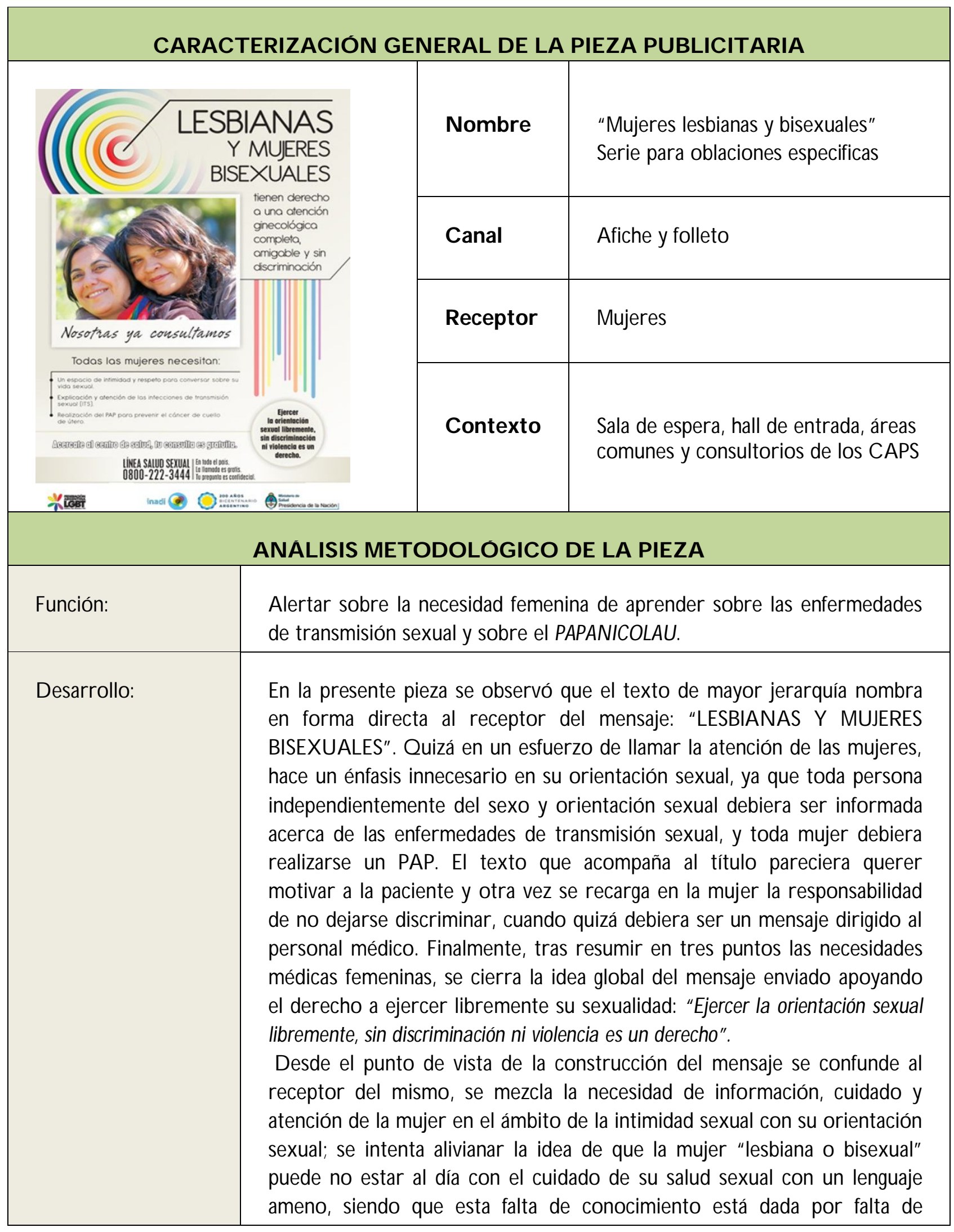




\begin{tabular}{|c|c|c|}
\hline & \multicolumn{2}{|c|}{$\begin{array}{l}\text { educación y no por el modo de obrar íntimamente. Se mezcla el derecho a } \\
\text { ejercer libremente la sexualidad con la falta de educación sexual. } \\
\text { Realizan un anclaje directo con el título del afiche, ya que se observa a dos } \\
\text { mujeres abrazadas con el texto "Nosotras ya consultamos" por debajo. Se } \\
\text { agregan líneas de color en referencia a la bandera que representa a la } \\
\text { comunidad homosexual. }\end{array}$} \\
\hline Conclusión: & \multicolumn{2}{|c|}{$\begin{array}{l}\text { El mensaje es confuso, se construye un solo mensaje con dos contenidos } \\
\text { distintos. Se apoyan en la idea de la mujer homosexual, siendo la } \\
\text { receptora universal "la mujer". La pieza carece de peso e impacto. Se } \\
\text { utilizan demasiadas líneas de texto que generan dudas en el receptor } \\
\text { acerca de cuál es la información importante; podrían ser dos piezas } \\
\text { separadas. No existe pieza similar dirigida avarones en el mismo ámbito. }\end{array}$} \\
\hline \multicolumn{2}{|c|}{ Roles de género y roles sexuales predominantes } & No tradicionales \\
\hline \multicolumn{2}{|c|}{ Mensaje predominante } & Tradicional \\
\hline \multicolumn{3}{|c|}{$\begin{array}{l}\text { Dentro de la pieza publicitaria se identificó la presencia del rol tradicional en el que las mujeres } \\
\text { tienen el control sobre su situación de salud, esto se refleja en la frase "Nosotras ya consultamos", } \\
\text { se observó además la manifestación abierta de su sexualidad y la aceptación frente a otra orientación } \\
\text { sexual, sin embargo no se mencionan otras orientaciones sexuales existentes además de la } \\
\text { bisexualidad y el lesbianismo. En el análisis del mensaje se observa que existe una relación desigual } \\
\text { frente a otros géneros reflejado en que solo se visualiza el acceso a los servicios de salud necesarios } \\
\text { para las mujeres bisexuales y lesbianas sin visualizar su equivalente para los varones homosexuales, } \\
\text { limitando la franca prevención frente a otros géneros. Al realizar el cruce con la matriz sugerida, se } \\
\text { concluye que esta es un pieza sensible, dado que promueve el ejercicio del derecho de las mujeres } \\
\text { bisexuales y lesbianas al acceso a los servicios de salud, sin tolerar la discriminación por su } \\
\text { orientación sexual; sin embargo la pieza como tal no pretende transformar las relaciones de poder } \\
\text { existentes entre las usuarias y los y las proveedoras de servicios de salud, lo que hace es } \\
\text { empoderarlas frente a la discriminación de la puedan ser víctimas. }\end{array}$} \\
\hline & & \\
\hline
\end{tabular}




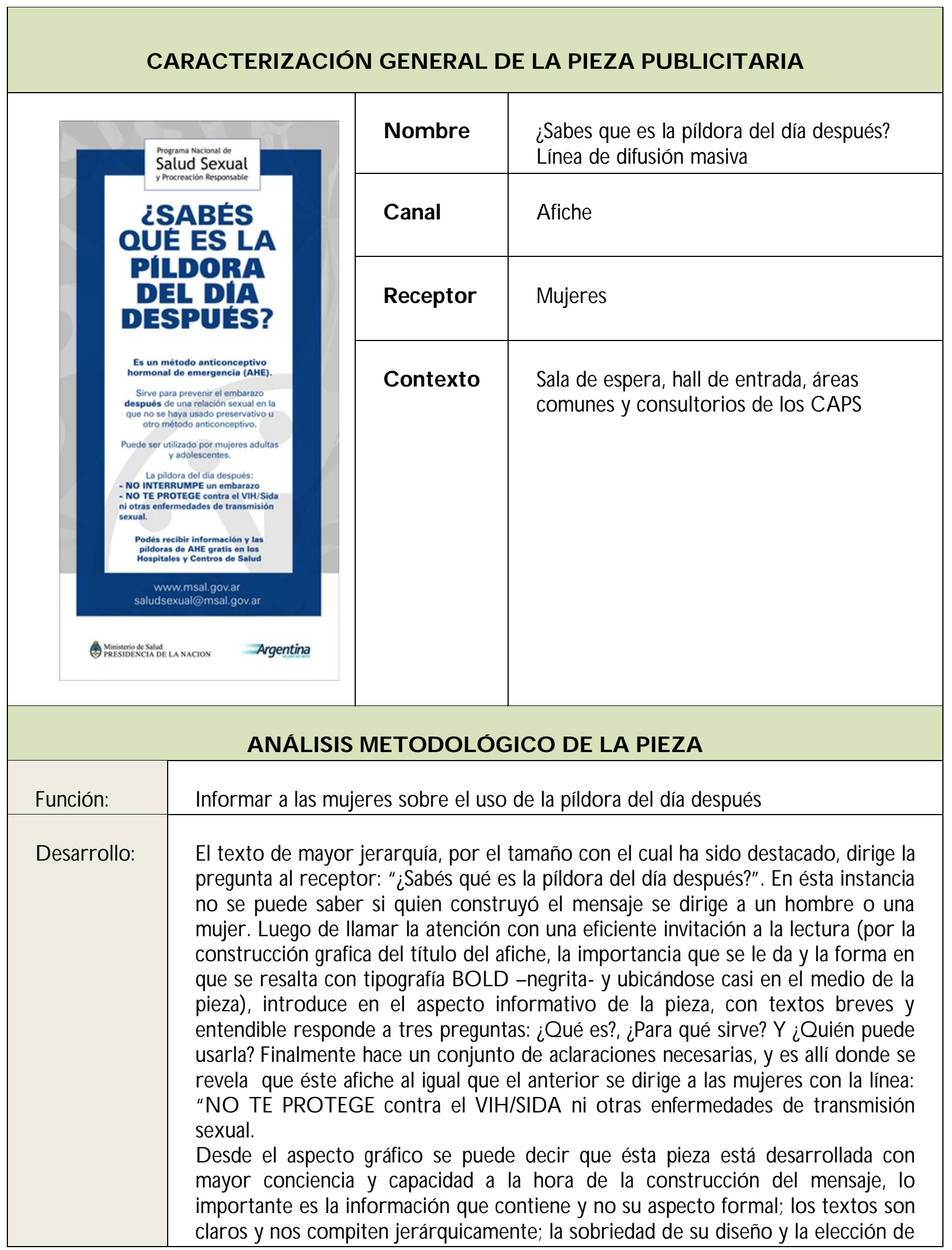




\begin{tabular}{|c|c|c|}
\hline & \multicolumn{2}{|c|}{$\begin{array}{l}\text { color generan una idea de institucionalidad que puede convivir con entornos } \\
\text { como hospitales, sanatorios y lugares afines e igualmente destacarse para ser } \\
\text { lédo. }\end{array}$} \\
\hline Conclusión: & \multicolumn{2}{|c|}{$\begin{array}{l}\text { El mensaje es directo y conciso, acotado pero útil. Sólo se puede agregar que } \\
\text { nuevamente se responsabiliza a la mujer en la toma de la píldora del día después, } \\
\text { se le informa y se desliga al hombre de la información tan importante que brinda } \\
\text { ésta pieza y de las consecuencias de mantener relaciones sexuales sin protección. } \\
\text { El meta mensaje (mensaje que se transmite por debajo del mensaje principal, } \\
\text { requiere de una decodificación más especializada para descubrirlo) de ésta pieza } \\
\text { obliga a la mujer a informarse al igual que la pieza anterior, no se sabe si sobre } \\
\text { entiende que el hombre está informado o si cree que no es su responsabilidad. }\end{array}$} \\
\hline \multicolumn{2}{|c|}{ Roles de género y roles sexuales predominantes } & Tradicionales \\
\hline \multicolumn{2}{|c|}{ Mensaje predominante } & Tradicional \\
\hline \multicolumn{3}{|c|}{$\begin{array}{l}\text { Esta pieza visibiliza el rol predominante de las mujeres como tomadoras de decisiones en materia } \\
\text { de salud sexual y reproductiva, invisibiliza completamente el derecho del varón a ser parte de este } \\
\text { tipo de decisiones y a acceder a estos servicios. Es posible leer además una marcada desigualdad de } \\
\text { roles de género dado que el varón no es mencionado en ninguna parte, se presenta un mensaje } \\
\text { tradicional. }\end{array}$} \\
\hline Categoría & \multicolumn{2}{|l|}{ Desigual } \\
\hline
\end{tabular}




\begin{tabular}{|c|c|c|c|}
\hline \multicolumn{4}{|c|}{ CARACTERIZACION GENERAL DE LA PIEZA PUBLICITARIA } \\
\hline \multicolumn{2}{|c|}{ 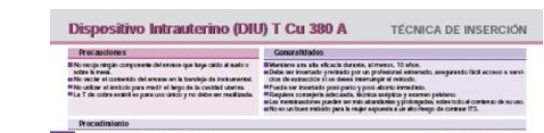 } & Nombre & $\begin{array}{l}\text { “Dispositivo intrauterino (DIU)" } \\
\text { Línea actualización profesional }\end{array}$ \\
\hline \multicolumn{2}{|c|}{ 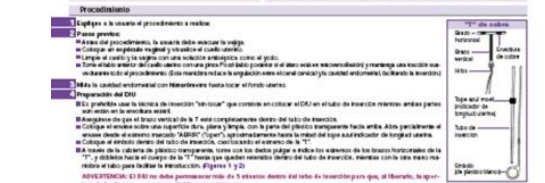 } & Canal & Afiche \\
\hline is & 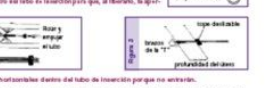 & Receptor & Personal medico \\
\hline \multicolumn{2}{|c|}{ 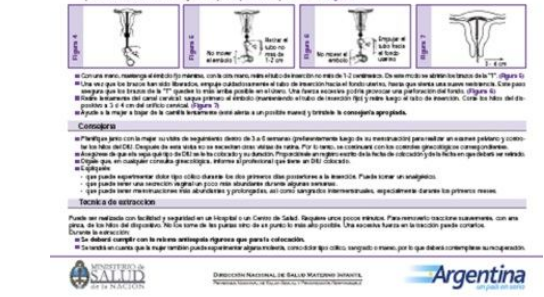 } & Contexto & $\begin{array}{l}\text { Sala de espera, hall de entrada, áreas } \\
\text { comunes y consultorios de los CAPS }\end{array}$ \\
\hline \multicolumn{4}{|c|}{ ANALISIS METODOLOGICO DE LA PIEZA } \\
\hline Función: & \multicolumn{3}{|c|}{ Instrucciones sobre el manejo y colocación del dispositivo } \\
\hline Desarrollo: & \multicolumn{3}{|c|}{$\begin{array}{l}\text { En éste caso se encuentra un material desarrollado para personal especializado } \\
\text { en el tema; por la forma de aplicación de los textos y el lenguaje médicamente } \\
\text { codificado, se descubre que el receptor es alguien que puede utilizar ésta pieza } \\
\text { como material de consulta en su espacio de trabajo. Es de entender que ésta } \\
\text { debiera ser una práctica "aceitada" y llevada a cabo por manos profesionales, que } \\
\text { no se requeriría de una pieza gráfica para el correcto tratamiento de éste } \\
\text { dispositivo, pero son conocidas las realidades con las que se trabaja en algunos } \\
\text { centros de salud, con lo cual es posible comprender la necesidad de su creación. } \\
\text { Así mismo parece ser una información muy importante en una explicación } \\
\text { demasiado extensa y poco práctica, no es posible imaginar a ningún profesional } \\
\text { de la ginecología colocando el DIU y leyendo esos textos, podría contener } \\
\text { gráficos que faciliten la lectura al médico y al paciente, que concientice y y } \\
\text { tranquilice a la mujer que va a someterse a ésta práctica medicinal }\end{array}$} \\
\hline Conclusión: & \multicolumn{3}{|c|}{$\begin{array}{l}\text { Se ha atendido a una presunta necesidad práctica con la creación de éste afiche; } \\
\text { pero es necesaria una síntesis del contenido y el uso de un lenguaje más ameno, } \\
\text { que pueda incluir a la paciente como receptor secundario de la pieza, en el } \\
\text { desarrollo del metamensaje, como medio tranquilizador e informador acerca la } \\
\text { técnica que se le practicará, de esa forma quizá podría entender de manera } \\
\text { sencilla que va a suceder dentro de su cuerpo y a que se está sometiendo. A } \\
\text { diferencia de las dos primeras piezas, la mujer no es el destinatario del mensaje } \\
\text { aunque finalmente será la usuaria del elemento que se promociona en este } \\
\text { mensaje. }\end{array}$} \\
\hline
\end{tabular}




\begin{tabular}{|l|l|}
\hline Roles de género y roles sexuales predominantes & Tradicional \\
\hline Mensaje predominante & Tradicional \\
\hline $\begin{array}{l}\text { Si bien es cierto que al utilizar un lenguaje técnico esta pieza publicitaria está dirigida a los y las } \\
\text { proveedoras de los servicios de salud sexual y reproductiva, en el contenido se puede identificar } \\
\text { cómo la consejería sobre el uso de este método anticonceptivo está dirigida exclusivamente a las } \\
\text { mujeres, en ningún momento se percibe como opción el acompañamiento del varón ni en la toma } \\
\text { de decisiones ni en el procedimiento, se observa un mensaje tradicional frente a la desigualdad en } \\
\text { los roles de género }\end{array}$ \\
\hline Categoría & Desigual \\
\hline
\end{tabular}

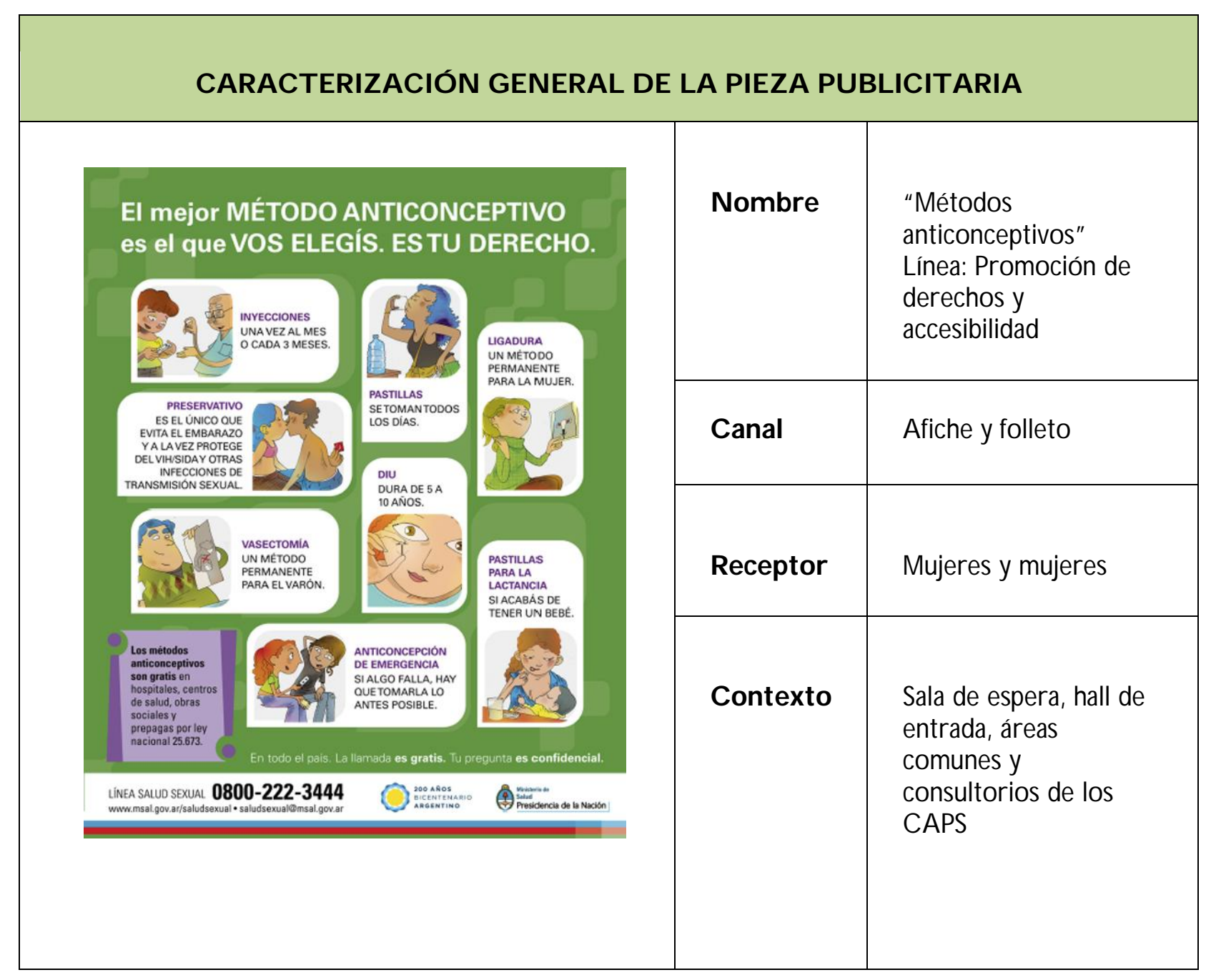




\section{ANALISIS METODOLOGICO DE LA PIEZA}

\begin{tabular}{|c|c|c|}
\hline Función: & \multicolumn{2}{|c|}{ Educar sobre los distintos métodos anticonceptivos } \\
\hline Desarrollo: & \multicolumn{2}{|c|}{$\begin{array}{l}\text { Es una pieza (Afiche) que, aparentemente, ha sido pensada para } \\
\text { aplicarse en lugares públicos, donde se tenga el tiempo suficiente para } \\
\text { leer los textos informativos y prestar atención a las ilustraciones que } \\
\text { ofician de anclaje a los textos explicativos que las rodean. La primer } \\
\text { decisión del constructor del mensaje es el de dirigirse imperativamente } \\
\text { al receptor y desliza en un metamensaje la obligación de elegir un } \\
\text { método anticonceptivo. Ésta vez encontramos que el mensaje está } \\
\text { dirigido a ambos sexos, aunque de los ocho métodos que se nombran } \\
\text { y explican, seis son para la mujer, esto pudiera ser una cuestión más } \\
\text { dirigida a la industria farmacológica o a la medicina, en su búsqueda de } \\
\text { métodos anticonceptivos, más que una elección de diseño o } \\
\text { construcción del mensaje desarrollado. } \\
\text { El lenguaje ameno y generalizador tiene un efecto positivo a la hora de } \\
\text { leer el mensaje y de invitar a la lectura, los textos son breves aunque } \\
\text { no se entiende bien la elección de viñetas e ilustraciones caricaturescas } \\
\text { para un tema tan serio. Existe conciencia que en ocasiones este tipo de } \\
\text { recursos acerca más a la gente que una fotografía, sin embargo no } \\
\text { siempre ayuda a entender lo que se está leyendo (como es el caso del } \\
\text { DIU, también podemos incluir los casos de LIGADURA y } \\
\text { VASECTOMíA). En algunas ocasiones se confunde el criterio de } \\
\text { información: "Posología del método anticonceptivo" o "definición del } \\
\text { método en sí mismo", unificar criterios podría simplificar la lectura y } \\
\text { comprensión del contenido. }\end{array}$} \\
\hline Conclusión: & \multicolumn{2}{|c|}{$\begin{array}{l}\text { Desde el aspecto gráfico la pieza es correcta aunque perfectible de } \\
\text { algunas correcciones importantes. Se podrían diferenciar mejor los } \\
\text { métodos anticonceptivos para el hombre y para la mujer, además se } \\
\text { observa un caos organizativo que no ayuda a la pregnancia de la pieza } \\
\text { en el entorno hospitalario, el título carece de peso, pero es acertado } \\
\text { dirigir el mensaje a ambos sexos. Es de resaltar que de los ocho } \\
\text { mensajes que posee la pieza, solo dos vinculan al varón como } \\
\text { integrante de la pareja y solo uno está dirigido exclusivamente a este. }\end{array}$} \\
\hline \multicolumn{3}{|c|}{ Roles de género y roles sexuales predominantes } \\
\hline \multicolumn{2}{|c|}{ Mensaje predominante } & No tradicionales \\
\hline
\end{tabular}

Desde el análisis de los roles sexuales y de género, es posible observar varones con roles ejecutivos a los que les es difícil expresar su emociones o tienen desconocimiento de los temas de salud sexual y reproductiva, las mujeres muestran control personal frente al tema y en una imagen se ven encargadas del cuidado de los y las hijas. Es un mensaje predominantemente no tradicional 
partiendo de la promoción del uso de anticonceptivos, el disfrute mutuo de la sexualidad, el empoderamiento y la comunicación franca de la prevención, sin embargo se visualiza desigualdad en los roles de género al presentar en la mayoría de las imágenes decisiones tomadas por una sola parte de la pareja.

Categoría Sensible

\begin{tabular}{|c|c|c|c|}
\hline \multicolumn{4}{|c|}{ CARACTERIZACIÓN GENERAL DE LA PIEZA PUBLICITARIA } \\
\hline \multirow{3}{*}{\multicolumn{2}{|c|}{ 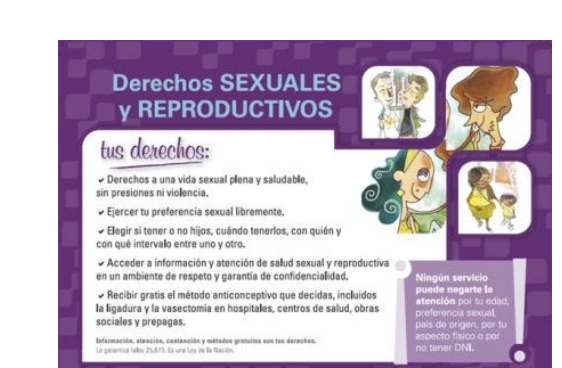 }} & Nombre & $\begin{array}{l}\text { "Derechos sexuales y reproductivos" } \\
\text { Serie derechos sexuales y reproductivos }\end{array}$ \\
\hline & & Canal & Afiche y folleto \\
\hline & & Receptor & Mujeres y hombres \\
\hline \multicolumn{2}{|c|}{ 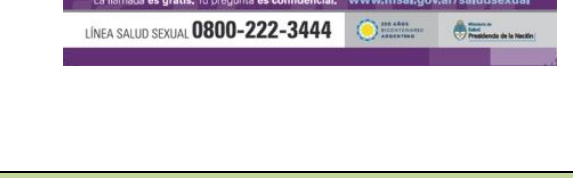 } & Contexto & $\begin{array}{l}\text { Sala de espera, hall de entrada, áreas } \\
\text { comunes y consultorios de los CAPS }\end{array}$ \\
\hline \multicolumn{4}{|c|}{ ANÁLISIS METODOLÓGICO DE LA PIEZA } \\
\hline Función: & \multicolumn{3}{|c|}{$\begin{array}{l}\text { Concientizar sobre los derechos de cada persona en relación a su vida sexual, } \\
\text { reproducción y salud. }\end{array}$} \\
\hline Desarrollo: & \multicolumn{3}{|c|}{$\begin{array}{l}\text { Este afiche desarrolla casi en forma de lista los distintos derechos que posee cada } \\
\text { persona en el aspecto sexual y reproductivo, los derechos que posee al acceso a } \\
\text { métodos anticonceptivos, información y atención médica } \\
\text { Se observa que los receptores de ésta pieza son tanto hombres como mujeres, } \\
\text { esto se revela en la última línea del listado de derechos cuando indluye en un } \\
\text { mismo plano: Ligadura y Vasectomía, antes de esto el lenguaje es generalizador, no } \\
\text { discrimina sexo ni orientación sexual. El metamensaje de éste afiche es la } \\
\text { comunicación del teléfono que se brinda para información al público acerca del } \\
\text { tema, en la piezas anteriores también se podía leer ésta información, pero debido a } \\
\text { la diagramación de ésta pieza, cobra mayor importancia, tras la enumeración de } \\
\text { derechos sexuales y reproductivos que se despliegan, al pie de la lista se encuentra } \\
\text { el número de contacto: 0800-222-3444. } \\
\text { Se agrega en un recuadro un mensaje concientizador a los receptores, para no } \\
\text { dejarse discriminar en los centros de atención y la obligación de éstos de }\end{array}$} \\
\hline
\end{tabular}




\begin{tabular}{|c|c|c|}
\hline & \multicolumn{2}{|c|}{$\begin{array}{l}\text { brindarles atención. } \\
\text { Como aspecto gráfico las ilustraciones son meramente decorativas y no refuerzan } \\
\text { ninguna idea, como tampoco guardan relación de anclaje, ni simplifican la } \\
\text { comprensión de ningún texto. El lenguaje de las mismas no coincide con la } \\
\text { importancia del contenido, aunque si con el de las piezas anteriores, esto revela } \\
\text { una toma de partido orientada a la estética más que a la funcionalidad. Se ve a dos } \\
\text { hombres abrazándose, pero no revela relación alguna con el contenido del afiche } \\
\text { (pueden ser amigos, hermanos, pareja, lo mismo da); también se observa una } \\
\text { mujer con un niño de la mano, ambos de tez oscura (se entiende que puede ser } \\
\text { una madre con su hijo y que quizá ésta imagen guarde relación con el mensaje de } \\
\text { "NO permitir ser discriminado", pero a su vez la asociación de ésta imagen con } \\
\text { dicha idea no es directa, el texto se encuentra demasiado alejado para relacionar } \\
\text { un andaje, más bien parece parte de la construcción ilustrativa/decorativa); } \\
\text { finalmente y con mayor jerarquía se ve a una pareja que pareciera estar } \\
\text { acariciándose, revelando una relación afectuosa que puede tener mayor } \\
\text { pertinencia con el tema que se ésta desarrollando en el afiche. }\end{array}$} \\
\hline Conclusión: & \multicolumn{2}{|c|}{$\begin{array}{l}\text { El mensaje fue pensado con conciencia sobre el texto a comunicar (los derechos } \\
\text { sexuales y reproductivos), sin embargo algunos aspectos del diseño atentan al } \\
\text { resultado final, como el uso de las imágenes y la diagramación. Nuevamente la } \\
\text { disposición en el espacio de los elementos que conforman la pieza gráfica no es la } \\
\text { correcta, ni la pertinente para el tipo de pieza y la importancia del contenido } \\
\text { desarrollado. Si bien el receptor puede ser de cualquier sexo, hay un hincapié en la } \\
\text { mujer a través de la importancia que se le da en la ilustración elegida. }\end{array}$} \\
\hline \multicolumn{2}{|c|}{ Roles de género y roles sexuales predominantes } & Tradicionales \\
\hline \multicolumn{2}{|c|}{ Mensaje predominante } & No tradicional \\
\hline \multicolumn{3}{|c|}{$\begin{array}{l}\text { Desde lo gráfico, se mantiene el común de presentar roles que no son fácilmente clasificables entre las } \\
\text { categorías definidas, es posible identificar roles de género tradicionales como los asignados a la imagen } \\
\text { de la madre con su hijo en donde se identifica fácilmente el rol cuidador de la mujer y su aspecto } \\
\text { menos ejecutivo. La imagen de los dos varones abrazados no es asociable a una pareja homosexual, } \\
\text { por lo que el rol de género no es fácilmente atribuible a un rol no tradicional. En el mensaje se puede } \\
\text { identificar de manera clara elementos no tradicionales como el uso de MAC, el apoyo a las diversas } \\
\text { orientaciones sexuales y al disfrute mutuo de la sexualidad. }\end{array}$} \\
\hline Categoría & \multicolumn{2}{|l|}{ Sensible } \\
\hline
\end{tabular}




\begin{tabular}{|c|c|c|c|}
\hline \multicolumn{4}{|c|}{ CARACTERIZACIÓN GENERAL DE LA PIEZA PUBLICITARIA } \\
\hline \multicolumn{2}{|c|}{$\begin{array}{l}\text { Ginecologia / Urologia / Proctologia / Endocinologia } \\
\text { Salud Sexual } \\
\text { y Reproductiva }\end{array}$} & Nombre & $\begin{array}{l}\text { "Identidades diversas" } \\
\text { Serie identidades diversas }\end{array}$ \\
\hline & & Canal & Afiche, autoadhesivo y folleto \\
\hline & & Receptor & Hombres y mujeres homosexuales \\
\hline & $\left.\begin{array}{l}\text { IVERSAS } \\
\text { erechos }\end{array}\right\}$ & Contexto & $\begin{array}{l}\text { Sala de espera, hall de entrada, áreas } \\
\text { comunes y consultorios de los CAPS }\end{array}$ \\
\hline \multicolumn{4}{|c|}{ ANÁLISIS METODOLÓGICO DE LA PIEZA } \\
\hline Función: & \multicolumn{3}{|c|}{ Dar a conocimiento la línea telefónica de salud sexual } \\
\hline Desarrollo: & \multicolumn{3}{|c|}{$\begin{array}{l}\text { La presente pieza contiene diversos elementos sintácticos y semánticos } \\
\text { susceptibles de análisis. Inicialmente, es posible observar una carencia de } \\
\text { jerarquías daras en los textos, lo que hace dudar sobre cuál es el título y cuál la } \\
\text { bajada del mismo: "Salud sexual y reproductiva" o "Identidades } \\
\text { diversas, los mismos derechos"; ésta falta de énfasis en alguna de las dos } \\
\text { líneas quita carácter a la pieza. El fondo que se ha elegido remite } \\
\text { semánticamente a la bandera usada por la comunidad LGTBI como estandarte, } \\
\text { lo que hace pensar que éste afiche se dirige a la comunidad homosexual } \\
\text { (hombres y mujeres). Quizá la intención de quien ideó éste mensaje era dirigirse } \\
\text { a ellos y resaltar que poseen los mismos derechos en lo que a salud sexual y } \\
\text { reproductiva se refiere; sin embargo, se vuelve a encontrar, como en otras } \\
\text { piezas, ante un mensaje ambiguo, poco claro y de énfasis algo errático en la } \\
\text { orientación sexual, cuando quizá se debería enfatizar en las distintas } \\
\text { especialidades médicas que deberían atender a toda persona sin importar su } \\
\text { orientación sexual: ginecología, urología, prodología, endocrinología. } \\
\text { En lo que a las imágenes se refiere son de poco interés semántico, no alcanzan a } \\
\text { reforzar la idea de "salud sexual reproductiva" ni la de "Identidades diversas, los } \\
\text { mismos derechos". Aquí los receptores son tanto hombres como mujeres, aunque } \\
\text { daramente se dirige la comunidad homosexual. }\end{array}$} \\
\hline Condusión: & \multicolumn{3}{|c|}{$\begin{array}{l}\text { La duda con la que se pensó el mensaje sobre qué idea enfatizar, se traslada } \\
\text { directamente a su diseño. Quizá sería necesario replantear la idea principal para }\end{array}$} \\
\hline
\end{tabular}




\begin{tabular}{|c|c|c|}
\hline & \multicolumn{2}{|c|}{$\begin{array}{l}\text { pulir ciertos defectos en la transmisión del mismo, suele repetirse una } \\
\text { ambigüedad en la elección del receptor: homosexuales y heterosexuales } \\
\text { poseemos los mismos derechos, pero la duda hace enfatizar en éste rasgo y no } \\
\text { en el deber de atender o ser atendido en una consulta médica, sin } \\
\text { discriminación. }\end{array}$} \\
\hline \multicolumn{2}{|c|}{ Roles de género y roles sexuales predominantes } & Tradicionales \\
\hline \multicolumn{2}{|c|}{ Mensaje predominante } & No tradicional \\
\hline \multicolumn{3}{|c|}{$\begin{array}{l}\text { En esta pieza es sumamente difícil identificar los roles de género, se presentan de manera aislada } \\
\text { imágenes sin carga de rol de género o rol sexual, los individuos se encuentran en diferentes planos y } \\
\text { no es posible identificar si pertenecen a parejas homosexuales, heterosexuales o lesbianas, es } \\
\text { lejanamente posible abstraer que las mujeres se muestran con escaso nivel de poder y educación y los } \\
\text { varones con escaso control en la toma de decisiones. El mensaje promueve el respeto por } \\
\text { orientaciones sexuales diversas. Se considera una pieza sensible, debido a que, aunque reconoce la } \\
\text { necesidad de equidad frente a las necesidades en salud de la población con orientaciones sexuales } \\
\text { diversas, no es clara en apuntar a la transformación de las relaciones de poder en el espacio de los } \\
\text { servicios médicos. }\end{array}$} \\
\hline Categor & & \\
\hline
\end{tabular}

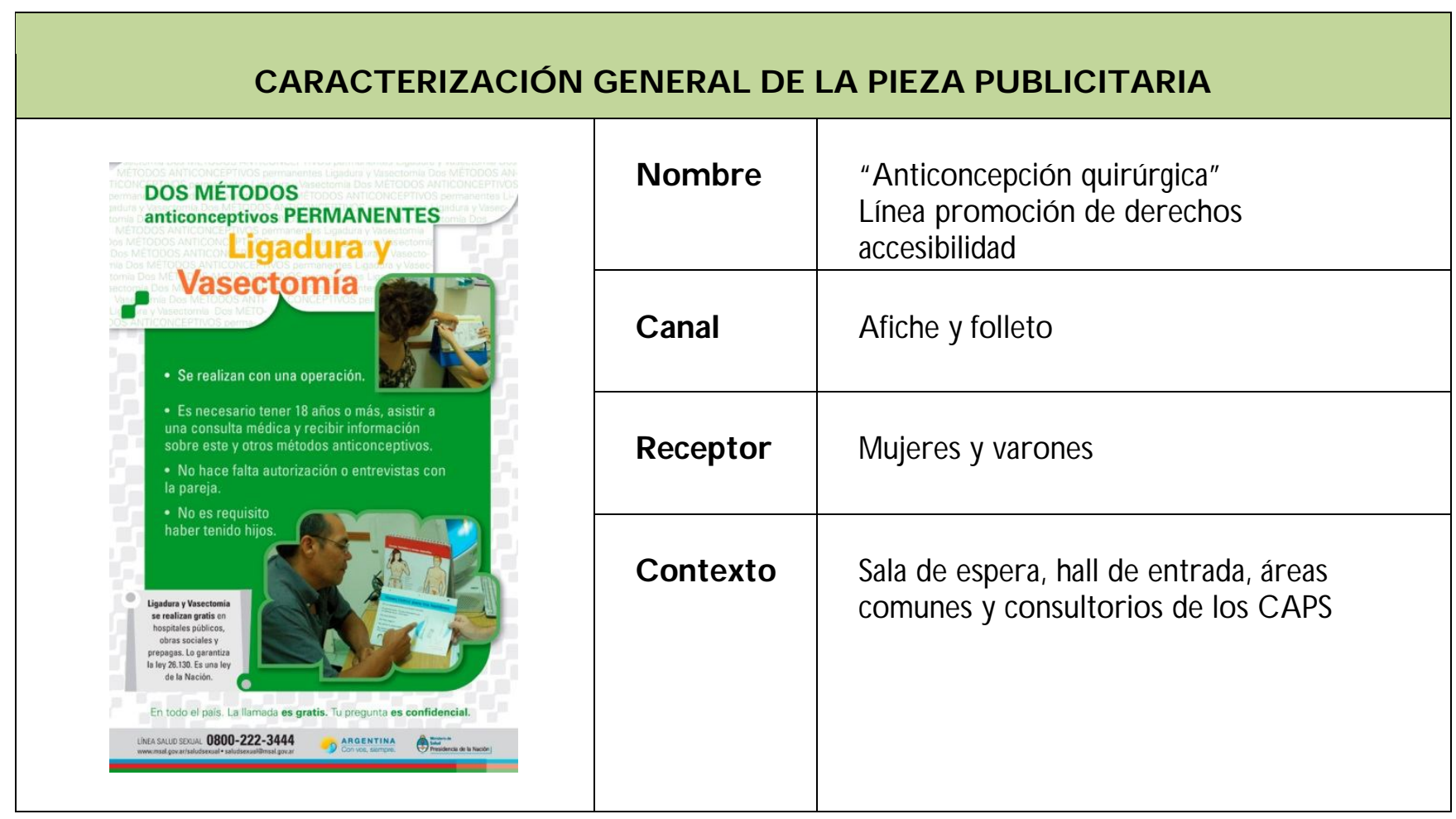




\begin{tabular}{|c|c|c|}
\hline \multicolumn{3}{|c|}{ ANALISIS METODOLOGICO DE LA PIEZA } \\
\hline Función: & \multicolumn{2}{|c|}{ Informar sobre los métodos anticonceptivos permanentes } \\
\hline Desarrollo: & \multicolumn{2}{|c|}{$\begin{array}{l}\text { Se puede ver en éste afiche que los receptores son hombres y mujeres, las } \\
\text { imágenes fueron elegidas con mayor pertinencia: sujetos a los que se les está } \\
\text { explicando el procedimiento médico, la forma en que encierra la imagen } \\
\text { masculina es muy perjudicial para la lectura del mensaje, un encuadre como el } \\
\text { que se eligó para la figura femenina facilita la lectura del afiche por su } \\
\text { simplificación, éste es un error recurrente en la mayoría de las piezas analizadas } \\
\text { en el presente trabajo, al igual que las texturas de fondo mal elegidas y demasiado } \\
\text { complejas para su función. } \\
\text { Aquí el texto de mayor jerarquía cuenta de que trata el afiche: "Ligadura y } \\
\text { vasectomá, aunque el lugar correcto para el texto de segunda jerarquía sería por } \\
\text { debajo del primero: "Dos métodos anticonceptivos permanentes". A continuación se } \\
\text { detalla ciertos requisitos para la intervención y otros datos importantes: edad } \\
\text { necesaria, gratuidad de la atención, y finalmente el medio de comunicación para } \\
\text { información anexa. } \\
\text { Se retoma el uso de fotografías para ilustrar la composición, lo cual revela la } \\
\text { indecisión para sostener en distintas piezas un mismo lenguaje y codificación. Por } \\
\text { primera vez la figura masculina se destaca por sobre la figura femenina en forma } \\
\text { notoria, hasta éste momento pareća ser que la mujer era la principal interesada } \\
\text { en la salud sexual, la más desinformada o al menos el receptor más indicado para } \\
\text { éstas piezas según el creador del mensaje y el diseñador del canal } \\
\text { comunicacional. }\end{array}$} \\
\hline Condusión: & \multicolumn{2}{|c|}{$\begin{array}{l}\text { Esta, como las piezas anteriores se encuentra viciada de errores de diseño y } \\
\text { comunicación visual; sin embargo. El análisis que nos corresponde es sobre el } \\
\text { receptor de la pieza, y aquí es posible decir que hombres y mujeres se ubican en } \\
\text { dicha posición, que se destaca al hombre por sobre la mujer, desde la imagen. }\end{array}$} \\
\hline \multicolumn{2}{|c|}{ Roles de género y roles sexuales predominantes } & No tradicionales \\
\hline \multicolumn{2}{|c|}{ Mensaje predominante } & Tradicional \\
\hline \multicolumn{3}{|c|}{$\begin{array}{l}\text { Desde los roles de género es interesante identificar la fotografía de un varón adquiriendo la } \\
\text { responsabilidad en el rol de tomador de decisiones frente a la salud sexual y reproductiva, alejándose de } \\
\text { la concepción machista de la sexualidad y la reproducción como como representación de su virilidad. Sin } \\
\text { embargo se observa como la pieza es sensible mas no transformadora en el punto en que se muestra la } \\
\text { toma de decisiones como una acción aislada de cada individuo, en la que no se considera importante la } \\
\text { figura de la pareja en la toma de decisiones, alejándose de la construcción colectiva de la salud sexual y } \\
\text { reproductiva entre hombres y mujeres. }\end{array}$} \\
\hline Categoría & Sensible & \\
\hline
\end{tabular}




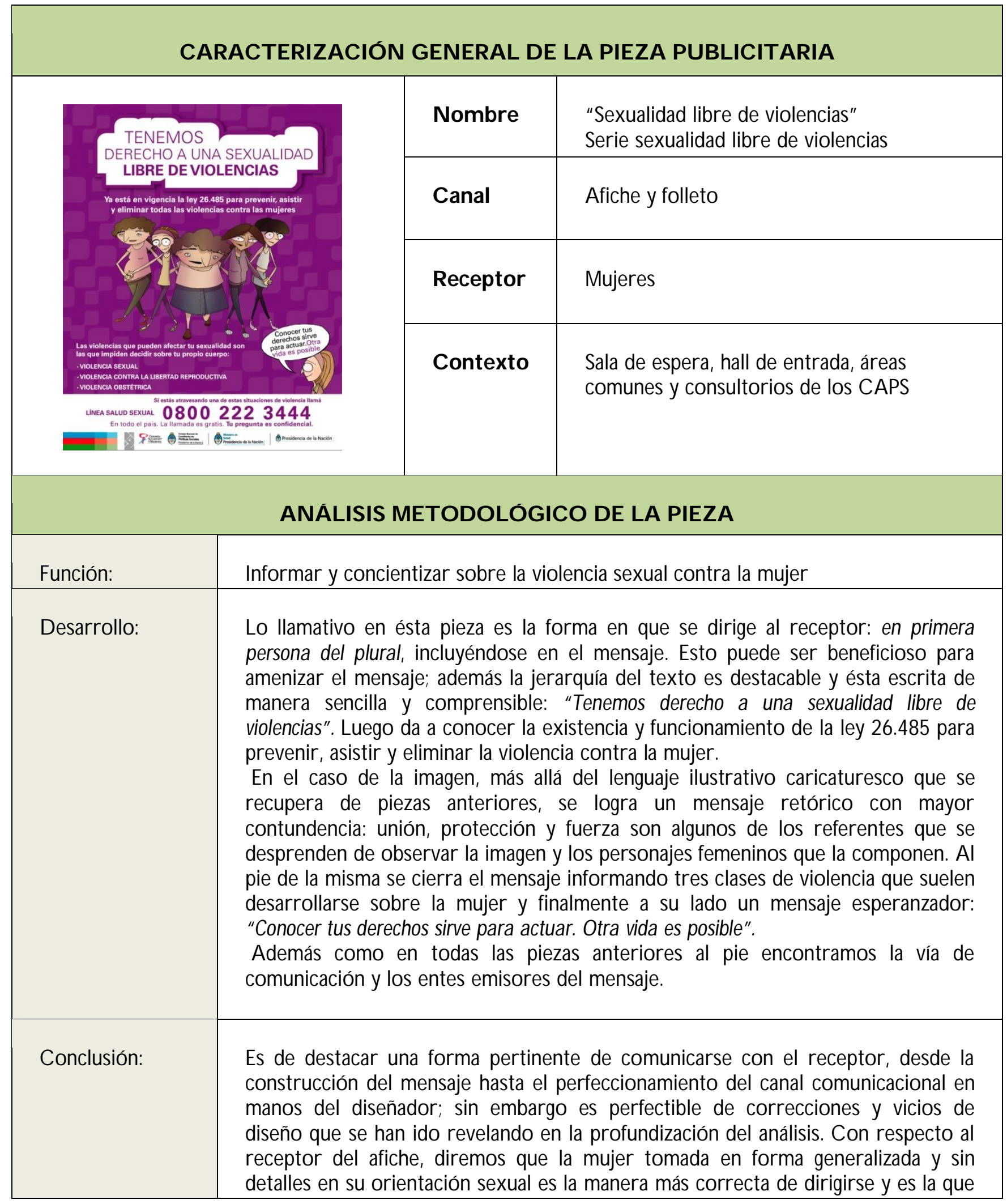


aquí se aplica a diferencia de afiches anteriores.

Roles de género y roles sexuales predominantes

Mensaje predominante
Tradicionales

No tradicionales

En la pieza se representa a las mujeres como personas victimizadas, débiles frente a la toma de decisiones, que buscan apoyo en las relaciones solidarias de otras mujeres representando emociones centradas en los demás, por estas razones se consideró como una pieza de predominancia en los roles de género tradicionales. Desde el mensaje es posible identificar roles de género desiguales frente a la problemática de la sexualidad con presencia de violencias, al no vincular al varón como un elemento importante en la solución de dicha problemática; sin embargo, se convierte en un mensaje no tradicional en el punto en que visibiliza la no tolerancia frente a los diferentes tipos de violencia contra la mujer, desnaturaliza el maltrato en los diferentes escenarios y promueve el empoderamiento y el control personal. Es una pieza sensible ya que no pretende modificar las causas del problema sino que busca empoderar a las mujeres desde su rol de víctimas.

Categoría Sensible

El diseño de las piezas gráficas debe subordinarse al mensaje, pero a su vez convivir con él. En las piezas analizadas, sin embargo se observan recurrentes desconexiones entre la construcción del mensaje y el diseño; entre la forma de dirigirse al receptor y el tema en cuestión. Es posible destacar como se apela notablemente a la conciencia femenina más que a la masculina, independientemente de su orientación sexual o edad. Suele ser el sujeto al que se informa, alerta y concientiza de manera más regular. Un estudio más minucioso quizá pueda revelar el porqué de éste carácter tan particular del mensaje general en éste conjunto de piezas gráficas, puede ser resultado de una investigación previa o tan solo la consecuencia de un juicio de valor sobre la figura femenina en la sociedad, que viaja soslayadamente y de forma codificada en un metamensaje.

La mujer debe cuidar su salud sexual y reproductiva; debe conocer los métodos anticonceptivos (permanentes y temporales); debe conocer sus derechos y hacerlos valer, evitando ser una víctima de la violencia sexual; sin embargo no parecen ser temas que queden fuera del interés de todo hombre, es por ello que se plantea la pregunta: jpor qué el énfasis en la mujer?

Posterior al análisis cualitativo de las piezas publicitarias se cuantificaron los resultados a través de seis indicadores: 
Tabla 9. Caracterización de las piezas publicitarias utilizadas en los CAPS de la municipalidad de La Plata bajo el PPSSyPR 2012

\begin{tabular}{|l|c|c|c|c|c|}
\hline \multirow{2}{*}{ Pieza publicitaria } & \multicolumn{2}{|c|}{ Población objetivo } & \multicolumn{3}{c|}{ Categoría } \\
\cline { 2 - 6 } & Varones & Mujeres & Desigual & Sensible & Transformadora \\
\hline Mujeres lesbianas y bisexuales & & $X$ & & $X$ & \\
\hline $\begin{array}{l}\text { ¿Sabes que es la pildora del día } \\
\text { después? }\end{array}$ & & $X$ & $X$ & & \\
\hline $\begin{array}{l}\text { “Dispositivo intrauterino } \\
\text { (DIU)" }\end{array}$ & & $X$ & $X$ & & \\
\hline Métodos anticonceptivos & $X$ & $X$ & & $X$ & \\
\hline $\begin{array}{l}\text { Derechos sexuales y } \\
\text { reproductivos }\end{array}$ & $X$ & $X$ & & $X$ & \\
\hline Identidades diversas & $X$ & $X$ & & $X$ & \\
\hline Anticoncepción quirúrgica & $X$ & $X$ & & $X$ & \\
\hline Sexualidad libre de violencias & & $X$ & & $X$ & \\
\hline
\end{tabular}

El 50\% de las piezas publicitarias utilizadas en los CAPS vinculan de alguna manera a los varones, en las que son población objetivo, comparten esta vinculación con la población de mujeres. La mitad de las piezas publicitarias analizadas están dirigidas a las mujeres de manera exclusiva, es decir, el 100\% de las piezas publicitarias las vincula, mientras que ninguna está dirigida de manera exclusiva a la población de varones.

Desde la aplicación de la estrategia de categorización de la perspectiva de género propuesta por la OPS y descrita en el marco teórico, se pudo determinar que el $25 \%$ de las piezas publicitarias son de carácter desigual y el $75 \%$ restante de carácter sensible a las diferencias de género. No se encontró ninguna pieza transformadora.

En la tabla 10 se presentan los indicadores plateados para la variable de lenguaje incluyente en el PPSSyPR implementado en la municipalidad de La Plata. 
Tabla 10. Distribución porcentual de las características de lenguaje incluyente y vinculación de los varones en las piezas publicitarias del PPSSyPR usadas en los CAPS de la municipalidad de La Plata, 2012.

\begin{tabular}{|l|c|}
\hline \multicolumn{1}{|c|}{ Indicador } & $\%$ \\
\hline Porcentaje de publicaciones que usan el lencuaje incluyente en su contenido & 83.3 \\
\hline Porcentaje de piezas publicitarias con carácter desigual & 25 \\
\hline Porcentaje de piezas publicitarias con carácter sensible & 75 \\
\hline Porcentaje de piezas publicitarias con carácter transformador & 0 \\
\hline Porcentaje de piezas publicitarias dirigidas exclusivamente a varonec & 0 \\
\hline $\begin{array}{l}\text { Porcentaje de piezas publicitarias usadas en los CAPS, que fomentan la vinculación del } \\
\text { varón en el PPSSyPR }\end{array}$ & 50 \\
\hline
\end{tabular}

Fuente: Creación de la investigadora.

\subsection{Análisis descriptivo de la variable direccionamiento de acciones}

A partir del análisis de los documentos que orientan la implementación de las acciones dentro del PPSSyPR, se identificó la población objetivo de cada una de ellas, de esta manara fue posible identificar nueve acciones puntuales ofertadas por los CAPS de la Municipalidad de La Plata a los y las usuarias del programa, y su direccionalidad.

Tabla 11 Direccionamiento de acciones en el PPSSyPR. Municipalidad de La Plata, 2012

\begin{tabular}{|c|c|c|c|}
\hline \multirow[b]{2}{*}{ Acción } & \multirow[b]{2}{*}{ Fuente de la información } & \multicolumn{2}{|c|}{ Población objetivo } \\
\hline & & Varones & Mujeres \\
\hline Consejería en SSySR & Consejería en SSYSR (37) & $\mathrm{X}$ & $\mathrm{X}$ \\
\hline Entrega de AOC - ACOLAC - ACI & \multirow{5}{*}{$\begin{array}{l}\text { MAC. Guía para un acceso sin } \\
\text { barreras ( } 29)\end{array}$} & & $\mathrm{X}$ \\
\hline Entrega de AHE & & $\mathrm{X}$ & $\mathrm{X}$ \\
\hline Inserción DIU & & & $\mathrm{X}$ \\
\hline Entrega de preservativos & & $\mathrm{X}$ & $\mathrm{X}$ \\
\hline Entrega de materiales de difusión & & $\mathrm{X}$ & $\mathrm{X}$ \\
\hline Vasectomía & Vasectomía. Documento científico & $\mathrm{X}$ & \\
\hline Ligadura tubárica & $\begin{array}{l}\text { Ligadura Tubárica. Documento } \\
\text { científico }\end{array}$ & & $x$ \\
\hline Aborto no punible & $\begin{array}{l}\text { Guía de atención integral de } \\
\text { abortos no punibles (40) }\end{array}$ & & $\mathrm{x}$ \\
\hline Total de intervenciones & & 5 & 8 \\
\hline
\end{tabular}

Fuente: Creación de la investigadora, basada en PPSSyPR. 
De acuerdo con los indicadores propuestos para el análisis de esta variable:

Porcentaje de acciones dirigidas a mujeres dentro del PPSSyPR

$\operatorname{PADM}=\frac{\text { Número de acciones ofertadas en el programa dirigidas a mujeres }}{\text { Número de acciones ofertadas en el programa }} \times 100$

Porcentaje de acciones dirigidas a varones dentro del PPSSyPR

\author{
Número de acciones dirigidas a mujeres

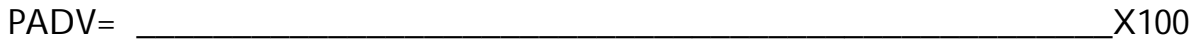 \\ Número de acciones ofertadas en el programa
}

Se encontró que en el PPSSyPR de la municipalidad de La Plata la población de varones puede acceder al 55.5\%de las acciones ofertadas, mientras que la población de mujeres tiene acceso al $88.8 \%$ de estas.

Dentro de las herramientas identificadas en el marco teórico como precursoras de la salud sexual y reproductiva de las poblaciones, se encuentra un fuerte énfasis, en el empoderamiento de la mujer dentro de las relaciones de poder y la toma de decisiones relacionadas con la SSYSR. No obstante se encuentra como elemento trascendental en el logro del objetivo, la vinculación de los varones para la generación de cambios estructurales.

El análisis de la direccionalidad de las acciones ofertadas por los CAPS de la municipalidad de La Plata dentro del PPSSyPR, permite señalar que son más las acciones dirigidas a las mujeres que aquellas que se encuentran direccionadas a los varones.

Adicionalmente, se puede afirmar que aquellas acciones que se encuentran dirigidas a varones o mujeres de forma individual, no visualizan la importancia de un trabajo colectivo de la pareja; se hace demasiado énfasis en la delimitación de la toma de decisiones individuales, sin obstáculo alguno por la no autorización de la pareja Lo anterior refuerza la toma de decisiones autónomas en el ejercicio de poder sobre el propio cuerpo, se invisibilizan las interacciones existentes en el espacio privado de dichas relaciones de pareja, sus interacciones sexuales y sus redes sociales y culturales.

\title{
7.3. Análisis descriptivo de la variable disponibilidad de Métodos Anticonceptivos
}

Para el análisis de las dos siguientes variables se utilizaron los datos recolectados en la población usuaria del PPSSyPR en los CAPS de la municipalidad de La Plata a través de la aplicación del Instrumento dirigido a usuarias y usuarios del Programa de salud Sexual y procreación responsable de la municipalidad de La Plata. Se recolectaron 312 datos, su comportamiento desde las medidas de tendencia central y dispersión se presenta en la siguiente tabla. 
Tabla 12. Distribución de la variable edad en la población usuaria del PSSyPR de la municipalidad de La Plata 2012

\begin{tabular}{|c|c|c|c|c|}
\hline Variable & Media & Mediana & Moda & $\begin{array}{c}\text { Desviación } \\
\text { Standar }\end{array}$ \\
\hline Edad & 27.30 & 27 & 30 & 7.17 \\
\hline
\end{tabular}

En cuanto al sexo de la población encuestada, se encontró que el 97.8\% de las encuestadas son mujeres y el $2.2 \%$ son varones que asistieron como acompañantes de sus parejas, no se identificó ningún varón que asistiera solo al servicio ofertado por el PPSSyPR.

Tabla 13. Disponibilidad de MAC ofertados por el PPSSyPR en los CAPS de la municipalidad de La Plata.

\begin{tabular}{|l|c|}
\hline \multicolumn{1}{|c|}{ Indicador } & $\%$ \\
\hline Porcentaje de mujeres que solicitaron preservativos dentro del PPSSyPR & 19.7 \\
\hline $\begin{array}{l}\text { Porcentaje de mujeres que solicitaron preservativos y les fueron entregados dentro } \\
\text { del PPSSyPR }\end{array}$ & 96.7 \\
\hline Porcentaje de varones que solicitaron preservativos dentro del PPSSyPR & 14.3 \\
\hline $\begin{array}{l}\text { Porcentaje de varones que solicitaron preservativos y les fueron entregados dentro } \\
\text { del PPSSyPR }\end{array}$ & 100 \\
\hline $\begin{array}{l}\text { Porcentaje de mujeres que solicitaron métodos anticonceptivos diferentes a } \\
\text { preservativos y vasectomía. }\end{array}$ & 80.3 \\
\hline $\begin{array}{l}\text { Porcentaje de mujeres que solicitaron MAC diferentes a vasectomía y preservativos y } \\
\text { les fueron entregados dentro del PPSSyPR }\end{array}$ & $82.4 \%$ \\
\hline $\begin{array}{l}\text { Porcentaje de varones que solicitaron vasectomía y les fue realizada dentro del } \\
\text { PPSSyPR en un tiempo inferior a un mes. }\end{array}$ & $0 \%$ ** \\
\hline
\end{tabular}

Fuente: Creación de la investigadora

*Razones de la no entrega: no incluidos en el PMO, cita previa, laboratorios, imágenes Dx, horarios o por no disponibilidad. ** Ningún varón solicitó vasectomía

Tomando como denominador un total 305 de mujeres encuestadas, se identificó que una pequeña cantidad de estas, (60), solicitaron preservativos, de las cuales, (58), tuvieron facilidad en el acceso; tan solo dos mujeres afirmaron que el CAPS no tenía disponibilidad del método. El comportamiento 
de este evento en la población de varones fue diferente, ya que de los siete encuestados solo uno solicito el método y le fue entregado sin dificultad.

De las 245 mujeres acudieron a los CAPS solicitando métodos anticonceptivos diferentes a la vasectomía y al preservativo, 202 afirmaron recibir el método solicitado sin complicación alguna y la minoría, (43), refirieron no tener acceso al MAC requerido, atribuyen este hecho a que los métodos no están incluidos en el PMO, a que se requiere cita previa para su suministro, a la solicitud de exámenes de laboratorio o pruebas diagnósticas y a la disponibilidad de horarios en los CAPS para la entrega.

Se puede analizar que la mayoría de las mujeres que acceden a los servicios de salud sexual y reproductiva, prefieren el uso de métodos anticonceptivos destinados a ellas y que existe disponibilidad de este método. Los varones que accedieron a los servicios de salud sexual y reproductiva, lo hicieron como acompañantes de sus parejas y durante la consejería en planificación familiar seleccionaron métodos diferentes a la vasectomía; este evento confirma la baja realización de este procedimiento en la población, tal como lo cita el documento "Políticas de salud sexual y reproductiva, avances y desafíos. Balance 2003 - 2011" (2).

\subsection{Análisis descriptivo de la variable promoción de la Vinculación del Varón en la Consejería de Planificación Familiar}

El análisis de esta variable se realizó a partir de las respuestas suministradas por la población usuaria del servicio de consejería en planificación familiar, en el instrumento utilizado se indagó en dos posibles situaciones. La primera, aquella en la que el varón ingresó a la consejería en planificación familiar en compañía de su pareja y el proveedor o la proveedora hizo un reconocimiento positivo a su participación o estimuló la continuidad de su vinculación en la toma de decisiones en esta materia La segunda situación abarca aquellas consejerías en las que solo ingresaron las mujeres, en estas se indagó acerca del estímulo hacia la participación del varón de manera verbal o con material escrito, la información entregada por el o la proveedora en cuanto a la importancia de la responsabilidad compartida entre hombre y mujeres en la SSyR y el derecho a la vinculación del varón en el PPSSyPR implementado en la municipalidad de La Plata.

Se identificó que el 67,9\% de la población encuestada recibió algún tipo de información sobre la vinculación del varón en la salud sexual y reproductiva, mientras que 100 personas encuestadas (32,1\%) refirieron no haber recibido ningún tipo de información frente al tema

Con respecto a la forma en que se abordó la participación de los varones en la salud sexual y reproductiva, se observó que es más común que provedores/as estimulen de manera verbal la participación del varón en la salud sexual y reproductiva, generando la duda de si es indispensable que en la consejería en planificación familiar se cuente con material exclusivo para este fin. 
En cuanto a la forma en que se percibe la vinculación de varón en la SSyR, se resalta que los y las proveedoras promueven mayoritariamente la vinculación del varón como una responsabilidad, y de menor manera como la promoción de un derecho. Los y las participantes de la investigación que asistieron en pareja refirieron que siempre se motivó a la continuación de la participación del varón en la toma de decisiones.

Los resultados cuantitativos que permitieron aterrizar el indicador planteado se expresan en la tabla 14

Tabla 14. Formas en que se informó sobre la importancia de la vinculación del varón en la consejería de planificación familiar

\begin{tabular}{|l|c|c|}
\hline $\begin{array}{l}\text { Forma de comunicación de la importancia de la vinculación del varón } \\
\text { en la SSyR }\end{array}$ & \multicolumn{2}{|c|}{ Porcentaje } \\
\cline { 2 - 3 } & $\mathrm{Si}$ & $\mathrm{No}$ \\
\hline $\begin{array}{l}\text { Se estimuló verbalmente la participación de varón en las actividades } \\
\text { del programa de salud sexual y procreación responsable }\end{array}$ & 31.4 & 68.6 \\
\hline $\begin{array}{l}\text { Se estimuló con material escrito la participación de varón en las } \\
\text { actividades del programa de salud sexual y procreación responsable }\end{array}$ & 11.2 & 88.8 \\
\hline $\begin{array}{l}\text { Se expresó la importancia de la responsabilidad compartida entre } \\
\text { hombre y mujeres en la SSyR }\end{array}$ & 60.3 & 39.7 \\
\hline Se expresó que la vinculación del varón es un derecho & 28.5 & 71.5 \\
\hline Se estimuló la continuación de la presencia del varón & 100.0 & 0.0 \\
\hline Se hizo reconocimiento a la presencia del varón en la consejería & 100.0 & 0.0 \\
\hline
\end{tabular}

Fuente: Creación de la investigadora

\subsection{Análisis descriptivo de la variable sensibilización de Proveedores de Consejería en Planificación Familiar en Perspectiva de Género}

Para el análisis de esta variable se encuestó a la población proveedora de la consejería en planificación familiar en los CAPS. Los hallazgos identificados se expresan a continuación.

Frente a la pregunta "¿La vinculación del varón en el Programa de Salud Sexual y Procreación Responsable es importante?", el $88.3 \%$ de la población encuestada considera que sí es importante, justificando su respuesta con argumentos que involucran la igualdad de derechos y reconociendo dicha participación como una estrategia para garantizar los DSR de manera igualitaria entre varones y mujeres. En 
menor porcentaje se reconoce la vinculación del varón en la PSSyPR como una manera de ampliar el abordaje de los DSR a otras comunidades como la de homosexuales. Las respuestas seleccionadas se expresan en la tabla 15.

Tabla 15. Distribución porcentual de las razones por las cuales la población proveedora de la consejería en planificación familiar considera importante la vinculación del varón en el PSSyPR

\begin{tabular}{|l|c|}
\hline \multicolumn{1}{|c|}{ Razón } & $\%$ \\
\hline $\begin{array}{l}\text { E varón tiene igualdad de derechos frente a la toma de decisiones } \\
\text { relacionadas con la salud sexual y reproductiva. }\end{array}$ & $\mathbf{8 8 . 3}$ \\
\hline $\begin{array}{l}\text { Es una estrategia para garantizar los derechos sexuales y reproductivos de } \\
\text { manera igualitaria entre varones y mujeres }\end{array}$ & $\mathbf{6 0 . 0}$ \\
\hline $\begin{array}{l}\text { Promociona las acciones de cuidado de la salud sexual y reproductiva en un } \\
\text { gupo de población que difícilmente acude a los servicios de salud por } \\
\text { cuestiones preventivas }\end{array}$ & $\mathbf{5 1 . 7}$ \\
\hline $\begin{array}{l}\text { Es una estrategia que permite hacer más integral en acceso a los servicios de } \\
\text { salud en materia de salud sexual y reproductiva }\end{array}$ & $\mathbf{5 1 . 7}$ \\
\hline $\begin{array}{l}\text { Amplia el abordaje de derechos a otras comunidades como la de } \\
\text { homosexuales }\end{array}$ & $\mathbf{4 8 . 3}$ \\
\hline
\end{tabular}

Fuente: Creación de la investigadora

Frente a esta misma pregunta el $11.7 \%$ de la población encuestada consideró que la vinculación del varón en el PSSyPR no es importante, argumentando este hecho con razones como que la mayoría de los MAC son para mujeres y el acceso a la vasectomía es limitado; y además que los servicios de salud sexual y reproductiva están dirigidos en mayor parte a las mujeres.

Tabla 16. Distribución porcentual de las razones por las cuales la población proveedora de la consejería en planificación familiar no considera importante la vinculación del varón en el PSSyPR

\begin{tabular}{|l|c|}
\hline \multicolumn{1}{|c|}{ Razón } & $\%$ \\
\hline $\begin{array}{l}\text { La mayoría de los métodos anticonceptivos son para mujeres y el acceso a la vasectomía } \\
\text { es limitado. }\end{array}$ & $\mathbf{1 1 . 7}$ \\
\hline $\begin{array}{l}\text { Los servicios de salud relacionados con la anticoncepción están dirigidos en mayor parte } \\
\text { a las mujeres }\end{array}$ & $\mathbf{8 . 3}$ \\
\hline Por tradición la anticoncepción es cosa de mujeres & $\mathbf{3 . 3}$ \\
\hline $\begin{array}{l}\text { Las mujeres son las que se embarazan y por eso ellas son las que deben usar los } \\
\text { anticonceptivos }\end{array}$ & $\mathbf{0 . 0}$ \\
\hline Son las mujeres las que tienen tiempo para eso, los varones no & $\mathbf{0 . 0}$ \\
\hline
\end{tabular}

Fuente: Creación de la investigadora 
A partir de estos datos, es posible percibir que los y las proveedores/as tienen un importante grado de sensibilidad frente a la importancia de la vinculación de los varones en la salud sexual y reproductiva, sin embargo, al confrontar esta información con la expresada por la población usuaria, fueron muchos más los y las proveedoras que expresaron sensibilidad frente a la importancia de la vinculación del varón (88.3\%) que los y las usuarias que manifestaron haber recibido esta información (67.9\%).

Al indagar sobre las actividades de capacitación y sensibilización que ha implementado el PPSSyPR, dirigidas a la población proveedora sobre temas como a la importancia de la vinculación del varón en la salud sexual y reproductiva y la importancia de la perspectiva de género, se identificó que la mayoría refiere no haber recibido ningún tipo de capacitación bajo el programa, siendo la perspectiva de género el tema más reconocido como eje de la capacitación. En la tabla 17 se exponen los resultados obtenidos en la pregunta "¿Dentro del Programa de Salud Sexual y Procreación Responsable ha recibido sensibilización o capacitación en perspectiva de género o vinculación del varón?.

Tabla 17. Distribución porcentual de proveedores/as de consejería en planificación familiar que refieren haber sido sensibilizados/as en la importancia de la perspectiva de género o importancia de la vinculación del varón.

\begin{tabular}{|l|l|}
\hline Proveedores/as que refieren haber sido sensibilizados/as en: & $\%$ \\
\hline Perspectiva de género & $\mathbf{4 0}$ \\
\hline Importancia de la Vinculación del varón & $\mathbf{2 0}$ \\
\hline
\end{tabular}

Fuente: Creación de la investigadora

La percepción de la población encuestada, es contradictoria con la información suministrada por las referentes del programa, quienes expresaron que aproximadamente un año atrás esta población había sido capacitada y sensibilizada, además esta estrategia es planteada desde los lineamientos del programa como una manera de extender la garantía del ejercicio de los DSR a todo el colectivo usuario del programa

\subsection{Análisis descriptivo de la variable, reconocimiento de las estrategias de vinculación del varón en el PPSSyPR}

Previo a la estructuración de los instrumentos de recolección de datos, se realizó la revisión de los contenidos del programa y de los objetivos de la investigación. El primer avance fue la aplicación de una entrevista semi-estructurada a las referentes del Programa de Salud Sexual y Procreación Responsable de la Municipalidad de La Plata, Lic. Mariza Matias y la Dra. Liliana Romero, quienes aportaron los elementos fundamentales para la identificación de las estrategias implementadas en el programa con el fin de promover la vinculación de los varones. En el discurso manejado por las 
referentes del programa se identificaron tres estrategias para la promoción de la vinculación de los varones en el PSSyPR:

- Entrega de folletería y material publicitario que promueve la participación del varón.

- Consejería integral en planificación familiar

- Capacitaciones en derechos sexuales y reproductivos a los y las profesionales de los CAPS

Los resultados obtenidos frente a la pregunta "Actualmente las estrategias que usa el Programa de Salud Sexual y Procreación Responsable de la Municipalidad de La Plata para la vinaulacón del varón a la salud sexual y reproductiva son:", muestran que la mayoría de los y las proveedores/as del PPSSyPR reconocen la consejería en planificación familiar como una estrategia para el logro del objetivo de vincular al varón en la salud sexual y reproductiva Los resultados detallados se expresan en la tabla 18.

Tabla 18. Distribución porcentual del reconocimiento de las estrategias de vinculación del varón en el PPSSyPR implementado en la Municipalidad de La Plata

\begin{tabular}{|l|c|}
\hline \multicolumn{1}{|c|}{ Estrategia } & $\%$ \\
\hline Consejería integral en planificación familiar & $\mathbf{6 3 . 3}$ \\
\hline $\begin{array}{l}\text { Entrega de folletería y material publicitario que promueve la } \\
\text { participación del varón. }\end{array}$ & $\mathbf{5 0 . 0}$ \\
\hline $\begin{array}{l}\text { Capacitaciones en derechos sexuales y reproductivos a los } \\
\text { profesionales de los CAPS }\end{array}$ & $\mathbf{4 1 . 7}$ \\
\hline
\end{tabular}

En la tabla 19 es posible observar que el porcentaje de porvedoras/es que reconoce las tres estrategias del programa para la vinculación del varón, es mínimo.

Tabla 19 Distribución porcentual del reconocimiento de las estrategias de vinculación del varón en el PPSSyPR de la Municipalidad de La Plata

\begin{tabular}{|l|c|}
\hline \multicolumn{1}{|c|}{ Estrategia reconocida } & $\%$ \\
\hline No reconoce ninguna estrategia & $\mathbf{2 1 . 7}$ \\
\hline Reconoce por lo menos una estrategia & $\mathbf{2 8 . 3}$ \\
\hline Reconoce por lo menos dos estrategias & $\mathbf{2 3 . 3}$ \\
\hline Reconoce las tres estrategias verdaderas & $\mathbf{2 6 . 7}$ \\
\hline
\end{tabular}

Fuente: Creación de la investigadora 
Partiendo del reconocimiento de las estrategias de vinculación del varón en la SSyR usadas por el programa, se preguntó a la población proveedora si consideraba que dichas estrategias eran implementadas en su lugar de trabajo; se encontró que en promedio el $80 \%$ de esta considera que así es. La tabla 20 muestra los resultados por cada estrategia

Tabla 20. Distribución porcentual de las y los proveedores/as que consideran que las estrategias de vinculación del varón en el PPSSyPR de la Municipalidad de La Plata, son implementadas en su lugar de trabajo.

\begin{tabular}{|l|c|}
\hline \multicolumn{1}{|c|}{ Estrategia } & $\%$ \\
\hline $\begin{array}{l}\text { Entrega de folletería y material publicitario que promueve la } \\
\text { participación del varón. }\end{array}$ & $\mathbf{8 3 . 3}$ \\
\hline Consejería integral en planificación familiar & $\mathbf{7 8 . 9}$ \\
\hline $\begin{array}{l}\text { Capacitaciones en derechos sexuales y reproductivos a los } \\
\text { profesionales de los CAPS }\end{array}$ & $\mathbf{8 0 . 0}$ \\
\hline
\end{tabular}

Fuente: Creación de la investigadora

El reconocimiento de las estrategias de vinculación de los varones por parte de los y las provedoras/es en el PPSSyPR, es el primer y esencial paso para la implementación exitosa de estas. Dicho reconocimiento es importante, sobre todo, como un elemento que permitirá avanzar a un nivel más elevado de conciencia en el quehacer diario, como parte de un proceso integral en pro de la salud sexual y reproductiva de la población y no como meras acciones aisladas sin un eje especifico. 


\section{DISCUSIÓN Y CONCLUSIONES}

El inicio de este trabajo de investigación surgió bajo la iniciativa de realizar una interacción entre la salud pública y el contexto, no tan reciente, de la transversalización de la perspectiva de género en sectores ajenos a las ciencias humanas. Las ciencias y disciplinas de la salud han pretendido, con un modelo biologisista hegemónico, alejarse de las relaciones sociales de las personas y el enorme impacto de estas en su estado de salud individual. Grandes esfuerzos se han realizado frente a indicadores básicos como el de mortalidad materna y la mortalidad infantil; de manera más reciente por la epidemia de VIH y su letalidad se ha incorporado en las políticas de salud sexual y reproductiva elementos que permiten salir de las estructuras biológicas y dar una mirada a otras causas un tanto más estructurales. De esta manera el inagotable esfuerzo de muchos y muchas se ha visto reflejado en el rescátate de información que permita vislumbrar el acceso a métodos anticonceptivos, servicios de salud sexual y reproductiva eficientes y accesibles tomando como estandarte una estructura mucho más amplia: un enfoque de derechos sexuales y reproductivos.

En la revisión de líneas de tiempo a nivel internacional y nacional, siguiendo los contextos sociales, políticos, económicos, demográficos y de avance tecnológico, fueron identificados avances interesantes, que sin duda, han impactado en el descenso en indicadores de mortalidad y morbilidad en materia de salud sexual y reproductiva en las mujeres mayoritariamente, y sus repercusiones en la población infantil. Sin embargo, el camino que resta por recorrer es extenso, y cómo a través de la historia, profundamente determinado por contextos, que en algunos casos limitan y en otros potencian el ejercicio pleno de los derechos sexuales y reproductivos.

Los indicadores género-sensibles de desarrollo humano y de bienestar muestran sin duda la vulnerabilidad de las mujeres frente a la realidad mundial, y han obligado a que las cifras sean analizadas minuciosamente por los gobiernos, entonces, para mejorar de esta situación suele incluirse esta problemática como prioridad en las políticas públicas, invirtiendo miles de recursos y esfuerzos. Además, es común observar que temas trascendentales cómo el de los derechos sexuales y reproductivos ocupa en la actualidad lugares públicos; las calles pasan a ser escenarios de movilizaciones sociales exigiendo cambios en la normatividad que permita garantizar derechos en cuestiones de salud y salud sexual y reproductiva. A esto se suma el tampoco nuevo, pero si en auge, reconocimiento de las diferentes orientaciones sexuales e identidades de género, que exigen nuevas maneras de pensar la salud pública.

Sin embargo los avances son lentos, y mientras tanto el problema sigue cobrando vidas en muchas generaciones.

Dos aspectos que se tuvieron en cuenta para dar foco al tema de investigación, fueron: una aparente sobrecarga en materia de salud sexual y reproductiva atribuida casi de manera exclusiva a las mujeres, y un discurso al interior de los servicios de salud que hace posible que este estereotipo se perpetúe.

La revisión de la literatura frente a este tema permite identificar que no es nuevo el dato de la indica una proporción uno a uno entre varones y mujeres, por lo que no es posible lograr avances 
trascendentales incorporando solo a la mitad de la población. La duda es: hasta qué punto la autonomía de las mujeres en la toma de decisiones y la importancia de su empoderamiento en las sociedades, se convierte en una manera de exclusión de los varones?

Entonces no se trata de concluir que todo está mal hecho, se trata de dar una mirada diferente y alejarse de los vicios que sesgar a aquellos y aquellas que abogan por la salud de las mujeres y su derechos y que son considerados como enemigos de los varones. Empoderar a las mujeres en cualquier campo incluye apuntar a un cambio estructural en las relaciones de poder al interior de las sociedades, que sin duda están compuestas por varones y mujeres, aunque estos no necesariamente se incorporen como pareja.

El análisis general de las estrategias de vinculación del varón en los servicios de salud sexual y reproductiva ofertados por el PPSSyPR, permitió identificar que existe una gran intencionalidad en sus directrices y que están en construcción elementos que sin duda generaran el impacto deseado. Muchos son los mensajes que reconocen la importancia de la vinculación de los varones en materia de salud sexual y reproductiva, pero es comprensible que la ruptura de paradigmas necesita de procesos complejos y extensos.

El desarrollo del estudio permitió identificar las siguientes conclusiones:

La perspectiva de género en el programa ha evolucionado con mayor fuerza en el periodo comprendido entre 2010 a 2012, esta característica se puede visualizar en los mensajes emitidos en las publicaciones y sus canales de comunicación. Sin embargo, no es posible identificar gran variedad de indicadores sensibles al género que permitan determinar el acceso de los varones a los servicios de SSyR. La debilidad en el sistema de información y la generación de estos indicadores es un obstáculo para analizar detenidamente quienes son los o las que se acercan a los CAPS en busca de soluciones en SSyR.

El uso del lenguaje incluyente desde el sentido gramatical no garantiza un discurso de igualdad de acceso a los varones en las acciones de salud sexual y reproductiva A pesar de que se usan las normas gramaticales del lenguaje incluyente, las publicaciones y piezas publicitarias tienen un gran componente direccional hacia el empoderamiento de las mujeres y a reconocer la vulneración de sus derechos. Esta situación no permite visualizar la importancia de la actuación de los varones en las relaciones privadas que se dan al interior de las parejas. En los contenidos de las publicaciones se encuentra que con el fin de generar equidad a las mujeres, como una población con derechos vulnerados, se anula a los varones dificultando la modificación de las relaciones estructurales de poder.

En los contenidos de las publicaciones y en los mensajes es evidente una jerarquía en cuanto a la importancia del ejercicio de los derechos sexuales y reproductivos, en primer lugar se encuentran las mujeres, después la población LGTBI, seguida de adolescentes, niños y niñas y en último lugar y casi inexistentes, los varones heterosexuales. 
La escasa disponibilidad de las herramientas publicitarias diseñadas en el programa, limitan la promoción de la vinculación del varón en la salud sexual y reproductiva. En el contenido de las piezas se identifican elementos que son sensibles a las situaciones de vulnerabilidad de las mujeres, pero no son transformadoras en cuanto a la distribución de poder entre varones y mujeres, frente a la toma de decisiones relacionadas en materia de salud sexual y reproductiva Por ejemplo, en una de las publicaciones se identificó una pieza publicitaria que involucra a los varones en roles diferentes a los estereotipados, pero este material no se encontró expuesto en ninguno de los CAPS ni en la página oficial del PPSSyPR.

El diseño de las piezas gráficas debe subordinarse al mensaje, pero a su vez convivir con él. En las piezas analizadas, sin embargo se observan recurrentes desconexiones entre la construcción del mensaje y el diseño; entre la forma de dirigirse al receptor y el tema en cuestión. Es posible destacar como se apela notablemente a la conciencia femenina más que a la masculina, independientemente de su orientación sexual o edad. Suele ser el sujeto al que se informa, alerta y concientiza de manera más regular a las mujeres.

Las acciones ofertadas por el PPSSyPR son mayoritariamente dirigidas a las mujeres. La población de varones tiene acceso a tan solo la mitad de estas y en la mayoría de las acciones en que participa lo hace de manera paralela con las mujeres; solo en la vasectomía es posible identificar su exclusividad en la participación. Las acciones en las que el varón no tiene vinculación, lo excluyen completamente, bien sea desde la toma de decisiones o en el acceso como tal, es el caso de la inserción del DIU, la ligadura, el ANP y entrega de hormonales (excepto AHE). esto ignora las relaciones sociales, emocionales y de poder en las que interactúan las personas.

La disponibilidad de los MAC en el programa es de gran impacto en la población, ya que son escasas las personas usuarias del PPSSyPR que refieren no tener acceso a estos, por lo tanto, es importante destacar que la disponibilidad de los MAC en los CAPS, tanto para hombre como para mujeres, no representan un factor determinante en la elección de estos, ya que todos los MAC se encuentran generalmente disponibles. No fue posible identificar la facilidad en el acceso a la vasectomía debido a que en el estudio no participo ningún varón que acudiera a solicitarla

La vinculación de los varones en el PPSSyPR como una estratega implementada desde la consejería en planificación familiar, fue percibida en dos terceras partes de la población usuaria encuestada, mayoritariamente por medio de material escrito. Respecto a la forma de vinculación de los varones, es común que los y las proveedoras promuevan su participación en la salud sexual y reproductiva como una responsabilidad más que como un derecho. Esto puede dar un carácter obligatorio que no siempre es bien recibido en las poblaciones, ya que, por años los sistemas de salud han manejado el mismo discurso en la prevención de múltiples enfermedades sin obtener los resultados esperados. La vinculación del varón es un terreno casi inexplorado y es la oportunidad de incursionar en él con un mensaje de ejercicio de derechos que logre elevar niveles de conciencia 
Los y las proveedores no están completamente sensibilizados con respecto a la importancia de la vinculación del varón en la SSyR, esto se refleja en que la toma de decisiones en este tema, es promovida como una carga que debe ser compartida, y en que existe una pérdida de la transmisión del mensaje, pues la población no lo percibe. Es significativo que este proceso de vinculación sea estructurado desde los CAPS como un derecho de suma importancia, como un objetivo indispensable en el reto de lograr la participación de los varones y así contribuir en el logro del bienestar de toda la población.

Del presente estudio se desprende, que, claramente el PPSSyPR, implementado en la municipalidad de La Plata, dirige sus acciones en mayor proporción hacia las mujeres que hacia los hombres y por lo tanto omite al $50 \%$ de los involucrados en la sexualidad y la reproducción.

La inclusión de los varones en el Programa d Salud Sexual y Procreación Responsable podrá entonces mejorar los resultados obtenidos con el mismo. 


\section{LA INCLUSIÓN DE LOS VARONES EN EL PPSSYPR. Premisas propuestas}

Después de haber analizado el PPSSyPR implementado en la Municipalidad de La Plata, se propone fortalecer unos elementos mínimos a partir de las variables analizadas en este estudio.

- Definición, implementación y seguimiento de indicadores sensibles al género al interior del PPSSyPR. Uno de los elementos más importantes para la toma de decisiones en cualquier programa en especial de salud, es el conocimiento pleno del estado del arte de la población objetivo; así pues, se sugiere como línea de partida la creación de indicadores que permitan tener un conocimiento continuo del acceso al programa y del uso de los recursos de que se disponen. Su implementación y seguimiento permitirán fortalecer las estrategas exitosas o modificar el curso de las ya existentes y así generar el impacto deseado según los objetivos planeados.

- Fortalecimiento de las campañas de comunicación. E análisis de las piezas publicitarias y de las publicaciones permite sugerir que es necesario reforzar las estrategias de comunicación, a través de la utilización de códigos, que como se plantea en la estrategia de análisis, reconozcan y tomen en cuenta las diferencias de género en los roles y en el acceso a los recursos y busquen cambiar las causas que subyacen la desigual dad, promoviendo la equidad de género mediante la renegociación del status quo y las relaciones de poder. De la misma manera se sugiere que dichas piezas publicitarias estén socializadas en todos los CAPS y se encuentren a disposición de los y las proveedoras/as de acciones del programa y de la población usuaria

- Servicios amigables incluyentes. Si bien es cierto que la estrategia ha sido implementada en diversas partes del mundo, esta ha sido dirigida especialmente a la población adolescente y LGTBI, se sugiere que esta sea también implementada como una herramienta dirigida a los varones, donde se solucionen sus dudas y necesidades,no como una condición exótica de los servicios sino como una oferta que reconozca su importancia en el ejercicio de los derechos sexuales y reproductivos; y como un elemento trascendental y necesario en la generación del impacto deseado por el programa Esta debe incluir proveedores sensibilizados y conocedores de las necesidades de salud sexual y reproductiva de los varones, de la misma manera debe tener la capacidad de ofertar de manera oportuna los métodos anticonceptivos para estos y sus parejas. 
- Posicionamiento de la perspectiva de género en la consejería en salud sexual y reproductiva. Es necesario capacitar y sensibilizar a los y las proveedoras/as de la consejería en salud sexual y reproductiva con el fin de que sean replicadores de nuevos patrones culturales, en donde la vinculación de los varones sea comprendida con el ejercicio de un derecho.

\section{LIMITANTES DEL ESTUDIO}

Uno de los limitantes del estudio es la imposibilidad de extrapolación a todo el territorio de la Argentina de los resultados obtenidos, esto se relaciona con causas como la administración federal que genera que las provincias e inclusive los diferentes municipios, implementen el programa con algunas variaciones según su normatividad; la diversidad de culturas que se encuentran en el país, también es una delas causas, ya que generaría la necesidad de análisis de diversos enfoques en cuanto a la vinculación del varón en las acciones de salud sexual y reproductiva.

Así mismo se identifica que la estructura del sistema de salud, partiendo de los subsectores público, obras sociales, prepagas y privado, también limitarían la extrapolación de los resultados a los diferentes ámbitos, ya que aunque en la provincia de Buenos Aires los lineamientos del programa son los mismos, los subsectores de obras sociales, prepagas y privado, cuentan con cierta autonomía en la implementación de los programas y por lo tanto podrían existir otras situaciones que varían desde la publicación de materiales de comunicación diferentes hasta estrategias de sensibilización adicionales.

Otro de los factores limitantes del estudio se relaciona con el impacto de las estrategias de vinculación del varón a las acciones de salud sexual y reproductiva, ya que este no pretende determinar sus resultados en la población.

\section{REFLEXIÓN Y RECOMENDACIONES}

Comprender contextos históricos, políticos económicos, sociales y culturales diferentes a los vividos en mi país de origen, sumado a los aportes académicos y pedagógicos de la Maestría en Salud Pública de la UNLP- Centro INUS, sin duda permitieron realizar un abordaje integral frente a la problemática de la salud sexual y reproductiva, e hicieron posible su articulación con la perspectiva de género y la salud pública. El desarrollo de este estudio me permitió confirmar uno de los emblemas de las asignaturas desarrolladas en los dos años de la maestría, "la salud es una construcción social", finalmente los indicadores básicos de 
mortalidad materna y mortalidad infantil permiten visualizar solo la punta del iceberg de esta problemática. Concluyendo que es indispensable observar de una manera más minuciosa a las poblaciones en todo su contexto.

Al analizar los diferentes matices que pueden darse al interior de un programa de salud pública desde la construcción y difusión de sus líneas de acción, hasta su implementación; identifiqué que varones y mujeres perciben los contextos de diferentes maneras, se apropian de los recursos en salud a partir de decisiones personales y que por lo tanto requieren diferentes abordajes dados los roles culturales que les han sido asignados. Frente a esto, se sugiere para estudios posteriores utilizar estas variables en el análisis de otros programas, de tal manera que sea posible determinar el grado de perspectiva de género que maneja cada uno y así establecer estrategias que finalmente generen el impacto deseado.

La determinación de los roles asignados por las características biológicas, tan solo una mínima manera de abordar las respuestas de los varones y las mujeres frente a la salud. Una clasificación mucho más amplia se abre al incluir la categoría de géneros, esta nueva y cada vez más popular perspectiva, quizás permita descubrir nuevas maneras de generar impacto en las poblaciones objetivo de los programas, por esta razón se sugiere también un posterior análisis frente a la vinculación de la población LGTBI.

De la misma manera se sugere utilizar este estudio como línea de base para la medición de los resultados obtenidos tras la posible implementación de la propuesta generada

Un estudio más minucioso quizá pueda revelar el porqué de éste carácter tan particular del mensaje general en éste conjunto de piezas gráicas, puede ser resultado de una investigación previa o tan solo la consecuencia de un juicio de valor sobre la figura femenina en la sociedad, que viaja soslayadamente y de forma codificada en un metamensaje

Dado que la mayor parte de la población proveedora de los servicios de salud sexual y reproductiva no considera que el programa haya desarrollado acciones de capacitación y sensibilización en perspectiva de género e importancia de la vinculación del varón en la SSyR, es necesario fortalecer este proceso si se quiere promover dicha participación en la toma de decisiones.

Es importante dar continuidad al fortalecimiento del proceso de toma de decisiones en relación a la SSyR tanto en varones como en mujeres y de esta manera continuar avanzando en el logro de igualdad de oportunidades, no solo desde el reconocimiento del derecho sino en la garantía de su ejercicio por parte de los varones, será importante entonces continuar con la intencionalidad de vincularlos al PPSSyPR 


\section{Bibliografía}

1. ORGANIZACIÓN MUNDIAL DE LA SALUD. Las Mujeres y la Salud. Los Datos de Hoyla Agenda del Mañana. Suiza : Organización Mundial de la Salud, 2009.

2. MINISTERIO DE SALUD DE LA NACIÓN - ARGENTINA. Politicas de Salud Sexual y Reproductiva. Avances y Desafíos. Programa Nacional de salud Sexual y Procreación Responsable Balance 2003 - 2011. Buenos Aires : Ministerios de Salud de la Nación, 2011.

\section{PROGRAMA DE NACIONES UNIDAS PARA EL DESARROLLO - PNUD}

ARGENTINA. República de Argentina. Desarrollo de los Objetivos del Milenio, Rendición de cuentas 2010. Argentina : Programa de Naciones Unidas para el Desarrollo- Argentina, 2010.

\section{PROGRAMA PARA EL DESARROLLO DE LAS NACIONES UNIDAS. PNUD-} ARGENTINA. Aportes para el Desarrollo Humano en Argentina / 2011. Género en Cifras: Mujeres y Varones en la Sociedad Argentina. Argentina : Programa para el Desarrollo de las Naciones Unidas, 2011.

5. Ministerio de Salud de la Nación. Dirección de Estadisticas e Infrmación en Salud - Estadisticas Vitales 2012. [En línea] Ministerio de Salud de la Nación, Diciembre de 2013. [Citado el: 24 de Enero de 2014.] http://www.deis.gov.ar/Publicaciones/Archivos/Serie5N ro56.pdf.

6. Conferencia Internacional de Poblacion y Desarrollo. El Cairo. NACIONES UNIDAS. El Cairo : Naciones Unidas, 1994.

7. MINISTERIO DE SALUD. PROVINCIA DE BUENOS AIRES. Ministerio de Salud de la Provincia de Buenos Aires. Programa de Salud Sexual y Procrecion Responsable. [En línea] [Citado el: 10 de junio de 2012.] http://www.ms.gba.gov.ar/programas/saludreproductivaypr/index.html.

8. Conferencia Internaional de Derechos HUmanos en Teherán. NACIONES UNIDAS. Teherán : Naciones Unidas, 1968.

9. Guarta conferencia Mundial sobre la Mujer. Bejing. NACIONES UNIDAS. Beijing : Naciones Unidas, 1995.

10. GRUPO DE TRABAJO INTERINSTITUCIONAL DE GÉNERO. Manual de Integradón de una Perspectiva de Género en Programas de Salud Reproductiva y $\mathrm{MH}$ : Del compromiso a la acción. Washington : Grupo de Trabajo Interintitucional de Género, 2005.

11. SENADO Y CAMARA DE DIPUTADOS DE LA NACIÓN ARGENTINA. Ministerio de salud. Presidencia de la Nación. [En línea] 2003. [Citado el: 16 de 08 de 2011.]

http://www.msal.gov.ar/saludsexual/downloads/ley_25673_SSR.pdf. 
12. Senado y Camara de Dipuados de la Provincia de Buenos Aires. Buenos Aires Provincia. Ministerio de Jefatura de Gabinete de Ministros. [En línea] 2012. [Citado el: 10 de 06 de 2012.] http://www.gob.gba.gov.ar/legislacion/legislacion/l-13066.html.

13. ORGANIZACION INTERNCIONAL DEL TRABAJO. Las Mujeres yel Derecho internacional. Conferecnias Internacionales, Organzacion Internacional del Trabajo. Mexico D.F. : Organización Internacional del Trabajo, 2004.

14. Conferencia Sobre la Eliminacion de Todas las Formas de Discriminacion contra la Mujer. NACIONES UNIDAS. S.I. : Naciones Unidas, 1979.

15. NACIONES UNIDAS. Mujer 2000.Igualdad entre Generos, Desarrollo, y Paz para el siglo XXI. [En línea] Naciones Unidas, 5 de junio de 2000. [Citado el: 8 de junio de 2012.] http://www.un.org/spanish/conferences/Beijing/Mujer2011.htm

16. —. Cumbre Mundial sobre Desarrollo Social. Copenhague, 1995. [En línea] 2000. [Citado el: 30 de 07 de 2012.] http://www.un.org/spanish/esa/socdev/.

17. INSTITUTO INTERAMERICANO DE DERECHOS HUMANOS. Promoción y Defensa de los Derechos Reproductivos: Nuevo Reto para las Institudiones Nacionales de Deredhos Humanos. Costa Rica : Instituto Interamenricano de Derechos Humanos, 2003.

18. Asociación Mundial de Sexología W AS. Declaración de Valencia de los Drechos Sexuales. [En línea] junio de 1997. [Citado el: 12 de 05 de 2012.]

http://es.scribd.com/doc/50218404/51/DECLARACION-DE-VALENCIA-DE-LOS-DERECHOSSEXUALES.

19. NACIONES UNIDAS. DECARACÓN DEL MILENIO. Nueva York : Naciones Unidas, 2000.

20. - . Inidcadores para le Seguimiento de los Objetivos de Milenio: Definiciones, Justificación, Conceptos y Fuentes. Nueva York : Naciones Unidas, 2006. ISBN 9213612206.

21. - . Mision Permanente de la Republica Argentina ante Naciones Unidas. [En línea] 2012. [Citado el: 15 de 06 de 2012.] http://enaun.mrecic.gov.ar/content/comisiones-de-la-asamblea-general.

22. Politica de la OMS en materia de género. Integracion de las perspectivas de género en la labor d ela OMS. Organización Mundial de la Salud. Washington : Organizacion Mundial de la Salud, 2002.

23. Organización Panamericana de la Salud. Politia de lgualdad de Género. Washington : Organización Panamericana de la Salud, 2005.

24. Provenzano, Sergio. Salud sexual y reproductiva en la Argentina de hoy. [En línea] 1998. [Citado el: 07 de 08 de 2012.] http://www.ispmorg.ar/pdfs/salud_sexual_argentina.pdf.

25. OBSERVATORIO DE SALUD SEXUAL Y REPRODUCTIVA. ARGENTINA. Historia de la salud sexual y reproductiva en Argentina. [En línea] 2010. [Citado el: 07 de 08 de 2012.] http://www.ossyr.org.ar/linea_tiempo.html. 
26. Organización Panamericana de la Salud. Vinculación de programas y senvicios de salud sexual y reporoductiva, género y prevención de UH elTS. W ashington : Organización Panamericana de la Salud, 2010. ISBN 978-92-75-33077-7.

27. Agencia Española de Cooperacion Internacional (AECI). Guía para programas y proyectos de salud sexual y reproductiva en África. Madrid : Agencia Española de Cooperacion Internacional (AECI), 2005.

28. Organización Panamericana de la Salud. Organización Panamericana de la Salud. [En línea] 2012. [Citado el: 15 de 09 de 2012.] http://www1.paho.org/spanish/ad/ge/MenSRHsp.pdf.

29. Programa Nacional de Salud Sexual y Procreación Responsable. Métodos anticonceptivos. Guia para un acceso sin barreras. Argentina : Ministerio de Salud, 2010.

30. "Lenguajes induyentes" o lenguajes "politicamente correctos"? Cómo construir equidad en el discurso. Castellanos, Gabriela. 2, Colombia : Univalle, Numero 2 de Volumen 4, Vol. 4.

31. Ayala, Marta, Guerrero, Susana y Medina, Antonia. Manual de Lenguaje Administrativo No Sevista. España : Asociación de Estudios Historicos Sobre la Mujer. Universidad de Malaga, 2002. ISBN 84-600-9829-X.

32. Instituto Nacional de Desarrollo Social INDESOL. Manual. Uso de Lenguaje Induyente en Texos y Comunicados Oficiales . Mexico Distrito Federal : Instituto Nacionald e Desarrollo Social INDESOL, 2011.

33. Organización Panamericana de la Salud. La Perspectiva de Género en las Cuñas Televisivas Sobre VH. Washington : Organización Panamericana de la Salud, 2010. ISBN 978-92-75-33187-3.

34. Departamento Administrativo Nacional de Estadistica DANE. Manual de indicadores. Bogotá, colombia : Departamento Administrativo Nacional de Estadistica, 2008.

35. INTITUTO NACIONAL DE DESARROLLO SOCIAL DE MEXICO. Manual para uso de Lenguaje Induyenteen Textos y Comunicados Oficiales. Mexico : Instituto Nacional de Desarrollo Social (INDESOL), 2011.

36. Ministerio de Salud de la Nación. Programa Nacional de Salud Sexual y Procreación Responsable. Identidades diversas los mismos derechos. Buenos Aires. Argentina : Ministerio de Salud de la Nación, 2011.

37. Ministerio de salud de la Nación. Programa Nacional de Salud Sexual y Procreación Responsable. Consejerías en salud sexual y salud reproductiva. Propuesta de diseño, organización e implementación. Argentina : Ministerio de salud de la Nación, 2011.

38. Ministerio de Salud de la Nación. Programa Nacional de Salud Sexual y Procreación Responsable. Serie participación comunitaria, modulo 1. Derechos sexuales y reproductivos. Argentina : Ministerio de Salud de la Nación, 2012. 
39. ¿Cual es tu pregunta? Lamá a la línea de Salud Sexual 080002223444. Ministerio de Salud de la Nación. Programa Nacional de Salud Sexual y Procreación Responsable. 1, Argentina : Ministerio de de salud de la Nación, 2011, Vol. 1.

40. Minitserio de Salud de la Nación. Programa . Guía técnica para la atendón integral de abortos no punibles. Buenos Aires : Ministerio de Salud de la Nación, 2010.

41. Ministerio de Salud de la Nación. Programa Nacional de Salud Sexual y Procreación Responsable. Serie Participadón comunitaria, modulo 2 . Sexualidad y acceso a métodos anticonceptivos. Argentina : Ministerio de Salud de la Nación, 2011.

42. Ministerio de Salud de la Nación. Programa Nacional de salud Sexual y Procreación Responsable. Protocolo de atencón integral de personas víctimas de vidaciones sexuales . Argentina : Ministerio de la Salud de la Nación, 2011.

43. Ministerio de salud de la Nación. programa nacional de Salud sexual y procereación Responsable. Serie Partiajación comunitaria, modulo 3. Conocemos, divertimos y auidamos. Argentina : Ministerio de la Nación, 2011.

44. Ministerio de Salud de la Nación. Programa nacional de Salud Sexual y Procreación Responsable. De la investigación a la acción. Aportes para la reflexión de los equipos que hacen Consejeria en Salud Sexual y Reproductiva. Argentina : Ministerio de salud de la Nación, 2012.

45. Ministerio de Salud de la Nación y Ministerio de Educacíon de la Nación. Cuanto más sepan, mejor. Educación sexual integral. Argentina : Ministerio de Educacion de la Nación, 2011.

46. Programa Nacional de Salud Sexual y Procreación Responsable. Serie derechos sexuales y reproductivos. "Derechos sexuales y reproductivos tus derechos". Ĺnea Institucional. Argentina : Ministerio de Salud de la Nación, 2010.

47. Ministerio de Salud de la Nación. Programa Nacional de Salud Sexual y Procreacion Responsable. "Anticoncepción quirúrgica Un derecho de todas y todos. Una garantía en los servicios de salud. Argentina : Ministerio de Salud de la Nación, 2010.

48. Programa Nacional de Salud Sexual y Procreación Responsable. Línea promoción de los derechos y accesibilidad. Métodos anticonceptivos. Argentina : Ministerio de la Salud de la Nación, 2010.

49. Programa nacional de Salud Sexual y Procreación Responsable. Serie identidades diversas. "Identidades diversas los mismos derechos". Argentina : Ministerio de Salud de la Nación, 2010.

50. Ministerio de Salud de la Nación. Programa Nacional de Salud Sexual y Procreación Responsable. Línea promoción de derechos y accesibilidad. Anticoncepción hormonal de emergencia Argentina : Ministerio de Salud de la Nación, 2010. 
51. Programa Nacional de Salud Sexual y Procreación Responsable. Serie sexualidad libre de violencias. "Tenemos derecho a una sexualidad libre de violencias" . Argentina : Ministerio de Salud de la nacion, 2010.

52. Programa Nacional de Salud Sexual y Procreación Respnsable. Serie Actualizacion profesional "Anticoncepción quirúrgica". Argentina : Ministerio de Salud de la Nación, 2010.

53. Margariños de Morentin, Juan. El signo, las fuentes teóricas de la semiología Saussure, Peirce y Moris. Buenos Aires : Hachette, 1988.

54. Saussure, F. Curso de linguistica general. Madrid : Alianza, 1991.

55. Foucault, M. Las palabras y las cosas. Mexico : Siglo veintiuno, 1999.

56. Barthes, R. La aventura de la semiología. Buenos Aires : Piados, 1993.

57. Casetti, F. Cómo analizar un film Barcelona : Piados, 1993.

58. Prieto, D. Elementos para el análisis de mensajes. México : Instituto Latinoamericano de Comunicación Educativa, 1991.

59. Ravera, M. Cuestiones de estetica, "Plástica e ideología -Ua primavera de Boticcelli". Madrid : Correo de Arte, 1983.

60. Munari, Bruno. Diseño y comunicación visual. Barcelona : Gustavo Gili, 1985. ISBN

9788425212031.

61. Calvera, Ana. La idea en el diseño gráfico. Madrid : Experimenta, 1996.

62. Ministerio de Salud de la Nación. Programa Nacional de Salud Sexual y Procreación Responsable. Métodos anticonceptivos. Guía para un acceso sin brreras. Argentina : Ministerio de Salud de la Nacion, 2010. 


\section{ANEXOS}

Anexo 1 Ficha técnica de Indicadores de la variable lenguaje incluyente

1.1. Porcentaje de publicaciones que usan el lenguaje incluyente en su contenido. Ficha técnica.

\begin{tabular}{|c|c|}
\hline Nombre del indicador & $\begin{array}{l}\text { Porcentaje de publicaciones que usan el lenguaje incluyente en su } \\
\text { contenido }\end{array}$ \\
\hline Sigla & PPCLI \\
\hline Objetivo & $\begin{array}{l}\text { Medir de la inclusión, tanto de las mujeres como de los varones, en } \\
\text { el uso del lenguaje. }\end{array}$ \\
\hline Definición y conceptos & $\begin{array}{l}\text { Criterios excluyentes } \\
\text { Uso del masculino genérico } \\
\text { Uso del término hombre (desde el sentido genérico) } \\
\text { Criterios incluyentes } \\
\text { Sustantivos genéricos y colectivos (personaje, colectivo, } \\
\text { población, ciudadanía) } \\
\text { Perífrasis (personal sanitario, personal docente, la } \\
\text { comunidad) } \\
\text { Uso de desdoblamientos (las y los, niños y niñas) } \\
\text { Uso de barras } \\
\text { Uso de aposiciones explicativas (tanto mujeres como } \\
\text { varones) } \\
\text { Determinantes sin marca de género (cada estudiante) } \\
\text { Omisión del determinante (eliminar el artículo: } \\
\text { profesionales) }\end{array}$ \\
\hline Método de medición & $\begin{array}{l}\text { División del número de publicaciones en las que se usa el lenguaje } \\
\text { incluyente entre el total de las publicaciones analizadas por } 100\end{array}$ \\
\hline Unidad de medida & Porcentaje \\
\hline Formula & $P P C L I=\frac{\# P A C L I}{\# P A} \times 100$ \\
\hline Variables & $\begin{array}{l}\text { \#PAC: Numero de publicaciones analizadas en las que se identificó } \\
\text { el lenguaje incluyente } \\
\text { \#PA: Numero de publicaciones analizadas }\end{array}$ \\
\hline Limitaciones del indicador & $\begin{array}{l}\text { El indicador no mide la direccionalidad de las publicaciones en } \\
\text { cuanto a mujeres o varones }\end{array}$ \\
\hline Fuente de datos & $\begin{array}{l}\text { Programa de Salud Sexual y Procreación Responsable de la } \\
\text { provincia de Buenos Aires. }\end{array}$ \\
\hline Desagregación geográfica & Provincia de Buenos Aires - La Platc \\
\hline
\end{tabular}




\begin{tabular}{|l|l|}
\hline Periodicidad de los datos & Unica \\
\hline $\begin{array}{l}\text { Fecha de información } \\
\text { disponible }\end{array}$ & 2010 a 2012 \\
\hline Responsable & Licenciado en Lenguas Modernas e investigadora \\
\hline Observaciones & \\
\hline
\end{tabular}




\subsection{Ficha técnica. Porcentaje de piezas publicitarias con carácter desigual}

\begin{tabular}{|c|c|}
\hline Nombre del indicador & Porcentaje de piezas publicitarias con carácter desigual \\
\hline Sigla & PPPCD \\
\hline Objetivo & $\begin{array}{l}\text { Determinar el carácter de cada pieza publicitaria } \\
\text { teniendo en cuenta la metodología de perspectiva de } \\
\text { género de la OPS. Se consideró como pieza } \\
\text { publicitaria con carácter desigual a aquella que } \\
\text { favorecen a un género sobre el otro, actividades o } \\
\text { políticas en las que las desigualdades están claras y se } \\
\text { transmiten como "hechos de la naturaleza", y en las } \\
\text { que se reconocen los derechos y oportunidades de los } \\
\text { hombres sobre los de las mujeres. }\end{array}$ \\
\hline Definición y conceptos & $\begin{array}{l}\text { Roles de género y roles sexuales } \\
\text { predominantes: Tradicional - No tradicional } \\
\text { Mensaje predominante: Tradicional - No } \\
\text { tradicional } \\
\text { Categoría: Desigual, Sensible y Transformadora }\end{array}$ \\
\hline Método de medición & $\begin{array}{l}\text { División entre el número de campañas publicitarias con } \\
\text { categoría desigual entre el total de las campañas publicitarias } \\
\text { analizadas por } 100\end{array}$ \\
\hline Unidad de medida & Porcentaje \\
\hline Formula & $P P P C D=\frac{\# P P C D}{\# P P A}$ \\
\hline Variables & $\begin{array}{l}\text { \#PPCD: Número de piezas publicitarias analizadas en las } \\
\text { que se identificó categoría desigual } \\
\text { \#PPA: Número de piezas publicitarias analizadas }\end{array}$ \\
\hline Limitaciones del indicador & $\begin{array}{l}\text { E indicador no mide la direccionalidad de las campañas } \\
\text { publicitarias en cuanto a mujeres o varones }\end{array}$ \\
\hline Fuente de datos & $\begin{array}{l}\text { Programa de Salud Sexual y Procreación Responsable de la } \\
\text { provincia de Buenos Aires, La Plata. }\end{array}$ \\
\hline Desagregación geográfica & Provincia de Buenos Aires, La Platẽ \\
\hline Periodicidad de los datos & Unicẽ \\
\hline Fecha de información disponible & 2012-2103 \\
\hline Responsable & $\begin{array}{l}\text { Semiólogo facultad de diseño UNLP, Diseñador Gráico } \\
\text { UNC e investigadora }\end{array}$ \\
\hline Observaciones & $\begin{array}{l}\text { Se identificaron } 8 \text { piezas publicitarias en las que se variaba el } \\
\text { formato manteniendo el contenido. }\end{array}$ \\
\hline
\end{tabular}




\subsection{Ficha técnica. Porcentaje de piezas publicitarias con carácter sensible.}

\begin{tabular}{|c|c|}
\hline Nombre del indicador & Porcentaje de piezas publicitarias con carácter sensibles \\
\hline Sigla & PPPCS \\
\hline Objetivo & $\begin{array}{l}\text { Determinar el carácter de cada pieza publicitaria } \\
\text { teniendo en cuenta la metodología de perspectiva de } \\
\text { género de la OPS. Se consideró como pieza } \\
\text { publicitaria con carácter sensible aquella que } \\
\text { Reconoce y toma en cuenta las diferencias de género } \\
\text { en los roles y en el acceso a los recursos. Sin embargo } \\
\text { no trata de cambiar las causas profundas de la } \\
\text { desigualdad de género, buscan de forma específica } \\
\text { empoderar a las mujeres como el polo más débil de la } \\
\text { relación. }\end{array}$ \\
\hline Definición y conceptos & $\begin{array}{l}\text { Roles de género y roles sexuales } \\
\text { predominantes: Tradicional - No tradicional } \\
\text { Mensaje predominante: Tradicional - No } \\
\text { tradicional } \\
\text { Categoría: Desigual, Sensible y Transformadora }\end{array}$ \\
\hline Método de medición & $\begin{array}{l}\text { División entre el número de campañas publicitarias con } \\
\text { categoría sensible entre el total de las campañas publicitarias } \\
\text { analizadas por } 100\end{array}$ \\
\hline Unidad de medida & Porcentaje \\
\hline Formula & $P P P C S=\frac{\# P P C S}{\# P P A}$ \\
\hline Variables & $\begin{array}{l}\text { \#PPCS: Número de piezas publicitarias analizadas en las que } \\
\text { se identificó categoría sensible. } \\
\text { \#PPA: Número de piezas publicitarias analizadas }\end{array}$ \\
\hline Limitaciones del indicador & $\begin{array}{l}\text { E indicador no mide la direccionalidad de las campañas } \\
\text { publicitarias en cuanto a mujeres o varones }\end{array}$ \\
\hline Fuente de datos & $\begin{array}{l}\text { Programa de Salud Sexual y Procreación Responsable de la } \\
\text { provincia de Buenos Aires, La Plata. }\end{array}$ \\
\hline Desagregación geográfica & Provincia de Buenos Aires, La Platẽ \\
\hline Periodicidad de los datos & Unicẽ \\
\hline Fecha de información disponible & 2012-2103 \\
\hline Responsable & $\begin{array}{l}\text { Semiólogo facultad de diseño UNLP, Diseñador Gráico } \\
\text { UNC e investigadora }\end{array}$ \\
\hline Observaciones & $\begin{array}{l}\text { Se identificaron } 8 \text { piezas publicitarias en las que se variaba el } \\
\text { formato manteniendo el contenido. }\end{array}$ \\
\hline
\end{tabular}




\subsection{Ficha técnica. Porcentaje de piezas publicitarias con carácter transformador.}

\begin{tabular}{|c|c|}
\hline Nombre del indicador & $\begin{array}{l}\text { Porcentaje de piezas publicitarias con carácter } \\
\text { transformador }\end{array}$ \\
\hline Sigla & PPPCT \\
\hline Objetivo & $\begin{array}{l}\text { Determinar el carácter de cada pieza publicitaria } \\
\text { teniendo en cuenta la metodología de perspectiva de } \\
\text { género de la OPS. Se consideró como pieza } \\
\text { publicitaria con carácter transformador a aquellas que } \\
\text { reconocen y toman en cuenta las diferencias de género } \\
\text { en los roles y en el acceso a los recursos. Busca } \\
\text { cambiar las causas que originan la desigualdad y tratan } \\
\text { de generar equidad de género mediante la } \\
\text { renegociación del status quo y las relaciones de poder. }\end{array}$ \\
\hline Definición y conceptos & $\begin{array}{l}\text { Roles de género y roles sexuales } \\
\text { predominantes: Tradicional - No tradicional } \\
\text { Mensaje predominante: Tradicional - No } \\
\text { tradicional } \\
\text { Categoría: Desigual, Sensible y Transformadora }\end{array}$ \\
\hline Método de medición & $\begin{array}{l}\text { División entre el número de campañas publicitarias con } \\
\text { categoría transformadora entre el total de las campañas } \\
\text { publicitarias analizadas por } 100\end{array}$ \\
\hline Unidad de medida & Porcentaje \\
\hline Formula & $P P P C T=\frac{\# P P C T}{\# P P A}$ \\
\hline Variables & $\begin{array}{l}\text { \#PPCT: Número de piezas publicitarias analizadas en las que } \\
\text { se identificó categoría transformadora. } \\
\text { \#PPA: Número de piezas publicitarias analizadas }\end{array}$ \\
\hline Limitaciones del indicador & $\begin{array}{l}\text { El indicador no mide la direccionalidad de las campañas } \\
\text { publicitarias en cuanto a mujeres o varones }\end{array}$ \\
\hline Fuente de datos & $\begin{array}{l}\text { Programa de Salud Sexual y Procreación Responsable de la } \\
\text { provincia de Buenos Aires, La Plata. }\end{array}$ \\
\hline Desagregación geográfica & Provincia de Buenos Aires, La Platẽ \\
\hline Periodicidad de los datos & Unicẽ \\
\hline Fecha de información disponible & 2012-2103 \\
\hline Responsable & $\begin{array}{l}\text { Semiólogo facultad de diseño UNLP, Diseñador Gráfico } \\
\text { UNC e investigadora }\end{array}$ \\
\hline Observaciones & $\begin{array}{l}\text { Se identificaron } 8 \text { piezas publicitarias en las que se variaba el } \\
\text { formato manteniendo el contenido. }\end{array}$ \\
\hline
\end{tabular}




\subsection{Ficha técnica. Porcentaje de campañas publicitarias dirigidas exclusivamente a varones}

\begin{tabular}{|c|c|}
\hline Nombre del indicador & $\begin{array}{l}\text { Porcentaje de piezas publicitarias dirigidas exclusivamente a } \\
\text { varones }\end{array}$ \\
\hline Sigla & PPPDV \\
\hline Objetivo & $\begin{array}{l}\text { Medir la dirección de las campañas publicitarias en el uso de } \\
\text { palabras e imágenes. }\end{array}$ \\
\hline Definición y conceptos & $\begin{array}{l}\text { Roles de género y roles sexuales } \\
\text { predominantes: Tradicional - No tradicional } \\
\text { Mensaje predominante: Tradicional - No } \\
\text { tradicional } \\
\text { Categoría: Desigual, Sensible y Transformadora }\end{array}$ \\
\hline Método de medición & $\begin{array}{l}\text { División entre el número de campañas publicitarias en las } \\
\text { que se usan imágenes con lenguaje dirigido a los varones } \\
\text { entre el total de las publicaciones analizadas por } 100 \text {. }\end{array}$ \\
\hline Unidad de medida & Porcentaje \\
\hline Formula & $P C P D V=\frac{\# P P D V}{\# P P A}$ \\
\hline Variables & $\begin{array}{l}\text { \#PPDV: Número de piezas publicitarias analizadas en las que } \\
\text { se identificó una direccionalidad exclusivamente masculina. } \\
\text { \#PPA: Número de piezas publicitarias analizadas }\end{array}$ \\
\hline Limitaciones del indicador & $\begin{array}{l}\text { El indicador no tendrá en cuenta las campañas publicitarias } \\
\text { dirigidas a hombres y mujeres en conjunto. }\end{array}$ \\
\hline Fuente de datos & $\begin{array}{l}\text { Programa de Salud Sexual y Procreación Responsable de la } \\
\text { provincia de Buenos Aires, La Plata. }\end{array}$ \\
\hline Desagregación geográfica & Provincia de Buenos Aires, La Platč \\
\hline Periodicidad de los datos & Unicẽ \\
\hline Fecha de información disponible & $2012-2103$ \\
\hline Responsable & $\begin{array}{l}\text { Semiólogo facultad de diseño UNLP, Diseñador Gráfico } \\
\text { UNC e investigadora }\end{array}$ \\
\hline Observaciones & $\begin{array}{l}\text { Se identificaron } 8 \text { piezas publicitarias en las que se variaba el } \\
\text { formato manteniendo el contenido. }\end{array}$ \\
\hline
\end{tabular}


Anexo 2. Fichas técnicas de indicadores de la Variable Direccionalidad de Acciones

2.1. Ficha técnica. Porcentaje de acciones dirigidas a mujeres dentro del PPSSYPR

\begin{tabular}{|c|c|}
\hline Nombre del indicador & $\begin{array}{l}\text { Porcentaje de acciones dirigidas a mujeres dentro del } \\
\text { PPSSyPR }\end{array}$ \\
\hline Sigla & PADM \\
\hline Objetivo & $\begin{array}{l}\text { Medir la cantidad de acciones dirigidas de manera exclusiva } \\
\text { a las mujeres. }\end{array}$ \\
\hline Definición y conceptos & $\begin{array}{l}\text { Accesibilidad a varones } \\
\text { Accesibilidad a mujeres } \\
\text { Accesibilidad a mujeres y varones }\end{array}$ \\
\hline Método de medición & $\begin{array}{l}\text { División entre el número de acciones dirigidas } \\
\text { exclusivamente a mujeres entre el número de acciones } \\
\text { ofertadas en el programa por } 100\end{array}$ \\
\hline Unidad de medida & Porcentaje \\
\hline Formula & $P A D M=\frac{\# A D M}{\# A O P}$ \\
\hline Variables & $\begin{array}{l}\text { \#ADM: Numero de acciones dirigidas a mujeres. } \\
\text { \#AOP: Numero de acciones ofertadas en el programa }\end{array}$ \\
\hline Limitaciones del indicador & El indicador no mide el acceso a las acciones ofertadas \\
\hline Fuente de datos & $\begin{array}{l}\text { Programa de Salud Sexual y Procreación Responsable de la } \\
\text { provincia de Buenos Aires. }\end{array}$ \\
\hline Desagregación geográfica & Provincia de Buenos Aires \\
\hline Periodicidad de los datos & Unicẽ \\
\hline Fecha de información disponible & 2012 \\
\hline Responsable & Investigadorẽ \\
\hline Observaciones & \\
\hline
\end{tabular}




\subsection{Ficha técnica. Porcentaje de acciones dirigidas a varones dentro del PPSSYPR}

\begin{tabular}{|c|c|}
\hline Nombre del indicador & $\begin{array}{l}\text { Porcentaje de acciones dirigidas a varones dentro del } \\
\text { PPSSyPR }\end{array}$ \\
\hline Sigla & PADV \\
\hline Objetivo & $\begin{array}{l}\text { Medir la cantidad de acciones dirigidas de manera exclusiva } \\
\text { a los varones. }\end{array}$ \\
\hline Definición y conceptos & $\begin{array}{l}\text { Accesibilidad a varones } \\
\text { Accesibilidad a mujeres } \\
\text { Accesibilidad a mujeres y varones }\end{array}$ \\
\hline Método de medición & $\begin{array}{l}\text { División entre el número de acciones dirigidas } \\
\text { exclusivamente a varones entre el número de acciones } \\
\text { ofertadas en el programa por } 100\end{array}$ \\
\hline Unidad de medida & Porcentaje \\
\hline Formula & $P A D V=\frac{\# A D V}{\# A O P}$ \\
\hline Variables & $\begin{array}{l}\text { \#ADV: N úmero de acciones dirigidas a varones. } \\
\text { \#AOP: Número de acciones ofertadas en el programa }\end{array}$ \\
\hline Limitaciones del indicador & El indicador no mide el acceso a las acciones ofertadas \\
\hline Fuente de datos & $\begin{array}{l}\text { Programa de Salud Sexual y Procreación Responsable de la } \\
\text { provincia de Buenos Aires. }\end{array}$ \\
\hline Desagregación geográfica & Provincia de Buenos Aires \\
\hline Periodicidad de los datos & Unicē \\
\hline Fecha de información disponible & 2012 \\
\hline Responsable & Investigadorã \\
\hline Observaciones & \\
\hline
\end{tabular}




\section{Anexo 3. Fichas técnicas de indicadores de la variable disponibilidad de métodos anticonceptivos}

\subsection{Ficha técnica. Porcentaje mujeres que solicitaron preservativo dentro del PPSSYPR.}

\begin{tabular}{|c|c|}
\hline Nombre del indicador & $\begin{array}{l}\text { Porcentaje de mujeres que solicitaron preservativos dentro } \\
\text { del PPSSyPR }\end{array}$ \\
\hline Sigla & PMSP \\
\hline Objetivo & $\begin{array}{l}\text { Medir la cantidad de mujeres que solicitaron preservativos } \\
\text { (en una muestra) }\end{array}$ \\
\hline Definición y conceptos & $\begin{array}{l}\text { Mujeres que solicitan preservativos } \\
\text { Consejería en planificación familiar }\end{array}$ \\
\hline Método de medición & $\begin{array}{l}\text { División entre el número de mujeres encuestadas que } \\
\text { solicitaron preservativos en la consejería de planificación } \\
\text { familiar entre el número de mujeres encuestadas que } \\
\text { acudieron a consulta de planificación familiar por } 100 \text { (en } \\
\text { una muestra) }\end{array}$ \\
\hline Unidad de medida & Porcentaje \\
\hline Formula & $P M S P=\frac{\# M S P}{\# M A C}$ \\
\hline Variables & $\begin{array}{l}\text { \#MSF: Número de mujeres encuestadas que solicitaron } \\
\text { preservativos en la consejería de planificación familiar. } \\
\text { \#MAC: Número de mujeres encuestadas que acudieron a la } \\
\text { consejería en planificación familiar. }\end{array}$ \\
\hline Limitaciones del indicador & El indicador no mide la entrega de preservativos. \\
\hline Fuente de datos & $\begin{array}{l}\text { Encuesta realizada a las usuarias de la consejería en } \\
\text { planificación familiar. }\end{array}$ \\
\hline Desagregación geográfica & Provincia de Buenos Aires \\
\hline Periodicidad de los datos & Unicē \\
\hline Fecha de información disponible & 2011 \\
\hline Responsable & Investigadorã \\
\hline Observaciones & \\
\hline
\end{tabular}




\subsection{Ficha técnica. Porcentaje de mujeres que solicitaron preservativos y les fueron entregados dentro del PPSSyPR}

\begin{tabular}{|c|c|}
\hline Nombre del indicador & $\begin{array}{l}\text { Porcentaje de mujeres que solicitaron preservativos y les } \\
\text { fueron entregados dentro del PPSSyPR }\end{array}$ \\
\hline Sigla & PMEP \\
\hline Objetivo & $\begin{array}{l}\text { Medir la cantidad de mujeres a las que les fueron } \\
\text { entregados los preservativos que solicitaron preservativos } \\
\text { (en una muestra) }\end{array}$ \\
\hline Definición y conceptos & $\begin{array}{l}\text { Mujeres que solicitan preservativos } \\
\text { Mujeres a las que les entregan los preservativos } \\
\text { Consejería en planificación familiar }\end{array}$ \\
\hline Método de medición & $\begin{array}{l}\text { División entre el número de mujeres encuestadas que } \\
\text { solicitaron preservativos en la consejería de planificación } \\
\text { familiar y que les fueron entregados entre el número de } \\
\text { mujeres encuestadas que acudieron a consulta de } \\
\text { planificación familiar y solicitaron preservativos por } 100 \text { (en } \\
\text { una muestra) }\end{array}$ \\
\hline Unidad de medida & Porcentaje \\
\hline Formula & $P M E P=\frac{\# M E P}{\# M S P} \times 100$ \\
\hline Variables & $\begin{array}{l}\text { \#MEP: Número de mujeres encuestadas que solicitaron } \\
\text { preservativos en la consejería de planificación familiar y que } \\
\text { les fue entregado. } \\
\text { \#MSP: Número de mujeres encuestadas que acudieron a la } \\
\text { consejería en planificación familiar y solicitaron } \\
\text { preservativos. }\end{array}$ \\
\hline Limitaciones del indicador & El indicador no mide oportunidad en la entrega ni cantidad. \\
\hline Fuente de datos & $\begin{array}{l}\text { Encuesta realizada a las usuarias de la consejería en } \\
\text { planificación familiar. }\end{array}$ \\
\hline Desagregación geográfica & Provincia de Buenos Aires \\
\hline Periodicidad de los datos & Unice \\
\hline Fecha de información disponible & 2012 \\
\hline Responsable & Investigadorã \\
\hline Observaciones & \\
\hline
\end{tabular}




\subsection{Ficha técnica. Porcentaje varones que solicitaron preservativo}

\begin{tabular}{|c|c|}
\hline Nombre del indicador & $\begin{array}{l}\text { Porcentaje de varones que solicitaron preservativos dentro } \\
\text { del PPSSyPR }\end{array}$ \\
\hline Sigla & PVSP \\
\hline Objetivo & $\begin{array}{l}\text { Medir la cantidad de varones que solicitaron preservativos } \\
\text { (en una muestra) }\end{array}$ \\
\hline Definición y conceptos & $\begin{array}{l}\text { Varones que solicitan preservativos } \\
\text { Consejería en planificación familiar }\end{array}$ \\
\hline Método de medición & $\begin{array}{l}\text { División entre el número de varones encuestados que } \\
\text { solicitaron preservativos en la consejería de planificación } \\
\text { familiar entre el número de varones encuestados que } \\
\text { acudieron a consulta de planificación familiar por } 100 \text { (en } \\
\text { una muestra) }\end{array}$ \\
\hline Unidad de medida & Porcentaje \\
\hline Formula & $P V S P=\frac{\# V S P}{\# V A C}$ \\
\hline Variables & $\begin{array}{l}\text { \#VSP: Número de varones encuestados que solicitaron } \\
\text { preservativos en la consejería de planificación familiar. } \\
\text { \#VAC: Número de varones encuestados que acudieron a la } \\
\text { consejería en planificación familiar. }\end{array}$ \\
\hline Limitaciones del indicador & El indicador no mide la entrega de preservativos. \\
\hline Fuente de datos & $\begin{array}{l}\text { Encuesta realizada a los usuarios de la consejería en } \\
\text { planificación familiar. }\end{array}$ \\
\hline Desagregación geográfica & Provincia de Buenos Aires \\
\hline Periodicidad de los datos & Unicẽ \\
\hline Fecha de información disponible & 2012 \\
\hline Responsable & Investigadora \\
\hline Observaciones & \\
\hline
\end{tabular}




\subsection{Ficha técnica. Porcentaje varones que solicitaron preservativos y les fueron entregados}

\begin{tabular}{|c|c|}
\hline Nombre del indicador & $\begin{array}{l}\text { Porcentaje de varones que solicitaron preservativos y les } \\
\text { fueron entregados dentro del PPSSyPR }\end{array}$ \\
\hline Sigla & PVEP \\
\hline Objetivo & $\begin{array}{l}\text { Medir la cantidad de varones a las que les fueron entregados } \\
\text { los preservativos que solicitaron preservativos (en una } \\
\text { muestra) }\end{array}$ \\
\hline Definición y conceptos & $\begin{array}{l}\text { Varones que solicitan preservativos } \\
\text { Varones a las que les entregan los preservativos } \\
\text { Consejería en planificación familiar }\end{array}$ \\
\hline Método de medición & $\begin{array}{l}\text { División entre el número de varones encuestados que } \\
\text { solicitaron preservativos en la consejería de planificación } \\
\text { familiar y que les fueron entregados entre el número de } \\
\text { varones encuestados que acudieron a consulta de } \\
\text { planificación familiar y solicitaron preservativos por } 100 \text { (en } \\
\text { una muestra) }\end{array}$ \\
\hline Unidad de medida & Porcentaje \\
\hline Formula & $P V E P=\frac{\# V E P}{\# V S P} \times 100$ \\
\hline Variables & $\begin{array}{l}\text { \#VE: Número de varones encuestados que solicitaron } \\
\text { preservativos en la consejería de planificación familiar y que } \\
\text { les fue entregado. } \\
\text { \#SSP: Número de varones encuestados que acudieron a la } \\
\text { consejería en planificación familiar y solicitaron } \\
\text { preservativos. }\end{array}$ \\
\hline Limitaciones del indicador & El indicador no mide oportunidad en la entrega ni cantidad. \\
\hline Fuente de datos & $\begin{array}{l}\text { Encuesta realizada a los usuarios de la consejería en } \\
\text { planificación familiar. }\end{array}$ \\
\hline Desagregación geográfica & Provincia de Buenos Aires \\
\hline Periodicidad de los datos & Unicẽ \\
\hline Fecha de información disponible & 2012 \\
\hline Responsable & Investigadora \\
\hline Observaciones & \\
\hline
\end{tabular}




\subsection{Ficha técnica. Porcentaje de mujeres que solicitaron métodos anticonceptivos diferentes a preservativos y vasectomía.}

\begin{tabular}{|c|c|}
\hline Nombre del indicador & $\begin{array}{l}\text { Porcentaje de mujeres que solicitaron métodos } \\
\text { anticonceptivos diferentes a preservativos y vasectomía. }\end{array}$ \\
\hline Sigla & PMMAC \\
\hline Objetivo & $\begin{array}{l}\text { Medir la cantidad de mujeres que solicitaron MAC } \\
\text { diferentes a preservativos y vasectomía (en una muestra) }\end{array}$ \\
\hline Definición y conceptos & $\begin{array}{l}\text { Mujeres encuestadas que solicitaron MAC diferentes a la } \\
\text { vasectomía y preservativos. } \\
\text { Consejería en planificación familiar }\end{array}$ \\
\hline Método de medición & $\begin{array}{l}\text { División entre el número de mujeres encuestadas que } \\
\text { solicitaron MAC diferente a vasectomía y preservativos en } \\
\text { la consejería de planificación familiar entre el número de } \\
\text { mujeres encuestadas que acudieron a consulta de } \\
\text { planificación familiar por } 100 \text { (en unamuestra) }\end{array}$ \\
\hline Unidad de medida & Porcentaje \\
\hline Formula & $P M M A C=\frac{\# M M A C}{\# M A C}$ \\
\hline Variables & $\begin{array}{l}\text { \#MMAC: Número de mujeres encuestadas que solicitaron } \\
\text { MAC diferentes a la vasectomía y a preservativos en la } \\
\text { consejería de planificación familiar. } \\
\text { \#MAC: Número de mujeres encuestadas que acudieron a la } \\
\text { consejería en planificación familiar. }\end{array}$ \\
\hline Limitaciones del indicador & El indicador no mide la entrega de los MAC. \\
\hline Fuente de datos & $\begin{array}{l}\text { Encuesta realizada a las usuarias de la consejería en } \\
\text { planificación familiar. }\end{array}$ \\
\hline Desagregación geográfica & Provincia de Buenos Aires \\
\hline Periodicidad de los datos & Unicẽ \\
\hline Fecha de información disponible & 2012 \\
\hline Responsable & Investigadora \\
\hline Observaciones & \\
\hline
\end{tabular}




\subsection{Ficha técnica. Porcentaje mujeres que solicitaron MAC diferentesa vasectomía y preservativo, y les fueron entregados.}

\begin{tabular}{|c|c|}
\hline Nombre del indicador & $\begin{array}{l}\text { Porcentaje de mujeres que solicitaron MAC diferentes a } \\
\text { vasectomía y preservativos y les fueron entregados dentro } \\
\text { del PPSSYPR }\end{array}$ \\
\hline Sigla & PMMACE \\
\hline Objetivo & $\begin{array}{l}\text { Medir la cantidad de mujeres que solicitaron MAC } \\
\text { diferentes a preservativos y vasectomía y que les fueron } \\
\text { entregados (en una muestra) }\end{array}$ \\
\hline Definición y conceptos & $\begin{array}{l}\text { Mujeres que solicitaron MAC diferentes a preservativos y } \\
\text { vasectomía } \\
\text { Mujeres que solicitaron MAC diferentes a preservativos y } \\
\text { vasectomía y que les fueron entregados } \\
\text { Consejería en planificación familiar }\end{array}$ \\
\hline Método de medición & $\begin{array}{l}\text { División entre el número de mujeres encuestadas que } \\
\text { solicitaron MAC diferentes a vasectomía y preservativos y } \\
\text { que les fueron entregados entre el número de mujeres } \\
\text { encuestadas que solicitaron MAC diferentes a vasectomía y } \\
\text { preservativos por } 100 \text { (en una muestra) }\end{array}$ \\
\hline Unidad de medida & Porcentaje \\
\hline Formula & $P M M A C E=\frac{\# M M A C E}{\# M S M A C} \times 100$ \\
\hline Variables & $\begin{array}{l}\text { \#MMACE: Número de mujeres encuestadas que solicitaron } \\
\text { MAC diferentes a vasectomía y preservativo y que les } \\
\text { fueron entregados. } \\
\text { \#MSMAC: Número de mujeres encuestadas que solicitaron } \\
\text { MAC diferentes a preservativo y vasectomía. }\end{array}$ \\
\hline Limitaciones del indicador & E indicador no mide oportunidad en la entrega ni cantidad. \\
\hline Fuente de datos & $\begin{array}{l}\text { Encuesta realizada a las usuarias de la consejería en } \\
\text { planificación familiar. }\end{array}$ \\
\hline Desagregación geográfica & Provincia de Buenos Aires \\
\hline Periodicidad de los datos & Unicẽ \\
\hline Fecha de información disponible & 2011 \\
\hline Responsable & Investigadora \\
\hline Observaciones & \\
\hline
\end{tabular}




\subsection{Ficha técnica. Porcentaje varones que solicitaron vasectomía y les fue realizada en un tiempo inferior a un mes.}

\begin{tabular}{|c|c|}
\hline Nombre del indicador & $\begin{array}{l}\text { Porcentaje de varones que solicitaron vasectomía y les fue } \\
\text { realizada dentro del PPSSyPR en un tiempo inferior a un } \\
\text { mes. }\end{array}$ \\
\hline Sigla & PW \\
\hline Objetivo & $\begin{array}{l}\text { Medir la cantidad de varones que solicitaron vasectomía y } \\
\text { les fue realizada (en una muestra) }\end{array}$ \\
\hline Definición y conceptos & $\begin{array}{l}\text { Varones que solicitaron vasectomía } \\
\text { Varones que solicitaron vasectomía y que les fue realizada } \\
\text { Consejería en planificación familiar }\end{array}$ \\
\hline Método de medición & $\begin{array}{l}\text { División entre el número de varones encuestados que } \\
\text { solicitaron la vasectomía y que les fue realizada entre el } \\
\text { número se varones que solicitaron la vasectomía por } 100 \\
\text { (en una muestra) }\end{array}$ \\
\hline Unidad de medida & Porcentaje \\
\hline Formula & $P V V=\frac{\# P V V}{\# V S V} \times 100$ \\
\hline Variables & $\begin{array}{l}\text { \#W: Número de varones que solicitaron la vasectomía y les } \\
\text { fue realizada. } \\
\text { \#SV: Número de varones que solicitaron la vasectomía. }\end{array}$ \\
\hline Limitaciones del indicador & El indicador no mide oportunidad. \\
\hline Fuente de datos & $\begin{array}{l}\text { Encuesta realizada a los usuarios de la consejería en } \\
\text { planificación familiar con seguimiento de un mes después. }\end{array}$ \\
\hline Desagregación geográfica & Provincia de Buenos Aires \\
\hline Periodicidad de los datos & Unica \\
\hline Fecha de información disponible & 2012 \\
\hline Responsable & Investigadora \\
\hline Observaciones & \\
\hline
\end{tabular}




\section{Anexo 4. Ficha técnica indicador de la variable promoción de la vinculación del varón en las acciones de salud sexual y reproductiva}

\subsection{Porcentaje de usuarios/as que refieren haber recibido información sobre vinculación del varón en la SSR durante la consejería en planificación familiar}

\begin{tabular}{|c|c|}
\hline Nombre del indicador & $\begin{array}{l}\text { Porcentaje de usuarios/as que refieren haber recibido } \\
\text { información sobre vinculación del varón en la SSR durante } \\
\text { la consejería en planificación familiar. }\end{array}$ \\
\hline Sigla & PPPW \\
\hline Objetivo & $\begin{array}{l}\text { Medir la cantidad de usuarios/as encuestados que refieren } \\
\text { haber recibido información sobre la vinculación del varón } \\
\text { en la SSR durante la consejería en planificación familiar. }\end{array}$ \\
\hline Definición y conceptos & $\begin{array}{l}\text { Promoción de la vinculación del varón } \\
\text { Proveedor de la consejería } \\
\text { Consejería en planificación familiar }\end{array}$ \\
\hline Método de medición & $\begin{array}{l}\text { División entre el número de usuarios/as encuestados que } \\
\text { refieren haber recibido información sobre la vinculación del } \\
\text { varón en la SSR durante la consejería de planificación } \\
\text { familiar entre el número de usuarios/as encuestadas por } \\
100 .\end{array}$ \\
\hline Unidad de medida & Porcentaje \\
\hline Formula & $P P P V V=\frac{\# U P V V}{\# U E} \times 100$ \\
\hline Variables & $\begin{array}{l}\text { \#UPW: Número de usuarias/os que refieren haber recibido } \\
\text { información sobre la vinculación del varón en la SSR } \\
\text { durante la consejería en planificación familiar } \\
\text { \#UE: Número de usuarios/as encuestados. }\end{array}$ \\
\hline Limitaciones del indicador & El indicador no mide el impacto de la promoción. \\
\hline Fuente de datos & Encuesta a \\
\hline Desagregación geográfica & Provincia de Buenos Aires \\
\hline Periodicidad de los datos & Unice \\
\hline Fecha de información disponible & 2012 \\
\hline Responsable & Investigadorẽ \\
\hline Observaciones & \\
\hline
\end{tabular}




\section{Anexo 5. Fichas técnicas de indicadores de la variable sensibilización de proveedores de consejería en planificación familiar en perspectiva de género}

5.1. Ficha técnica. Porcentaje de proveedores de consejería en planificación familiar que refieren haber sido sensibilizados en la importancia de la perspectiva de género.

\begin{tabular}{|c|c|}
\hline Nombre del indicador & $\begin{array}{l}\text { Porcentaje de proveedores de consejería en planificación } \\
\text { familiar que refieren haber sido sensibilizados en la } \\
\text { importancia de la perspectiva de género. }\end{array}$ \\
\hline Sigla & PPSPG \\
\hline Objetivo & $\begin{array}{l}\text { Medir la cantidad de proveedores de la consejería en } \\
\text { panificación familiar que refieren haber sido sensibilizados } \\
\text { en la importancia de la perspectiva de género. }\end{array}$ \\
\hline Definición y conceptos & Sensibilización en perspectiva de género \\
\hline Método de medición & $\begin{array}{l}\text { División entre el número de proveedores de consejerías en } \\
\text { planificación familiar que refieren haber sido sensibilizados } \\
\text { en perspectiva de género entre el total de proveedores de } \\
\text { la consejería en planificación familiar por } 100 \text {. }\end{array}$ \\
\hline Unidad de medida & Porcentaje \\
\hline Formula & $P P S P G=\frac{\# P S P G}{\# T P} \times 100$ \\
\hline Variables & $\begin{array}{l}\text { \#PSPG: Numero de proveedores de la consejería en } \\
\text { planificación familiar sensibilizados en perspectiva de } \\
\text { género. } \\
\text { \#IP: Numero de total de proveedores. }\end{array}$ \\
\hline Limitaciones del indicador & $\begin{array}{l}\text { El indicador no mide los contenidos de la sensibilización ni } \\
\text { el impacto de esta. }\end{array}$ \\
\hline Fuente de datos & Encuesta a proveedores \\
\hline Desagregación geográfica & Provincia de Buenos Aires \\
\hline Periodicidad de los datos & Unice \\
\hline Fecha de información disponible & 2012 \\
\hline Responsable & Investigadora \\
\hline Observaciones & \\
\hline
\end{tabular}




\subsection{Ficha técnica. Porcentaje de proveedores de consejería en planificación familiar que consideran importante la vinculación del varón en la salud sexual y reproductiva.}

\begin{tabular}{|c|c|}
\hline Nombre del indicador & $\begin{array}{l}\text { Porcentaje de proveedores de consejería en planificación } \\
\text { familiar que consideran importante la vinculación del varón } \\
\text { en la salud sexual y reproductiva. }\end{array}$ \\
\hline Sigla & PPIW \\
\hline Objetivo & $\begin{array}{l}\text { Medir la cantidad de proveedores de la consejería en } \\
\text { panificación familiar que consideran importante la } \\
\text { vinculación del varón en la salud sexual y reproductiva. }\end{array}$ \\
\hline Definición y conceptos & $\begin{array}{l}\text { Proveedores encuestados } \\
\text { Importancia de la vinculación de varón }\end{array}$ \\
\hline Método de medición & $\begin{array}{l}\text { División entre el número de proveedores encuestados que } \\
\text { consideran importante la vinculación del varón en la salud } \\
\text { sexual y reproductiva entre el total de proveedores } \\
\text { encuestados por } 100 \text {. }\end{array}$ \\
\hline Unidad de medida & Porcentaje \\
\hline Formula & $P P I V V=\frac{\# P P I V V}{\# P E} \times 100$ \\
\hline Variables & $\begin{array}{l}\text { \#PPIW: Numero de proveedores de la consejería en } \\
\text { planificación que consideran importante la vinculación del } \\
\text { varón en la SSR. } \\
\text { \#IP: Numero de total de proveedores. }\end{array}$ \\
\hline Limitaciones del indicador & $\begin{array}{l}\text { El indicador no mide la implementación de acciones de } \\
\text { promoción de la vinculación del varón en la SSR. }\end{array}$ \\
\hline Fuente de datos & Encuesta a proveedores \\
\hline Desagregación geográfica & Provincia de Buenos Aires \\
\hline Periodicidad de los datos & Unicẽ \\
\hline Fecha de información disponible & 2012 \\
\hline Responsable & Investigadora \\
\hline Observaciones & \\
\hline
\end{tabular}




\section{Anexo 6. Fichas técnicas de indicadores de la variable reconocimiento de las estrategias de vinculación del varón en las acciones del PSSRyPR}

\subsection{Ficha técnica. Porcentaje de proveedores y proveedoras que reconocen las estrategias de vinculación del varón en las acciones del PPSSyPR.}

\begin{tabular}{|c|c|}
\hline Nombre del indicador & $\begin{array}{l}\text { Porcentaje de proveedores y proveedoras que reconocen } \\
\text { las estrategias de vinculación del varón en las acciones del } \\
\text { PPSSyPR. }\end{array}$ \\
\hline Sigla & PRREV \\
\hline Objetivo & $\begin{array}{l}\text { Medir la cantidad de proveedores y proveedorasdel } \\
\text { programa que reconocen las estrategias de vinculación del } \\
\text { varón PPSSyPR. }\end{array}$ \\
\hline Definición y conceptos & $\begin{array}{l}\text { Estrategias de vinculación del varón } \\
\text { Referentes del programa }\end{array}$ \\
\hline Método de medición & $\begin{array}{l}\text { División entre el número de proveedores y proveedoras } \\
\text { encuestadas en el programa que reconocen las estrategias } \\
\text { de vinculación del varón en el PPSSyPR y el número total } \\
\text { de proveedores y proveedoras encuestadas por } 100 \text {. }\end{array}$ \\
\hline Unidad de medida & Porcentaje \\
\hline Formula & $P R R E V=\frac{\# P R R E V}{\# R E} \times 100$ \\
\hline Variables & $\begin{array}{l}\text { \#PRREV: Número de proveedores y proveedoras } \\
\text { encuestadas que reconocen las estrategias de vinculación } \\
\text { del varón en el PPSSyPR. } \\
\text { \#RE: Número de total de proveedores y proveedoras } \\
\text { encuestadas. }\end{array}$ \\
\hline Limitaciones del indicador & $\begin{array}{l}\text { E indicador no mide la implementación de las estrategias de } \\
\text { vinculación del varón en el PPSSyPR. }\end{array}$ \\
\hline Fuente de datos & Encuesta a referentes del PPSSyPR BsAs \\
\hline Desagregación geográfica & Provincia de Buenos Aires \\
\hline Periodicidad de los datos & Unice \\
\hline Fecha de información disponible & 2012 \\
\hline Responsable & Investigadora \\
\hline Observaciones & \\
\hline
\end{tabular}




\subsection{Ficha técnica. Porcentaje de proveedores y proveedoras que consideran que en su lugar de trabajo se implementan las estrategias de vinculación del varón en las acciones del PPSSyPR.}

\begin{tabular}{|c|c|}
\hline Nombre del indicador & $\begin{array}{l}\text { Porcentaje de proveedores y proveedoras que consideran } \\
\text { que en su lugar de trabajo se implementan las estrategias de } \\
\text { vinculación del varón en las acciones del PPSSyPR. }\end{array}$ \\
\hline Sigla & PRIEV \\
\hline Objetivo & $\begin{array}{l}\text { Medir la cantidad de proveedores y proveedoras del } \\
\text { programa que consideran que en los lugares de trabajo se } \\
\text { implementan las estrategias de vinculación del varón } \\
\text { PPSSyPR. }\end{array}$ \\
\hline Definición y conceptos & $\begin{array}{l}\text { Estrategias de vinculación del varón } \\
\text { Proveedores y proveedoras del programa } \\
\text { Implementación de estrategias }\end{array}$ \\
\hline Método de medición & $\begin{array}{l}\text { División entre el número de proveedores y proveedorax } \\
\text { encuestadas del programa que consideran que en sus } \\
\text { lugares de trabajo se implementan las estrategias de } \\
\text { vinculación del varón en el PPSSyPR y el número total de } \\
\text { proveedores y proveedoras que reconocen las estrategias } \\
\text { de vinculación del varón encuestad@s por } 100 \text {. }\end{array}$ \\
\hline Unidad de medida & Porcentaje \\
\hline Formula & PRIEV $=\frac{\# P R I E V}{\# R R E V} \times 100$ \\
\hline Variables & $\begin{array}{l}\text { \#PRIEV: Numero de proveedores y proveedoras } \\
\text { encuestadas que consideran que en su lugar de trabajo se } \\
\text { implementan las estrategias de vinculación del varón en el } \\
\text { PPSSyPR. } \\
\text { \#RREV: Numero de total de proveedores y proveedoras } \\
\text { encuestadas. que reconocen las estrategias de vinculación } \\
\text { del varón }\end{array}$ \\
\hline Limitaciones del indicador & $\begin{array}{l}\text { E indicador no mide la implementación de las estrategias de } \\
\text { vinculación del varón en el PPSSyPR. }\end{array}$ \\
\hline Fuente de datos & Encuesta a referentes del PPSSyPR BsAs \\
\hline Desagregación geográfica & Provincia de Buenos Aires \\
\hline Periodicidad de los datos & Unice \\
\hline Fecha de información disponible & 2012 \\
\hline Responsable & Investigadora \\
\hline Observaciones & \\
\hline
\end{tabular}


Anexo 7. Instrumento de verificación del lenguaje incluyente en las publicaciones emitidas por el PPSSyPR

\section{INSTRUMENTO DE ANÁUSIS DE LAS PUBLCACIONES EMITIDAS DESDE EL PPSSYPR DE LA MUNICIPALIDAD DE LA PLATA, PERIODO 2010- 2012.}

\begin{tabular}{|l|l|}
\hline \multicolumn{2}{|c|}{ CARACTERIZACION GENERAL DE LA PUBLICACION } \\
\hline Título de la publicación & \\
\hline Fecha de publicación & \\
\hline Tema & \\
\hline \multicolumn{2}{|c|}{ ANALISSDE LA PUBLICACION } \\
\hline Criterios excluyentes & Eventos identificados \\
\hline Uso del masculino genérico & Eventos identificados \\
\hline $\begin{array}{l}\text { Uso del término hombre (desde el sentido } \\
\text { genérico) }\end{array}$ & \\
\hline Criterios incluyentes & \\
\hline $\begin{array}{l}\text { Sustantivos genéricos y colectivos (personaje, } \\
\text { colectivo, población, ciudadanía) }\end{array}$ & \\
\hline $\begin{array}{l}\text { Perífrasis (personal sanitario, personal docente, la } \\
\text { comunidad) }\end{array}$ & \\
\hline Uso de desdoblamientos (las y los, niños y niñas) & \\
\hline Uso de barras & \\
\hline $\begin{array}{l}\text { Uso de aposiciones explicativas (tanto mujeres } \\
\text { como varones) }\end{array}$ & \\
\hline $\begin{array}{l}\text { Determinantes sin marca de género (cada } \\
\text { estudiante) }\end{array}$ & $\begin{array}{l}\text { Omisión del determinante (eliminar el artículo: } \\
\text { profesionales, ) }\end{array}$ \\
\hline
\end{tabular}


Anexo 8. Instrumento de análisis de piezas publicitarias emitidas por el PPSSyPR de la municipalidad de la plata

INSTRUMENTO DE ANÁLISIS DE LAS PIEZAS PUBUCITARIAS EMITIDAS POR EL PPSSYPR DE LA MUNICIPALIDAD DE LA PLATA, PERIODO 2010- 2012.

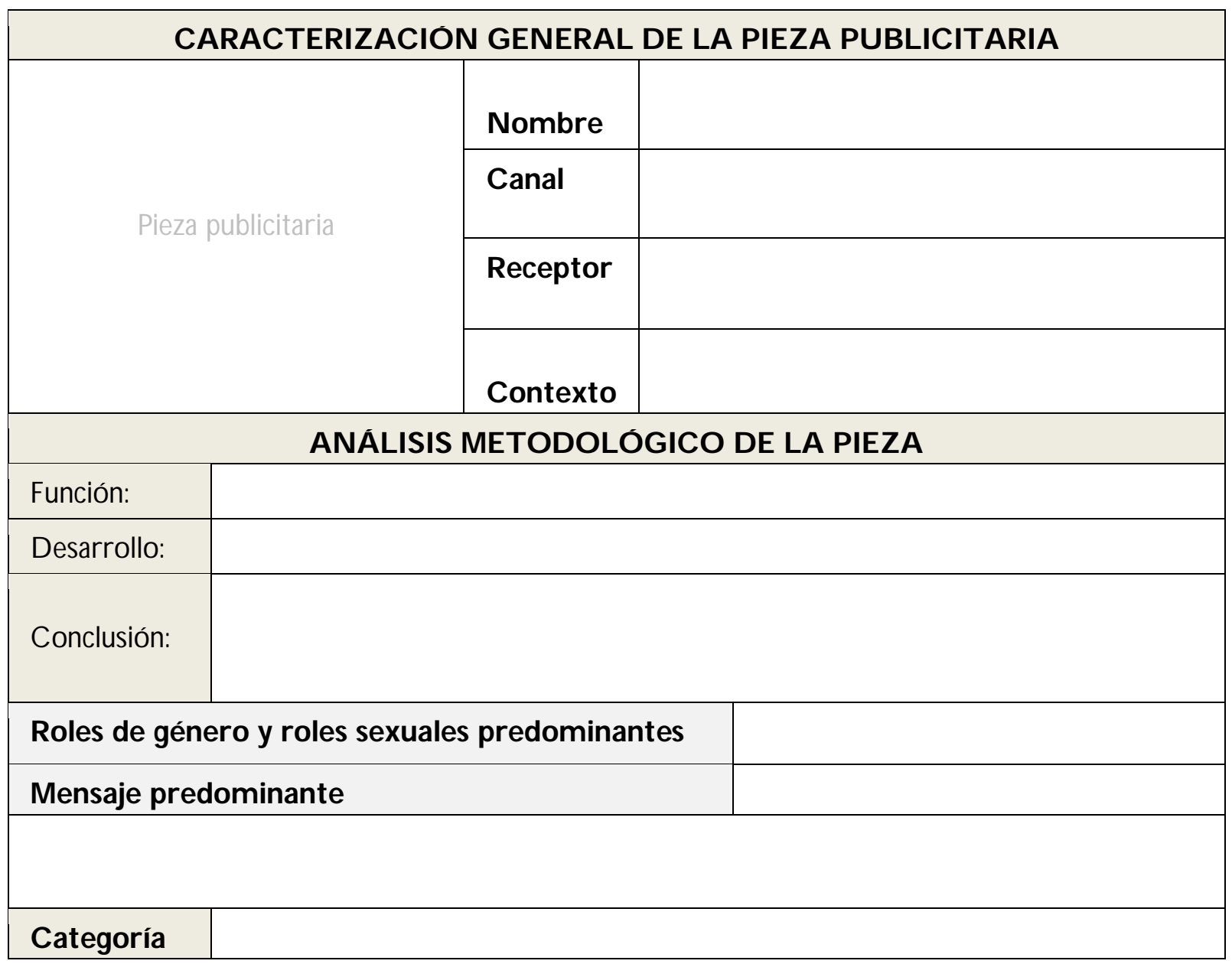


Anexo 9. Instrumento determinación del direccionamiento de las acciones ofertadas por el PPSSyPR

\section{INSTRUMENTO DETERMINACIÓN DEL DIRECCIONAMIENTO DE LASACCIONES OFERTADAS POR EL PROGRAMA DE SALUD SEXUAL Y PROCREACIÓN RESPONSABLE, DE LA MUNICIPALIDAD DE LA PLATA}

\begin{tabular}{|c|l|l|l|l|l|}
\hline Acción & \multicolumn{5}{|l|}{} \\
\hline $\begin{array}{c}\text { Fuente de } \\
\text { información }\end{array}$ & \multicolumn{4}{|l|}{$\begin{array}{l}\text { Accesibilidad a } \\
\text { mujeres y varones }\end{array}$} & \\
\hline $\begin{array}{c}\text { Población } \\
\text { objeto }\end{array}$ & $\begin{array}{l}\text { Accesibilidad a } \\
\text { varones }\end{array}$ & $\begin{array}{l}\text { Accesibilidad } \\
\text { a mujeres }\end{array}$ & \\
\hline
\end{tabular}

\begin{tabular}{|c|l|l|l|l|l|}
\hline Acción & \multicolumn{5}{|l|}{} \\
\hline $\begin{array}{c}\text { Fuente de } \\
\text { información }\end{array}$ & \multicolumn{4}{|l|}{$\begin{array}{l}\text { Accesibilidad a } \\
\text { mujeres y varones }\end{array}$} & \\
\hline $\begin{array}{c}\text { Población } \\
\text { objeto }\end{array}$ & $\begin{array}{l}\text { Accesibilidad a } \\
\text { varones }\end{array}$ & & $\begin{array}{l}\text { Accibilidad } \\
\text { a mujeres }\end{array}$ & & \\
\hline
\end{tabular}

\begin{tabular}{|c|l|l|l|l|l|}
\hline Acción & \multicolumn{5}{|l|}{} \\
\hline $\begin{array}{c}\text { Fuente de } \\
\text { información }\end{array}$ & \multicolumn{2}{|l|}{$\begin{array}{l}\text { Accesibilidad } \\
\text { a mujeres }\end{array}$} & & $\begin{array}{l}\text { Accesibilidad a } \\
\text { mujeres y varones }\end{array}$ & \\
\hline $\begin{array}{c}\text { Población } \\
\text { objeto }\end{array}$ & $\begin{array}{l}\text { Accesibilidad a } \\
\text { varones }\end{array}$ & &
\end{tabular}

\begin{tabular}{|c|c|c|c|}
\hline \multicolumn{4}{|l|}{ Acción } \\
\hline $\begin{array}{c}\text { Fuente de } \\
\text { información }\end{array}$ & & & \\
\hline $\begin{array}{l}\text { Población } \\
\text { objeto }\end{array}$ & $\begin{array}{l}\text { Accesibilidad a } \\
\text { varones }\end{array}$ & $\begin{array}{l}\text { Accesibilidad } \\
\text { a mujeres }\end{array}$ & $\begin{array}{l}\text { Accesibilidad a } \\
\text { mujeres y varones }\end{array}$ \\
\hline
\end{tabular}

\begin{tabular}{|c|l|l|l|l|l|}
\hline Acción & \multicolumn{5}{|l|}{} \\
\hline $\begin{array}{c}\text { Fuente de } \\
\text { información }\end{array}$ & \multicolumn{4}{|l|}{$\begin{array}{l}\text { Accesibilidad a } \\
\text { mujeres y varones }\end{array}$} & \\
\hline $\begin{array}{c}\text { Población } \\
\text { objeto }\end{array}$ & $\begin{array}{l}\text { Accesibilidad a } \\
\text { varones }\end{array}$ & & $\begin{array}{l}\text { Acesibilidad } \\
\text { a mujeres }\end{array}$ & & \\
\hline
\end{tabular}


Anexo 10. Instrumento de observación estructurada aplicable a los centros de atención primaria en salud que ofertan acciones del programa de salud sexual y procreación responsable de la Municipalidad de la Plata.

INSTRUMENTO DE OBSERVACIÓN ESTRUCTURADA APLCABLE A LOS CENTROS DE ATENCION PRIMARIA EN SALUD QUE OFRTAN ACCIONES DEL PROGRAMA DE SALUD SEXUAL Y PROCREACION RESPONSABLE DE LA MUNICIPAUDAD DE LA PLATA

CAPS Fecha

\begin{tabular}{|l|l|l|l|}
\hline ITEM & SI & NO & OBSERVACIONES \\
\hline
\end{tabular}

AFICHES

1 Existen piezas publicitarias del Programa de Salud Sexual y Procreación Responsable?

2 Las piezas publicitarias expuestas son las emitidas por el Programa en el periodo 2010 a la fecha?

Existen piezas publicitarias relacionadas con la SSyPR, emitidas por otras organizaciones?

3 Las piezas publicitarias expuestas se encuentran en áreas comunes?

4 Las piezas publicitarias expuestas se encuentran en el interior del consultorio destinado a la consejería de planificación familiar?

FOLLETOS - POSTALES - AUTOADHESIVOS

5 El Centro de Atención Primaria en Salud dispone de este tipo de piezas publicitarias emitidas por el PPSSyPR?

6 Estas piezas publicitarias son las emitidas por el PPSSyPR en el periodo 2010 a la fecha?

7 Estas piezas se encuentran disponibles en los consultorios destinados a la consejería en planificación familiar?

Relación de las piezas publicitarias encontradas

\begin{tabular}{|c|c|}
\hline Tema & $\begin{array}{c}\text { Secuencial } \\
\text { de } \\
\text { fotografía }\end{array}$ \\
\hline & \\
\hline & \\
\hline & \\
\hline & \\
\hline & \\
\hline & \\
\hline
\end{tabular}


Anexo 11. Instrumento dirigido a usuarias y usuarios del Programa de salud Sexual y procreación responsable de la Municipalidad de La Plata

\section{INSTRUMENTO DIRIGIDO A USUARIAS Y USIARIOS DEL PROGRAMA DE SALUD SEXUAL Y PROCREACION RESPONSABLE DE LAMUNICIPAUDAD DE LA PLATA}

La informadón suministrada en esta encuesta es de carácter confidencial y será utilizada solo con los fines de la investigación

1. Género Femenino Masculino

2. Edad

3. Durante la consulta el proveedor o proveedora de la asesoría en métodos anticonceptivos:

\section{Si la mujer asistió sola a la asesoría}

$\checkmark$ Estimulo verbalmente la participación de varón en las actividades del programa de salud sexual y procreación responsable?

Si

No

$\checkmark$ Estimulo con material escrito la participación de varón en las actividades del programa de salud sexual y procreación responsable?

Independiente del genero de quien asiste a la consulta

Si No

$\checkmark$ Expresó la importancia de la responsabilidad compartida entre hombre y mujeres en lo relacionado a la salud sexual y reproductiva?

$\checkmark$ Expresó que la vinculación del varón es un derecho?

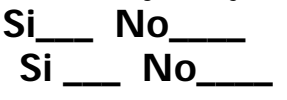

Si asistió a la consulta en pareja o solo el varón

$\checkmark$ El o la proveedora estimuló la continuación de la presencia del varón? Si__ No

$\checkmark$ Hizo reconocimiento a la presencia del varón en la consejería?

$\mathrm{Si}$ - No

4. Sobre cuales métodos anticonceptivos el o la profesional encargado de la asesoría le entregó información
Hormonales
Vasectomía
Ligadura
Preservativo
DIU

5. Cuál es el método anticonceptivo que solicitó en esta asesoría:

Hormonales__ Vasectomía___ Ligadura_ Preservativo_ DIU__

6. El servicio de salud le entrega el método anticonceptivo fácilmente? Si__ No__

Si la respuesta es No cual es el limitante:

Disponibilidad en la Farmacia:

Horarios de entrega

Otros, cuales 


\section{Anexo 12. Instrumento dirigido a referentes del Programa de salud sexual y procreación responsable de la Municipalidad de La Plata.}

\section{INSTRUMENTO DIRIGIDO A REFERENTES DEL PROGRAMA DE SALUD SEXUAL Y PROCREACIÓN RESPONSABLE DE LA MUNICIPALIDAD DE LA PLATA}

Que entiende por Perspectiva de Género?

Cree usted que la perspectiva de género en la salud sexual y reproductiva es importante? porque?

Que entiende por vinculación del varón a la Salud Sexual y Reproductiva?

Cuáles son las razones para considerar importante la vinculación del varón en la salud sexual y reproductiva?

Cuáles son las razones por las cuales la vinculación del varón en la salud sexual y reproductiva no suele considerarse importante?

Dentro del Programa de Salud Sexual y Procreación Responsable los proveedores de la consejería en planificación familiar han recibido sensibilización o capacitación en perspectiva de género? Cuando?

Dentro del Programa de Salud Sexual y Procreación Responsable ha recibido sensibilización o capacitación en la importancia de la vinculación del varón? Cuando?

Cuáles son las estrategias de vinculación del varón a la salud sexual y reproductiva en el Programa de Salud Sexual y Procreación Responsable de la Municipalidad de La Plata?

Considera que estas estrategias se aplican en la parte operativa del programa? 


\section{Anexo 13. Instrumento dirigido a proveedoras y proveedores del Programa de salud sexual y procreación responsable de la Municipalidad de La Plata.}

\section{INSTRUMENTO DIRIGIDO A PROVEEDORES DEL PROGRAMA DE SALUD SEXUAL Y PROCREACION RESPONSABLE DE LA MUNICIPALIDAD DE LA PLATA} La informadión suministrada en esta encuesta es de carácter confidencial y será utilizada solo con los fines de la investigación

1. La vinculación del varón en el Programa de Salud Sexual y Procreación Responsable es importante? (Seleccione una columna y las opciones que considere necesarias)

\begin{tabular}{|l|l|l|}
\hline \multicolumn{1}{|c|}{ SI PORQUE } & \multicolumn{2}{c|}{ NO PORQUE } \\
\hline $\begin{array}{l}\text { E varón tiene igualdad de derechos frente a la } \\
\text { toma de decisiones relacionadas con la salud } \\
\text { sexual y reproductiva. }\end{array}$ & $\begin{array}{l}\text { Las mujeres son las que se embarazan y } \\
\text { por eso ellas son las que deben usar los } \\
\text { anticonceptivos }\end{array}$ \\
\hline $\begin{array}{l}\text { Es una estrategia para garantizar los derechos } \\
\text { sexuales y reproductivos de manera igualitaria } \\
\text { entre varones y mujeres }\end{array}$ & $\begin{array}{l}\text { Los servicios de salud relacionados con la } \\
\text { anticoncepción están dirigidos en mayor } \\
\text { parte a las mujeres de manera }\end{array}$ \\
\hline $\begin{array}{l}\text { Es una estrategia que permite hacer más integral } \\
\text { en acceso a los servicios de salud en materia de } \\
\text { salud sexual y reproductiva }\end{array}$ & $\begin{array}{l}\text { Son las mujeres las que tienen tiempo } \\
\text { para eso, los varones no }\end{array}$ \\
\hline $\begin{array}{l}\text { Amplia el abordaje de derechos a otras } \\
\text { comunidades como la de homosexuales }\end{array}$ & $\begin{array}{l}\text { Por tradición la anticoncepción es cosa de } \\
\text { mujeres }\end{array}$ \\
\hline $\begin{array}{l}\text { Promociona las acciones de cuidado de la salud } \\
\text { sexual y reproductiva en un grupo de población } \\
\text { que difícilmente acude a los servicios de salud por } \\
\text { cuestiones preventivas }\end{array}$ & $\begin{array}{l}\text { La mayoría de los métodos } \\
\text { anticonceptivos son para mujeres y el } \\
\text { acceso a la vasectomía es limitado. }\end{array}$ \\
\hline
\end{tabular}

7. Dentro del Programa de Salud Sexual y Procreación Responsable ha recibido sensibilización o capacitación en perspectiva de género?
$\mathrm{Si}$ No
Cuando

8. Dentro del Programa de Salud Sexual y Procreación Responsable ha recibido sensibilización o capacitación en la importancia de la vinculación del varón?
$\mathrm{Si}$ No
Cuando

9. Actualmente las estrategias que usa el Programa de Salud Sexual y Procreación Responsable de la Municipalidad de La Plata para la vinculación del varón a la salud sexual y reproductiva son: (Marque las opciones que considere necesarias)

- Distribución gratuita de anticonceptivos

- Entrega de folletería y material publicitario que promueve la participación del varón.

- Atención gratuita a los varones

- Consejería integral en planificación familiar

- Capacitaciones en derechos sexuales y reproductivos a los profesionales de los CAPS

- Prioridad en la asignación de citas de consejería a los varones

10. Considera que estas estrategias se aplican en su lugar de trabajo?

No 
